OTÁVIO LUÍS DE OLIVEIRA

\title{
CONTRIBUIÇÕES METODOLÓGICAS À IMPLEMENTAÇÃO DA TECNOLOGIA PLC/BPL
}

\author{
Dissertação apresentada à Escola \\ Politécnica da Universidade de São Paulo \\ para obtenção do título de Mestre em \\ Engenharia
}




\title{
CONTRIBUIÇÕES METODOLÓGICAS À IMPLEMENTAÇÃO DA TECNOLOGIA PLC/BPL
}

\author{
Dissertação apresentada à Escola \\ Politécnica da Universidade de São Paulo \\ para obtenção do título de Mestre em \\ Engenharia
}

Área de Concentração:

Sistemas de Potência

Orientador: Prof. Dr. Silvio Ikuyo Nabeta 
Este exemplar foi revisado e alterado em relação à versão original, sob responsabilidade única do autor e com a anuência de seu orientador.

São Paulo, de julho de 2010.

Assinatura do autor

Assinatura do orientador

\section{FICHA CATALOGRÁFICA}

Oliveira, Otávio Luís de

Contribuições metodológicas à implementação da tecnologia PLC/BPL / O.L. de Oliveira. -- ed.rev. -- São Paulo, 2010.

$100 \mathrm{p}$.

Dissertação (Mestrado) - Escola Politécnica da Universidade de São Paulo. Departamento de Engenharia de Energia e Automação Elétricas.

1. Redes de comunicação 2. Redes de distribuição de energia elétrica 3. Compatibilidade eletromagnética 4. Interferência eletromagnética I. Universidade de São Paulo. Escola Politécni ca. Departamento de Engenharia de Energia e Automação Eletricas II. t. 


\section{DEDICATÓRIA}

Dedico este trabalho à minha esposa Keli por toda a dedicação, paciência e amor investidos em mim durante os últimos 10 anos e por me incentivar insistentemente a concluir este trabalho. 


\section{AGRADECIMENTOS}

Aos meus pais que não mediram esforços para que pudesse estudar, além de terem contribuído enormemente para minha formação humana.

Ao meu orientador Prof. Dr. Silvio Ikuyo Nabeta e ao Prof. Dr. Ivan Eduardo Chabu pela confiança em meu trabalho e pelo contínuo incentivo ao longo do tempo, desde a época da Graduação.

Aos meus amigos (em ordem alfabética), Dani, Edgar, Fabi, Lucas, Mangueira e Tiago, que participaram dos momentos bons e ruins ao longo do desenvolvimento deste trabalho e que constantemente tornam minha vida um contínuo aprendizado.

Aos colegas do Grupo de Máquinas e Acionamentos Elétricos e do Laboratório de Eletromagnetismo Aplicado da Escola Politécnica pelo ótimo convívio e permanente troca de experiências.

Finalmente, à Hypertrade Telecom pelo fornecimento dos equipamentos e acessórios necessários a execução dos trabalhos e pela autorização para a divulgação de inúmeras informações contidas neste trabalho. Além disso, agradeço aos colegas de trabalho que ajudaram em muitas das medições, fotos, construção de muitas das estruturas apresentadas neste trabalho e pelas discussões construtivas sobre a tecnologia PLC. 


\section{RESUMO}

Este trabalho tem como objetivo fornecer contribuições metodológicas à implementação da tecnologia PLC/BPL em seus diversos ambientes reais de instalação.

São apresentados os aspectos básicos envolvidos, princípio de operação, as topologias das redes PLC, vantagens e desvantagens e exemplos de aplicação.

Além disso, são apresentadas as contribuições deste trabalho, as quais visam estabelecer procedimentos no desenvolvimento dos projetos de redes de comunicação que utilizam a tecnologia PLC, assim como procedimentos de instalação nos diversos ambientes reais e os procedimentos para o comissionamento das redes implantadas.

São destacados os aspectos relacionados às redes comerciais, as quais possuem inúmeros requisitos de desempenho, manutenção preventiva e/ou corretiva, além dos aspectos financeiros dos projetos e os pontos importantes para atendimento da legislação atualmente em vigor.

Finalmente, para cada procedimento apresentado, o mesmo é contextualizado através da apresentação de um caso prático associado.

Palavras-chave: Power Line Communications. Broad Band Over Power Lines. Comunicação pela rede elétrica. Metodologia de implantação. Interferência eletromagnética. Compatibilidade eletromagnética. 


\begin{abstract}
This work aims to provide methodological contributions to PLC/BPL implementations in their several real installation environments.

It is presented the basic aspects of the technology as well as the operation principle, the networks topologies, the advantages and the disadvantages and application examples.

Furthermore, it is presented the contributions of this work, which goal is to establish procedures related to projects developments of PLC communication networks, some procedures related to the installation process in their real environments and the procedures for commissioning a deployed network.

It is emphasized the commercial networks aspects, which demand several performance requirements, the preventive and/or corrective maintenance, as well as the financial aspects and the main topics to comply with the current regulation.
\end{abstract}

Finally, every presented procedure is exemplified with a real case in order to demonstrate its practical functionality.

Keywords: Power Line Communications. Broad Band Over Power Lines. Communication over Power Lines. Implantation methodology. Electromagnetic interference. Electromagnetic compatibility. 


\section{LISTA DE ILUSTRAÇÕES}

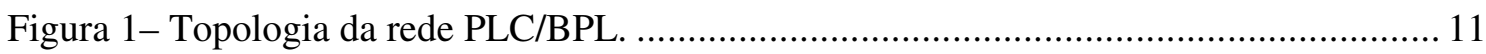

Figura 2 - Topologia simplificada da rede PLC/BPL. ........................................................ 12

Figura 3 - Exemplo de aplicação externa. .................................................................... 14

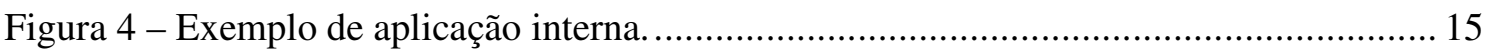

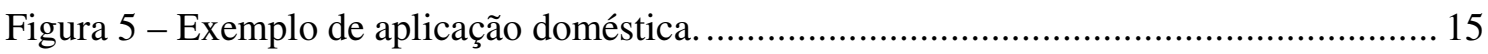

Figura 6 - (a) Foto da religadora utilizando o PLC como meio de comunicação. (b) Equipe de

linha viva da concessionária local instalando os acopladores na rede de média tensão.......... 17

Figura 7 - Comparativo entre FDM convencional e OFDM [51] ..................................... 18

Figura 8 - Exemplo de espectro de um sinal PLC banda larga.......................................... 19

Figura 9 - Espectro de um sinal PLC banda larga utilizando a máscara de potência. ............ 22

Figura 10 - Ilustração de um link ............................................................................ 23

Figura 11 - Esquema da topologia radial da rede PLC/BPL. ........................................ 25

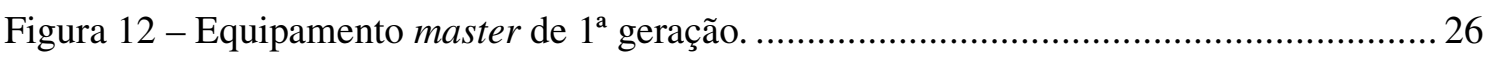

Figura 13 - Equipamento do tipo repeater (lado esquerdo da foto)................................. 27

Figura 14 - Equipamento do tipo CPE. .............................................................. 28

Figura 15 - Esquema de ligação de acoplador capacitivo. ................................................ 29

Figura 16 - Acoplador capacitivo para redes de baixa tensão. ..........................................29

Figura 17 - Acoplador capacitivo para redes de média tensão. ............................................ 30

Figura 18 - Régua comumente utilizada em instalações PLC/BPL.................................... 31

Figura 19 - Esquema de ligação da régua................................................................... 32

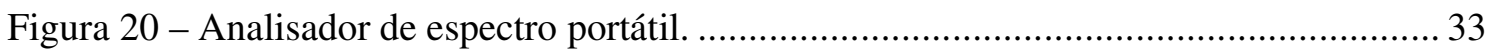

Figura 21 - Gerador de sinais PLC portátil............................................................... 34

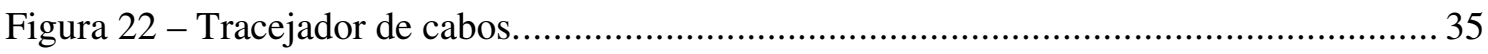

Figura 23 - Mala de ferramenta comumente utilizada por equipes de campo....................... 36

Figura 24 - Exemplo de planejamento de links........................................................ 40

Figura 25 - Foto de um ferrite comumente utilizado em redes banda larga......................... 41

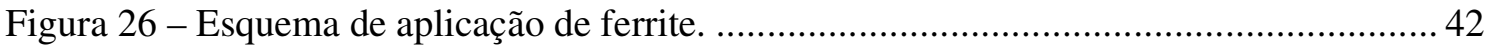

Figura 27 - Foto de uma bobina pronta para ser utilizada........................................... 42

Figura 28 - Estrutura física da rede comercial implantada.......................................... 43

Figura 29 - Planejamento de links da rede comercial implantada.................................... 44 
Figura 30 - (a) Caixa abrigo (superior) para o equipamento master; (b) Detalhe do master dentro da caixa abrigo; (c) Equipamento repeater instalado dentro da sala de informática.... 44 Figura 31 - Exemplo 1 de uma rede PLC/BPL simples. .................................................... 51

Figura 32 - Exemplo 2 de uma simples rede PLC/BPL. .................................................. 52

Figura 33 - Estrutura da rede PLC dentro da pousada. ................................................ 54

Figura 34 - Fotos da estrutura montada na pousada..................................................... 55

Figura 35 - Distribuição dos medidores e esquema da prumada do edifício.......................... 56

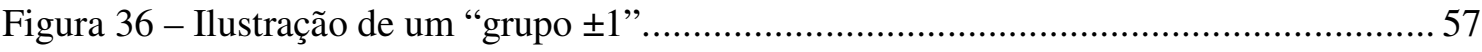

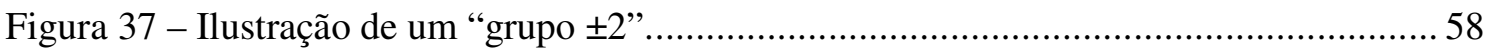

Figura 38 - Estrutura construída para abordagem do edifício comercial. ........................... 60

Figura 39 - Fotos do centro de medição do edifício comercial abordado. ........................... 61

Figura 40 - Divisão de um ramal secundário em 2 regiões. ........................................... 62

Figura 41 - Divisão de um ramal secundário em 3 regiões. ............................................ 63

Figura 42 - Estrutura do primeiro ramal secundário abordado........................................ 64

Figura 43 - Estrutura do segundo ramal secundário abordado. ....................................... 65

Figura 44 - Fotos da estrutura instalada na cidade de Barreirinhas. .................................. 65

Figura 45 - Ilustração do esquema de abordagem com cabo auxiliar. ................................... 67

Figura 46 - Exemplo de cabos auxiliares. (a) cabo AFD 1p-22 da RFS e (b) cabo coaxial.... 67 Figura 47 - Ceagesp. (a) Vista aérea com destaque para o pavilhão MFE-B e (b) vista interna

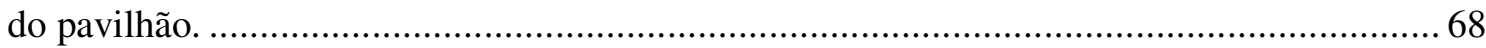

Figura 48 - Esquema para confinamento do sinal PLC em uma única tomada.................... 70

Figura 49 - Estrutura montada de um acoplador junto com ferrites. .................................. 71

Figura 50 - Ilustração do esquema de priorização de circuitos elétricos.............................. 72

Figura 51 - Foto de quadro de distribuição contendo ferrites para priorização de circuitos

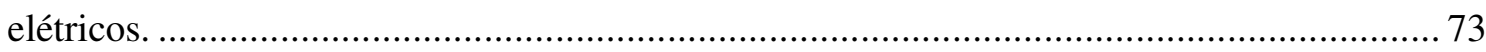

Figura 52 - Esquema básico para utilização da rede telefônica como meio de transporte dos

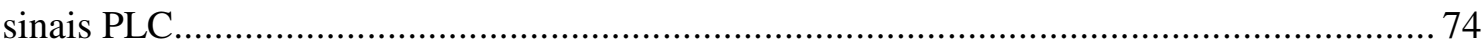

Figura 53 - Instalação utilizando a rede telefônica. (a) Injeção do sinal na rede telefônica e (b)

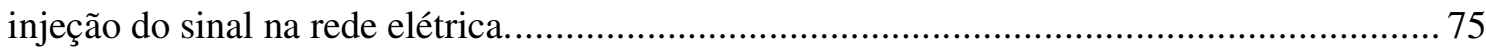

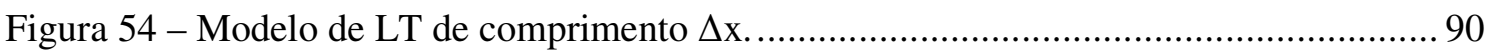

Figura 55 - Ilustração comparativa entre a (a) rede elétrica modelada em $60 \mathrm{~Hz}$ e a mesma rede (b) modelada em alta freqüência...................................................................... 93

Figura 56 - Forma de onda da corrente absorvida por LFCs.......................................... 94

Figura 57 - Espectro (em pu) das correntes absorvidas [70]....................................... 96 
Figura 58 - Espectro verificado na casa do presente autor........................................... 97 Figura 59 - Encarte de lâmpada fluorescente compacta comumente comercializada no Brasil. 


\section{LISTA DE TABELAS}

Tabela 1 - Divisão do espectro em faixas de trabalho...................................................... 23

Tabela 2 - Diversos tipos de injeção de sinal.................................................................... 46

Tabela 3 - Comandos para iniciar o aplicativo iperf em seus diversos modos de operação. .. 47

Tabela 4 - Características das lâmpadas testadas [70]. ................................................... 96 


\section{LISTA DE ABREVIATURAS E SIGLAS}

\begin{tabular}{|c|c|}
\hline ADSL & Asymmetric Digital Subscriber Line \\
\hline AM & Modulação em Amplitude \\
\hline ANATEL & Agência Nacional de Telecomunicações \\
\hline ANEEL & Agência Nacional de Energia Elétrica \\
\hline APTEL & Associação de Empresas Proprietárias de Infra-estrutura e de Sistemas \\
\hline \multicolumn{2}{|c|}{ Privados de Telecomunicações } \\
\hline BPL & Broad Band Over Power Lines \\
\hline CEM & Compatibilidade Eletromagnética \\
\hline COPEL & Companhia Paranaense de Energia \\
\hline $\mathrm{CoS}$ & Class of Service \\
\hline $\mathrm{CPE}$ & Customer Premises Equipment \\
\hline $\mathrm{CPqD}$ & Centro de Pesquisa e Desenvolvimento em Telecomunicações \\
\hline DS2 & Design of Systems on Silicon \\
\hline FCC & Federal Communications Commission \\
\hline FDM & Frequency Division Multiplexing \\
\hline FFT & Fast Fourier Transform \\
\hline GNU & Designação da licença para Software Livre \\
\hline IEC & International Electrotechnical Commission \\
\hline IEM & Interferência Eletromagnética \\
\hline Inmetro & Instituto Nacional de Metrologia Normalização e Qualidade Industrial \\
\hline IP & Internet Protocol \\
\hline ITU & International Telecommunication Union \\
\hline LFC & Lâmpada Fluorescente Compacta \\
\hline LT & Linha de Transmissão \\
\hline
\end{tabular}




\begin{tabular}{|c|c|}
\hline MAC & Media Access Control \\
\hline NTP & Network Time Protocol \\
\hline OFDM & Orthogonal frequency-division multiplexing \\
\hline OPERA & Open PLC European Research Alliance \\
\hline PLC & Power Line Communications \\
\hline QGBT & Quadro Geral de Baixa Tensão \\
\hline QoS & Quality of Service \\
\hline SAMBA & System for Advanced interactive digital television and Mobile services \\
\hline in Brazil & \\
\hline SEP & Sistema Elétrico de Potência \\
\hline SmartGrid & Redes elétricas inteligentes \\
\hline SO & Sistema Operacional \\
\hline STP & Spanning Tree Protocol \\
\hline TCP & Transmission Control Protocol \\
\hline THD & Total Harmonic Distortion \\
\hline TUE & Tomadas de uso específico \\
\hline TUG & Tomadas de uso geral \\
\hline UDP & User Datagram Protocol \\
\hline VLAN & Virtual Local Area Network \\
\hline VLC & Aplicativo multi plataforma para reprodução de mídias diversas \\
\hline
\end{tabular}




\section{SUMÁRIO}

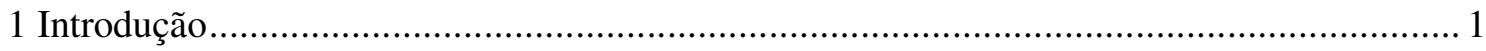

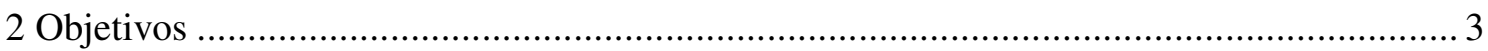

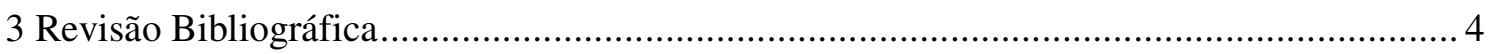

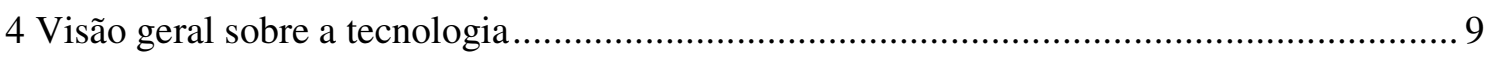

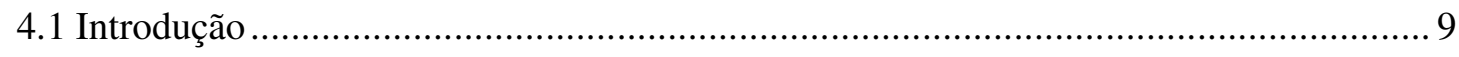

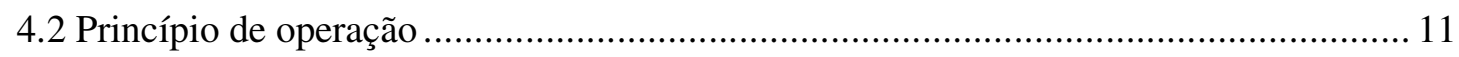

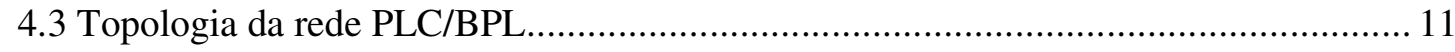

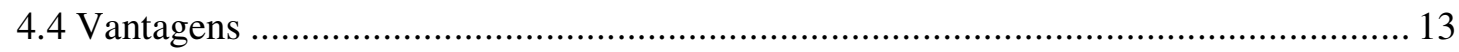

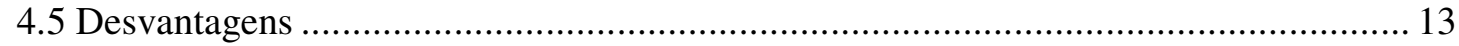

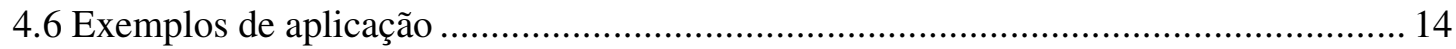

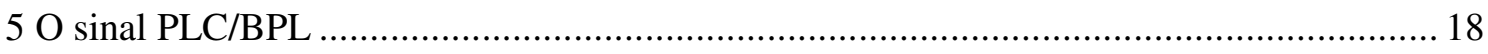

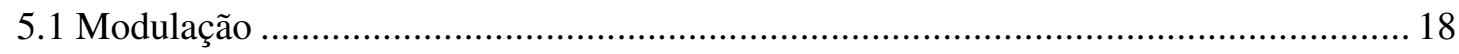

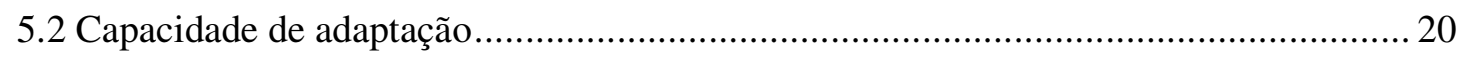

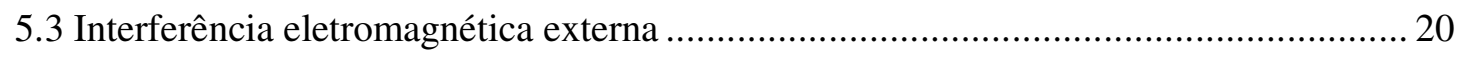

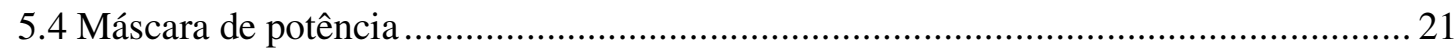

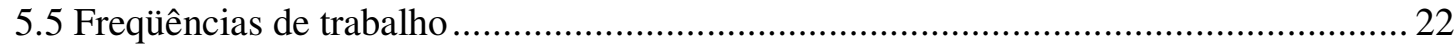

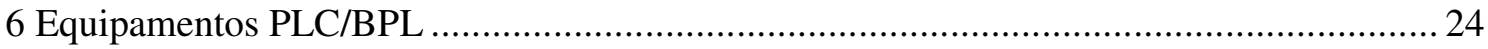

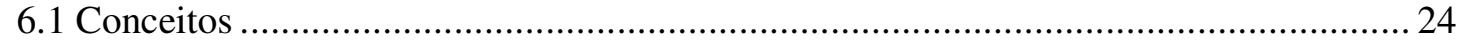

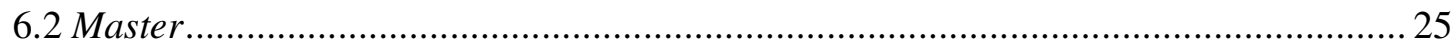

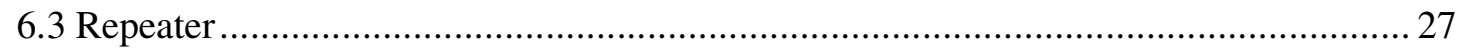

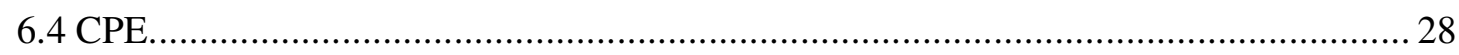

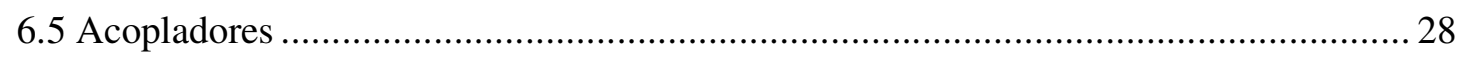

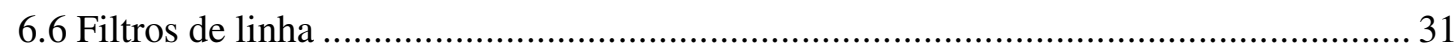

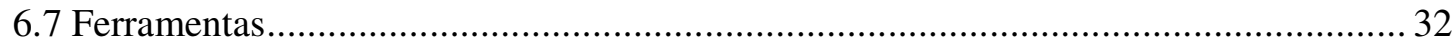

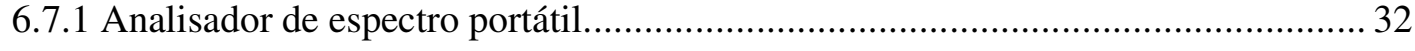

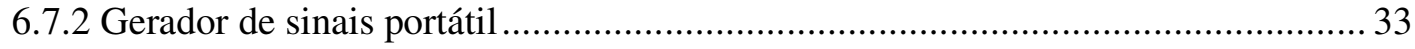

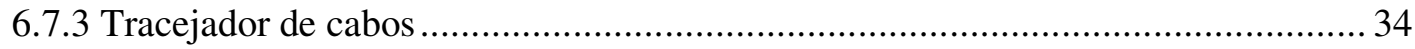

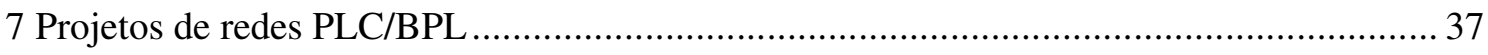

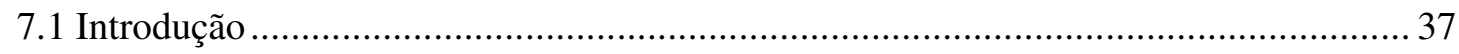

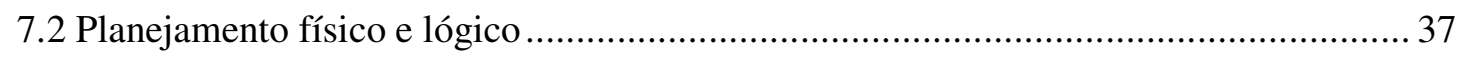

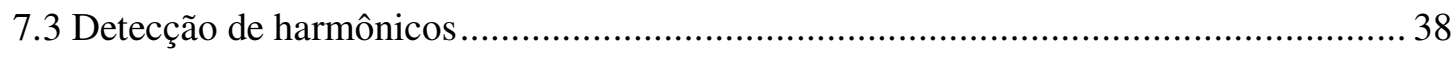




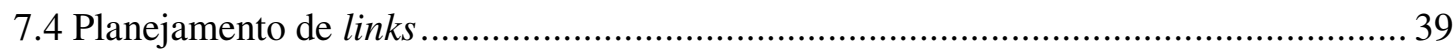

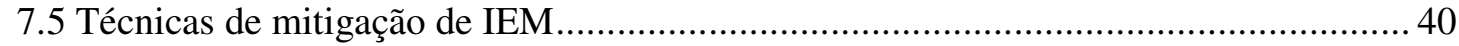

7.6 Alocação dos equipamentos, acoplamento e medições............................................... 45

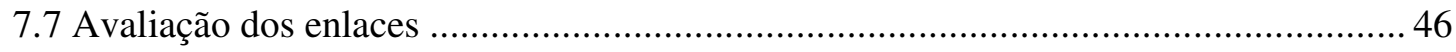

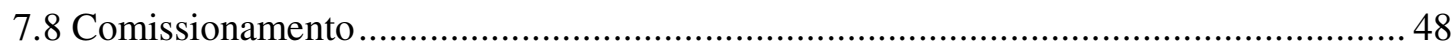

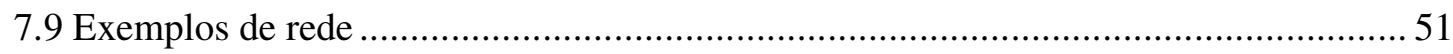

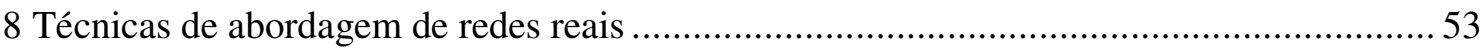

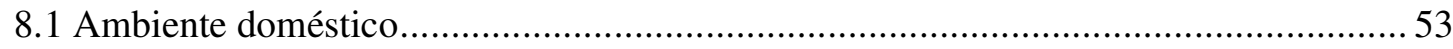

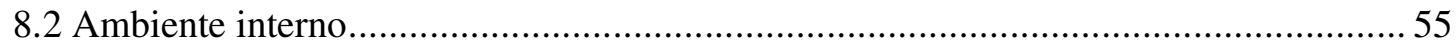

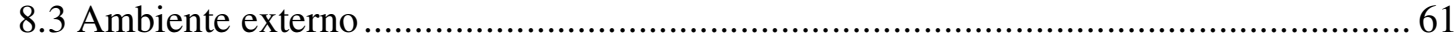

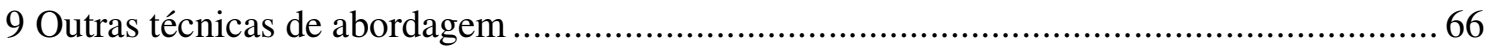

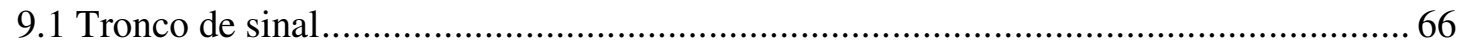

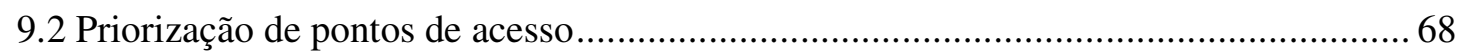

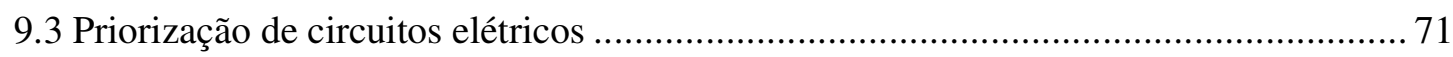

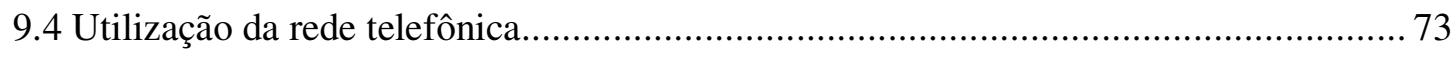

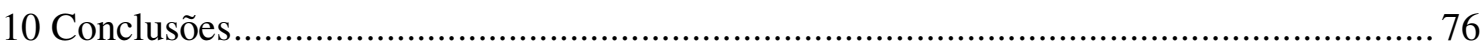

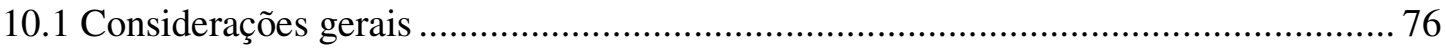

10.2 Resumo das contribuições e trabalhos desenvolvidos............................................... 76

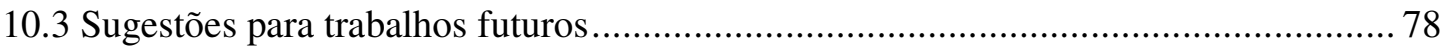

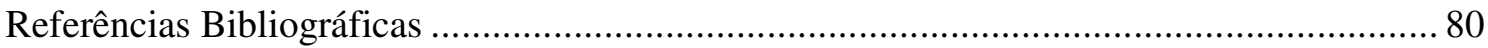

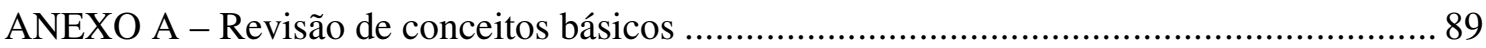

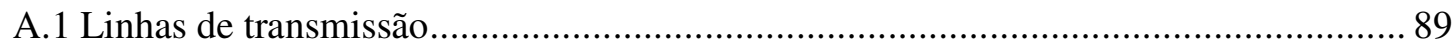

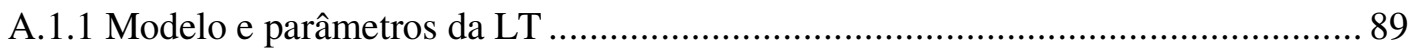

A.1.2 Parâmetros distribuídos x parâmetros concentrados ........................................ 92

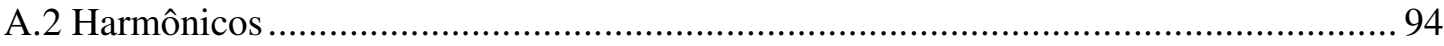

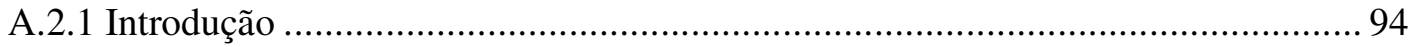

A.2.2 Importância para as redes PLC/BPL .................................................................. 97 


\section{Introdução}

A tecnologia de comunicação pela rede elétrica, conhecida como Power Line Communications (PLC) consiste em toda tecnologia que utiliza a rede elétrica como meio físico para transporte dos sinais.

Nos últimos anos aumentou muito o interesse por tal tecnologia no Brasil. Particularmente, com a recente publicação da regulamentação por parte da Agência Nacional de Telecomunicações (ANATEL) [1] e da regulamentação da Agência Nacional de Energia Elétrica (ANEEL) [2], verificou-se um aumento significativo no desenvolvimento de novos projetos.

Dentre todos os segmentos passíveis de adotarem a tecnologia, foi o segmento de telecomunicações que respondeu de forma mais rápida. Atualmente, a tecnologia PLC/BPL vem sendo usada comercialmente como solução de última jarda, ou seja, as operadoras de telecomunicações chegam com suas estruturas convencionais nos locais a serem abordados e então, dentro das edificações a tecnologia PLC/BPL é utilizada para entregar os sinais até o consumidor final. Outra particularidade é que a tecnologia é bem aceita em locais onde existe impossibilidade de obras civis, ou impeditivos como, por exemplo, tubulações obstruídas para passagem de cabeamento.

Assim, a tecnologia vem sendo usada comercialmente, no Brasil, como "uma solução para quem não tem solução", uma vez que ainda não existe escala de implantação para redução dos custos envolvidos, além das características acima citadas. Destaca-se que a carga tributária total incidente nos equipamentos pode chegar até $120 \%$, salientando, ainda, que não existem equipamentos de fabricação nacional [3].

Apesar do crescimento do número de projetos de redes PLC/BPL no Brasil, verifica-se, ainda, escassez de mão de obra qualificada. Nos últimos anos muitos projetos foram executados, porém seus resultados ficaram abaixo do esperado. Muitas vezes o que ocorreu na prática ficou caracterizado, a posteriori, como falta de capacitação técnica para o desenvolvimento dos trabalhos. Entende-se falta de capacitação técnica por falta de conhecimento do modo de operação dos equipamentos e, principalmente, o modo como os sinais PLC/BPL se comportam nas redes elétricas de potência. A consequiência crítica de tais aspectos foi colocar 
a tecnologia em dúvida, uma vez que se noticiou (informação verbal) ${ }^{1}$ que ela ainda não estava madura, necessitava de aperfeiçoamentos por parte dos fabricantes, assim como o desenvolvimento de inúmeros projetos piloto.

Como qualquer tecnologia, esta também possui dificuldades em sua implementação, assim, no capítulo a seguir, são descritos os objetivos deste trabalho.

\footnotetext{
${ }^{1}$ Informações veiculadas em algumas palestras do IX e X Seminário PLC da Aptel - www.aptel.com.br.
} 


\section{Objetivos}

Este trabalho tem como objetivo apresentar alguns aspectos relacionados à tecnologia PLC/BPL no sentido de contribuir para a metodologia de desenvolvimento de projetos de redes PLC/BPL ou de manutenções nas mesmas. As contribuições visam esclarecer e estabelecer procedimentos em uma área de recente e crescente interesse, mas que apresenta dificuldades inerentes de implementação.

Para tanto, serão apresentados os aspectos básicos da tecnologia, seu princípio de operação, as topologias das redes PLC/BPL, assim como suas vantagens e desvantagens e exemplos de aplicação. Adicionalmente, serão apresentados alguns equipamentos existentes, acessórios e equipamentos de medição, os quais têm papel essencial nas implantações.

Além disso, serão abordados alguns aspectos de projeto de redes PLC/BPL destacando-se o comissionamento dos mesmos, uma vez que o ponto de conexão entregue ao cliente deve estar em perfeitas condições de uso. Ademais, a documentação eficiente das redes instaladas tem papel fundamental na atividade de manutenção das mesmas, seja esta preventiva ou corretiva. Adicionalmente, a documentação da rede é fundamental para atendimento da regulamentação brasileira, a qual exige que informações mínimas sobre o projeto sejam documentadas e disponibilizadas para a ANATEL, além de auxiliar na resolução de eventuais problemas relacionados à Interferência e Compatibilidade Eletromagnética (IEM/CEM).

Finalmente, serão apresentadas técnicas de abordagem das edificações, as quais definem qual a melhor topologia de injeção dos sinais, assim como o melhor local para realizá-las. 


\section{Revisão Bibliográfica}

São vários os trabalhos presentes na literatura sobre a tecnologia PLC/BPL. Nos últimos 10 anos, com o advento de eventos e conferências específicas sobre tal assunto, aumentou muito o número de trabalhos publicados.

Muitos são os aspectos associados à tecnologia PLC, os quais estão presentes em grande parte dos artigos já publicados. Como exemplo desses aspectos, pode-se citar a caracterização do canal PLC, a compatibilidade e interferência eletromagnética, as técnicas de modulação e codificação, o processamento de sinais, as funções de rede, a interoperabilidade, a segurança, o gerenciamento de rede, as redes elétricas inteligentes (SmartGrid), as aplicações em banda larga, as redes experimentais, as redes comerciais, a regulamentação, as perspectivas de negócios, as aplicações em redes elétricas de veículos ou aeronaves, entre outros. Desta forma, as referências que serão discutidas na sequiência seguirão a divisão por assunto acima citada, logo as publicações internacionais aparecerão em conjunto com as nacionais.

No que se refere à transmissão do sinal PLC pela rede elétrica, pode-se citar as referências [4], [5], [6] e [7], as quais detalham diversas características da propagação e distribuição dos sinais. São utilizados os modelos de linha de transmissão para prever o comportamento dos sinais através de simulações computacionais ou métodos analíticos. Verificam-se ainda simulações para determinar as atenuações sofridas pelos sinais nas redes elétricas. Em praticamente todos os casos as análises são restritas a topologias simples de redes elétricas. Obviamente, é extremamente complexa a tarefa de modelar uma rede elétrica com todas as suas topologias, acessórios, dispositivos e cargas, do ponto de vista de alta freqüência $(\mathrm{MHz})$. Adicionalmente, pode-se citar a referência [8] onde é apresentada a influência de dispositivos de proteção contra surtos (DPS) na taxa de transmissão dos sistemas PLC/BPL.

Do ponto de vista de IEM e CEM destacam-se, inicialmente, os trabalhos que tratam o sistema PLC/BPL como o agente interferente. As referências [9] e [10] apresentam uma modelagem numérica para a análise das características de emissão dos sistemas PLC/BPL, a qual auxilia na compreensão das radiações não intencionais originadas pelo sistema. Da mesma maneira as referências [11], [12] e [13] apresentam contribuições relacionadas ao cálculo numérico das radiações não intencionais, assim como aos efeitos da redução da relação sinal ruído de uma estação receptora em ondas curtas devido aos sinais do sistema 
PLC/BPL. Além disso, apresentam a situação das normas pertinentes na Coréia e medições das emissões radiadas e conduzidas na faixa de rádios AM e rádio amador.

Para auxiliar o estudo das perturbações que podem ser ocasionadas pelos sistemas PLC/BPL, foi desenvolvido um receptor de rádio com o propósito de coletar e analisar sinais onde o acoplamento pode ser realizado de várias formas diferentes (galvânico, capacitivo, indutivo e radiado) [14].

No Brasil, foram desenvolvidos trabalhos no sentido de avaliar as potenciais interferências que os sistemas PLC/BPL podem causar. As referências [15] e [16] são frutos de um destes trabalhos desenvolvidos, onde o presente autor teve participação ativa nas atividades de campo. Foram realizadas inúmeras medições em campo nas cidades de Porto Alegre e Campinas. Um sistema de comunicação em HF entrou em operação no mesmo ambiente eletromagnético onde havia um sistema PLC/BPL em operação. Participaram das atividades o Instituto Nacional de Metrologia, Normalização e Qualidade Industrial (Inmetro), Anatel, Aeronáutica, Exército, Centro de Pesquisa e Desenvolvimento em Telecomunicações (CPqD) e fabricantes de equipamentos PLC/BPL. Verificou-se que os procedimentos adotados, ou seja, as recomendações da norma internacional ITU-T K-60 [15], não apresentaram resultados satisfatórios.

Existem diversas técnicas de mitigação para evitar a ocorrência de IEM. Verifica-se em [17] uma proposta para redução das emissões radiadas que consiste em injetar um sinal em oposição de fase de $180^{\circ}$, no sentido de criar uma interferência destrutiva nos locais onde não se deseja a presença de sinais PLC/BPL. Outras técnicas consistem em selecionar a fase do sinal a ser injetado de forma adaptativa [18] [19] [20].

Por outro lado, os sistemas PLC/BPL, muitas vezes, são considerados interferidos. Na prática, isso ocorre freqüentemente, como pode ser observado em [21], onde é apresentado o elevado nível das emissões provenientes de harmônicos das cargas elétricas comumente existentes nas residências. Verifica-se que tais emissões, muitas vezes, possuem intensidades iguais ou superiores às dos sinais PLC/BPL, constituindo-se em fontes potenciais de IEM.

Do ponto de vista regulatório, também são muitos os trabalhos presentes na literatura. Especificamente no Brasil destacam-se as referências [16] [22] [23], as quais apresentam resultados de medições realizadas por concessionárias de energia elétrica em conjunto com fabricantes e a Anatel. São destacados os agentes contrários à adoção da tecnologia no país, como os rádio amadores e Exército, assim como as diretrizes básicas que foram adotadas na 
regulamentação da tecnologia no Brasil, tendo como base a norma da Federal Communications Commission (FCC) americana [24]. Além disso, são apresentados os aspectos regulatórios em outros países do mundo.

Com relação ao desempenho dos equipamentos PLC/BPL, encontram-se diversos trabalhos na literatura. Muitas vezes tratam-se de avaliações que relacionam a distância do ponto de injeção dos sinais com o desempenho obtido, como pode ser verificado em [25]. Ademais, avaliações de desempenho mais complexas podem ser verificadas em [26], a qual analisa o desempenho de uma rede PLC/BPL que possui trechos tanto em média tensão quanto em baixa tensão. Trata-se de uma rede de acesso onde o objetivo é prover acesso em banda larga para cerca de 200 unidades consumidoras. Adicionalmente, são destacadas algumas dificuldades encontradas na avaliação objetiva do desempenho de redes PLC/BPL em ambientes reais.

Encontram-se ainda trabalhos apresentando os efeitos de múltiplos circuitos, a partir de modelos teóricos, no desempenho das redes PLC/BPL [27]. Na mesma linha destacam-se as referências [28] [29], as quais apresentam um método para estimar a largura de banda de redes PLC/BPL, considerando as influências do tamanho dos pacotes que trafegarão pela rede, assim como de interferências no canal de comunicação, por exemplo, harmônicos provenientes de motores elétricos, retificadores e reatores. De forma complementar, pode-se citar [30], no qual é apresentado o efeito do tamanho dos pacotes que trafegam na rede em diversas condições do canal de comunicação e verifica-se que nem sempre a utilização do maior pacote resultará em maior capacidade de comunicação. Em particular, a referência [31] destaca a influência de tais harmônicos no desempenho dos sistemas PLC/BPL, onde foram instalados equipamentos em um edifício e foram variadas as cargas elétricas conectadas à rede. Desta forma, verificou-se grande presença de harmônicos provenientes de tais cargas, sendo principalmente devido a cargas de iluminação. Os problemas de IEM foram minimizados com a utilização de filtros.

Do ponto de vista de aplicações reais é relativamente pequeno o número de trabalhos publicados. Inicialmente destaca-se [32], a qual apresenta um sistema PLC/BPL capaz de suprir as necessidades de comunicação existentes em um ambiente residencial, como aplicações do tipo triple play ${ }^{2}$. Do ponto de vista de redes PLC/BPL de maior escala em ambientes reais destacam-se as referências [33] e [34], as quais apresentam duas grandes redes PLC/BPL, onde o objetivo é prover serviços de banda larga para inúmeras unidades

\footnotetext{
${ }^{2}$ Trata-se da combinação de três serviços: acesso à internet banda larga, telefonia e vídeo.
} 
consumidoras, assim como serviços de monitoramento e vigilância. Uma das redes apresentadas é constituída de trechos em média e baixa tensão e a outra trata da abordagem de um edifício. São apresentados, ainda, muitos dos problemas encontrados na prática durante o desenvolvimento de projetos em ambientes reais. Além disso, durante a abordagem do edifício foi utilizada uma rede de cabos coaxiais para auxiliar no transporte dos sinais PLC/BPL até os pontos estratégicos de injeção dos sinais na rede elétrica. Destaca-se que até o elevador do edifício abordado oferecia conectividade, uma vez que seu circuito de alimentação auxiliar (iluminação) foi utilizado para transporte dos sinais.

Ainda no campo das aplicações, pode-se citar as referências [35] e [36], as quais apresentam a tecnologia PLC/BPL como uma solução factível para áreas rurais, remotas, ou ainda como uma solução para a inclusão digital. Na prática a utilização da tecnologia como uma solução para tais situações tem, necessariamente, que possuir custos aceitáveis no desenvolvimento dos projetos, fato que ainda não acontece devido aos altos custos dos equipamentos e baixa escala de utilização. Soma-se ainda o fato das referências não citarem, por exemplo, a necessidade de grande quantidade de equipamentos para atendimento de regiões remotas, além do fato de muitas vezes não existir uma rede de baixa tensão, por longos trechos de redes nas zonas rurais, para alimentação dos equipamentos que teriam que ser instalados ao longo de toda a rede.

Uma aplicação bastante interessante da tecnologia PLC/BPL é sua utilização como canal de retorno da TV Digital [37]. Em particular, a tecnologia foi implantada em dois ramais secundários de um bairro da cidade de Barreirinhas, no estado do Maranhão, e foi utilizada como um dos meios de transmissão dos comandos executados através da interface da TV Digital. Destaca-se que o presente autor coordenou a equipe que realizou a implantação de tal rede PLC/BPL.

Existem, ainda, inúmeras outras aplicações da tecnologia PLC/BPL. Pode-se citar a referência [38], a qual apresenta como a presente tecnologia pode ser utilizada no conceito de Smart Grid. O trabalho foca na necessidade de novas estratégias de controle e proteção das redes de distribuição do futuro com grande presença da geração distribuída. Relacionado à utilização da tecnologia na medição eletrônica, pode-se citar [39]. Destacam-se, ainda, aplicações da tecnologia no controle de iluminação pública [40], onde se verifica grande preocupação com a redução do consumo de energia, assim como a viabilidade financeira da solução. $\mathrm{Na}$ seqüência, pode-se citar [41], a qual apresenta a utilização da tecnologia no controle de velocidade de motores de indução. 
Com relação às experiências das concessionárias de energia elétrica do Brasil pode-se destacar a instalação realizada na cidade de Santo Antonio da Platina, no estado do Paraná, pela Companhia Paranaense de Energia (COPEL). Foram ativadas cerca de 110 unidades consumidoras, sendo que eles vivenciaram inúmeros dos problemas que podem ocorrer nas instalações em ambiente externo. Tais aspectos serão abordados ao longo deste trabalho.

Existem, ainda, as aplicações mais heterodoxas, como por exemplo, a utilização da tecnologia nas redes elétricas de aeronaves [42], nas redes elétricas de navios [43]. Muitas vezes a utilização de uma infra-estrutura já existente como meio de comunicação é um elemento extremamente importante na redução de peso do conjunto final. Verifica-se ainda o emprego da tecnologia em equipamentos comumente encontrados nas residências, os chamados eletrodomésticos do futuro [44]. 


\section{Visão geral sobre a tecnologia}

\subsection{Introdução}

Sem dúvida, um dos grandes fatores que motivou o desenvolvimento da tecnologia PLC/BPL foi o aproveitamento da grande capilaridade da rede elétrica.

Sua utilização surgiu, inicialmente, como uma forma de comunicação entre subestações. Esses sistemas são conhecidos como carrier e avançaram a ponto de permitir o tráfego de sinais de teleproteção, dados e voz sobre linhas de transmissão de alta tensão [45] [46] e atualmente existem inúmeros projetos desenvolvidos em diversos locais do país [47]. Destaca-se ainda uma das primeiras patentes relacionadas à tecnologia [48].

Conforme já citado, a tecnologia de comunicação pela rede elétrica, conhecida como Power Line Communications (PLC) consiste em toda tecnologia que utiliza a rede elétrica como meio físico para transporte dos sinais. Como exemplo inicial, pode-se citar a tecnologia PLC de banda estreita (narrow bandwidth), a qual opera na faixa de centenas de $\mathrm{kHz}$ com uma capacidade de transmissão da ordem de unidades de kibi bits por segundo (Kibit/s) ${ }^{3}$. Na sequiência, pode-se citar a tecnologia PLC de banda larga, também conhecida como Broadband Over Power Lines (BPL), sendo que a faixa de operação é da ordem de unidades a dezenas de $\mathrm{MHz}$ com uma capacidade de transmissão de dezenas a centenas de mebi bits por segundo (Mibit/s) ${ }^{4}$.

É importante ressaltar que assim como outras tecnologias de comunicação, a tecnologia PLC/BPL permite criar enlaces de comunicação e, portanto, quando esta é utilizada para realizar acessos à internet necessita-se de um ponto de conectividade com a mesma, como qualquer outra tecnologia. Tal informação é importante a ser destacada, uma vez que comumente veiculam-se informações transmitindo a idéia de que a tecnologia por si só oferecerá conectividade com a internet, fato este que não é real [49].

\footnotetext{
${ }^{3}$ Foi utilizada a nomenclatura da IEC60027 - Letter symbols to be used in electrical technology - Part 2: Telecommunications and electronics, onde 1 kibi $=2^{10}$.

${ }^{4}$ Foi utilizada a nomenclatura da IEC60027 - Letter symbols to be used in electrical technology - Part 2 : Telecommunications and electronics, onde 1 mebi $=\left(2^{10}\right)^{2}$.
} 
Do ponto de vista didático, a tecnologia PLC/BPL pode ser classificada em 3 grupos diferentes, relacionados à forma como a tecnologia é passível de ser empregada. Tais grupos são apresentados a seguir.

- PLC Externo: Trata-se da tecnologia utilizada na infra-estrutura elétrica de propriedade da concessionária, ou seja, nas ruas e avenidas das cidades. Pode ser aplicada tanto em redes de média quanto baixa tensão. Desta forma, a rede da concessionária passa a ser a última milha ${ }^{5}$ da rede de comunicação. Além disso, é um ambiente recém regulamentado pela Aneel [2] e sua exploração comercial é praticamente inexistente no país;

- PLC Interno: Trata-se da tecnologia utilizada dentro das edificações e/ou condomínios. Neste caso, quando se trata de uma rede de acesso, o usuário final não tem conectividade até a implantação da tecnologia PLC/BPL. Assim, o PLC/BPL passa a ser a última jarda ${ }^{6}$ da rede de comunicação. As aplicações são imediatas, como por exemplo, em prédios com tubulações entupidas ou impeditivos de obras civis, hospitais, museus, entre outros;

- PLC Doméstico: Trata-se da tecnologia utilizada dentro da área privativa do usuário final. Neste caso, o usuário final já possui conectividade com a internet, quando se tratar de uma rede de acesso. O objetivo é distribuir os sinais pelos cômodos ou ambientes da residência. O propósito é similar ao de um roteador Wi-fi comumente encontrado nas residências. Sua exploração comercial ainda é tímida devido ao baixo custo das tecnologias concorrentes.

\footnotetext{
${ }^{5}$ Termo utilizado pelas empresas de Telecomunicações para indicar a infra-estrutura de última milha responsável pela entrega dos serviços ao usuário final. Geralmente trata-se da infra-estrutura que transporta os sinais até as edificações.

${ }^{6}$ Termo utilizado pelas empresas de Telecomunicações para indicar a infra-estrutura de última jarda responsável pela entrega dos serviços ao usuário final. Geralmente trata-se da infra-estrutura presente na parte interna das edificações.
} 


\subsection{Princípio de operação}

O princípio de funcionamento da tecnologia consiste em sobrepor um sinal de alta frequiência $(\mathrm{MHz})$ ao $60 \mathrm{~Hz}$ existente na rede elétrica. Em se tratando da tecnologia de banda larga, a faixa de freqüência é tipicamente de $1 \mathrm{MHz}$ a $35 \mathrm{MHz}$. Obviamente, existem formas e métodos para realizar tal sobreposição, os quais serão apresentados no capítulo 7 deste trabalho.

\subsection{Topologia da rede PLC/BPL}

Basicamente, a rede PLC/BPL é uma rede ponto multi ponto (radial), ou seja, existe um ponto central que determina o início de toda a rede de comunicação. A Figura 1 apresenta um exemplo eletricamente extenso da topologia de aplicação da tecnologia nas redes elétricas.

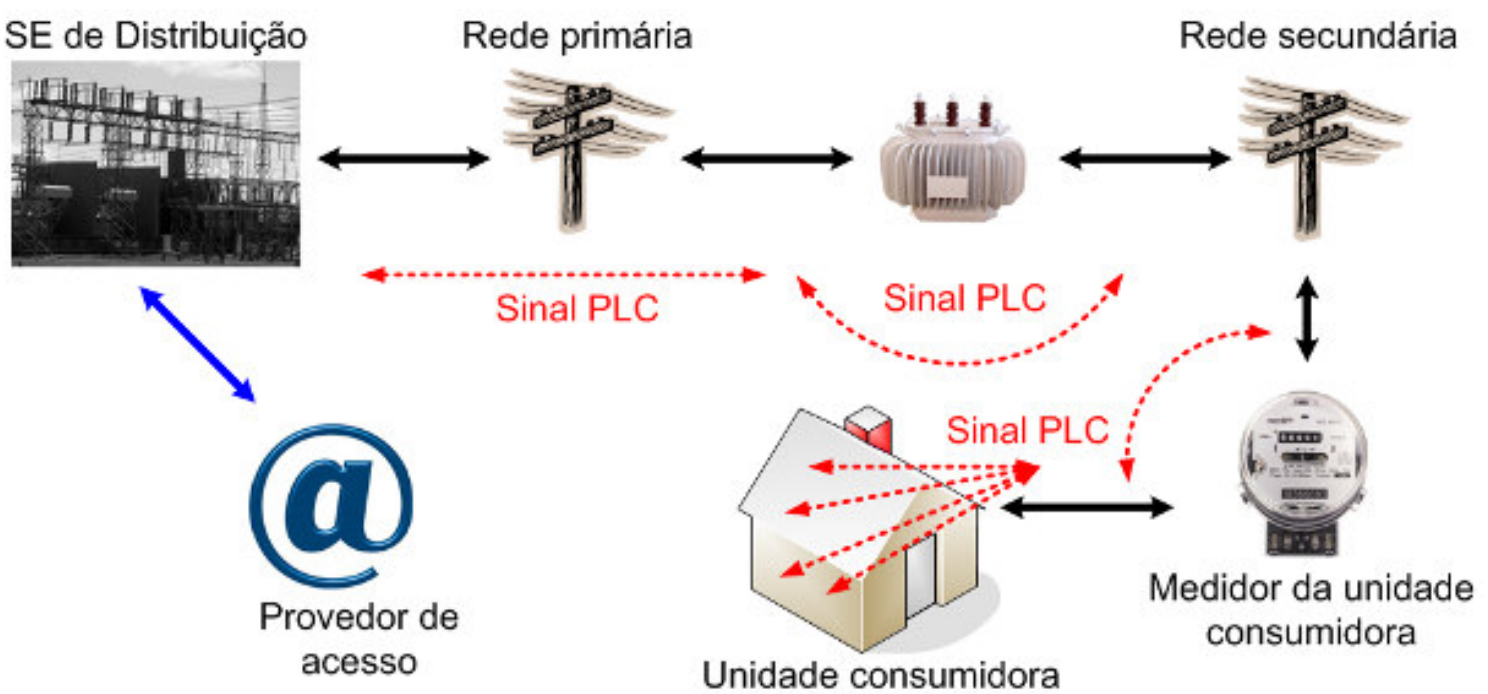

Figura 1- Topologia da rede PLC/BPL.

Através da análise da figura acima, verifica-se que a rede PLC/BPL, neste caso, tem início na subestação de distribuição (SE). Além disso, neste local encontra-se disponível um ponto de conectividade com a internet fornecido por um provedor qualquer. Na seqüência, o sinal 
PLC/BPL segue pela rede primária, ou alimentador, de média tensão no sentido de prover conectividade em toda a extensão da rede. Ao longo do alimentador estão presentes os transformadores, os quais consistem na interface entre as redes primárias e secundárias de baixa tensão. Não necessariamente nestes pontos, pode-se realizar o transporte do sinal PLC/BPL do alimentador para a rede de baixa tensão. Isso pode ser feito em cada um dos ramais secundários onde se deseja obter conectividade. A partir daí os sinais seguem em direção às residências, onde muitas vezes é necessário transpor os medidores de energia elétrica. Desta forma, os sinais adentram as residências oferecendo conectividade com a subestação de distribuição e, neste caso, com o provedor de acesso à internet, virtualmente, através de qualquer tomada.

Cabe destacar que, obviamente, os sinais não se propagarão indefinidamente através dos alimentadores, sendo necessária a existência de equipamentos ao longo da rede com a finalidade de reforçar os sinais.

Resumidamente, a Figura 2 apresenta a topologia radial da rede PLC/BPL.

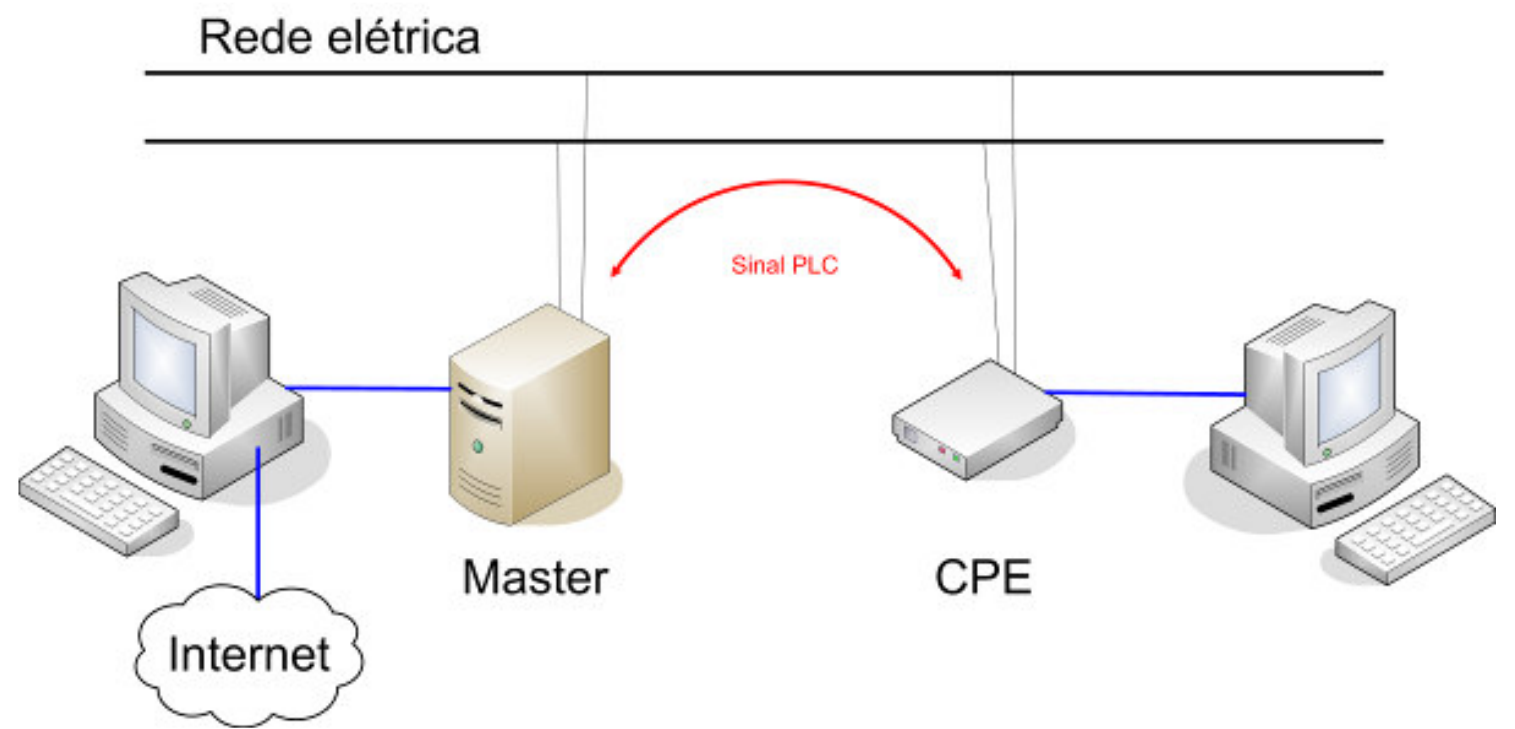

Figura 2 - Topologia simplificada da rede PLC/BPL. 


\subsection{Vantagens}

Dentre as vantagens oferecidas pela tecnologia PLC/BPL pode-se citar a capacidade de utilizar a infra-estrutura elétrica existente como meio de comunicação evitando custos associados à construção de novas redes. Além disso, a tecnologia de banda larga possui altas taxas de transferência, as quais vão de $45 \mathrm{Mbps}$ até $200 \mathrm{Mbps}$ na camada física [50], valores estes suficientes para a construção de redes de acesso. Outra característica interessante, já citada, é a topologia ponto multi ponto, a qual permite a conexão de inúmeros usuários a um único ponto de controle da rede.

\subsection{Desvantagens}

Como qualquer outra tecnologia, a tecnologia PLC/BPL também possui desvantagens. Podese citar que o desempenho da rede de comunicação depende fortemente das características da rede elétrica, assim como das cargas elétricas conectadas à mesma. Uma vez que tais características e cargas elétricas são variantes no tempo, torna-se relativamente complicada a tarefa de controlar tal ambiente.

É fato que tais características são levadas em conta no desenvolvimento dos projetos das redes PLC/BPL, portanto, a possibilidade de ocorrência de degradação no desempenho da rede de comunicação pode ser minimizada. 


\subsection{Exemplos de aplicação}

De acordo com a seção 4.1, a presente tecnologia é capaz de criar enlaces de comunicação entre dois pontos, como, por exemplo, uma rede de acesso. Desta forma, ela pode ser utilizada para oferta de serviços diversos de banda larga, vídeo conferências, monitoramento e vigilância, voz sobre IP, interfonia, entre outros.

Conforme a divisão didática de utilização da tecnologia apresentada no início deste capítulo serão mostrados na seqüência exemplos de aplicação da mesma.

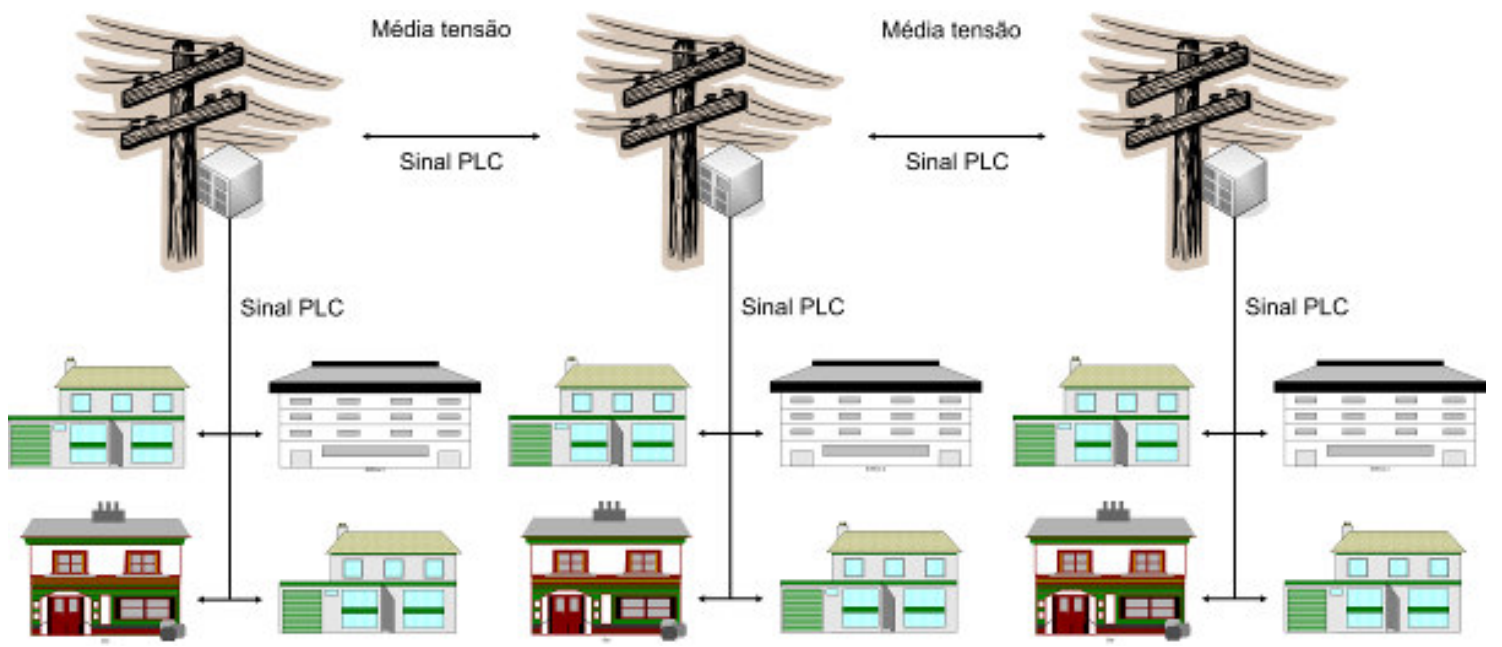

Figura 3 - Exemplo de aplicação externa.

Como se pode observar, a Figura 3 apresenta um exemplo de utilização da tecnologia onde os sinais PLC/BPL foram injetados em um dado alimentador e tais sinais foram transportados para as redes secundárias associadas. Desta forma, os sinais que estão presentes no alimentador são passíveis de oferecer conectividade às residências de tais redes secundárias de baixa tensão.

Na Figura 4 é possível verificar um exemplo de utilização da tecnologia em um ambiente interno. Considerando que a tecnologia está sendo utilizada numa rede de acesso, verifica-se que o sinal de conectividade com a internet já está disponível no subsolo da edificação. Desta forma, a tecnologia PLC/BPL faz o papel da última milha, ou seja, transporta os sinais do subsolo da edificação até os locais de interesse. 


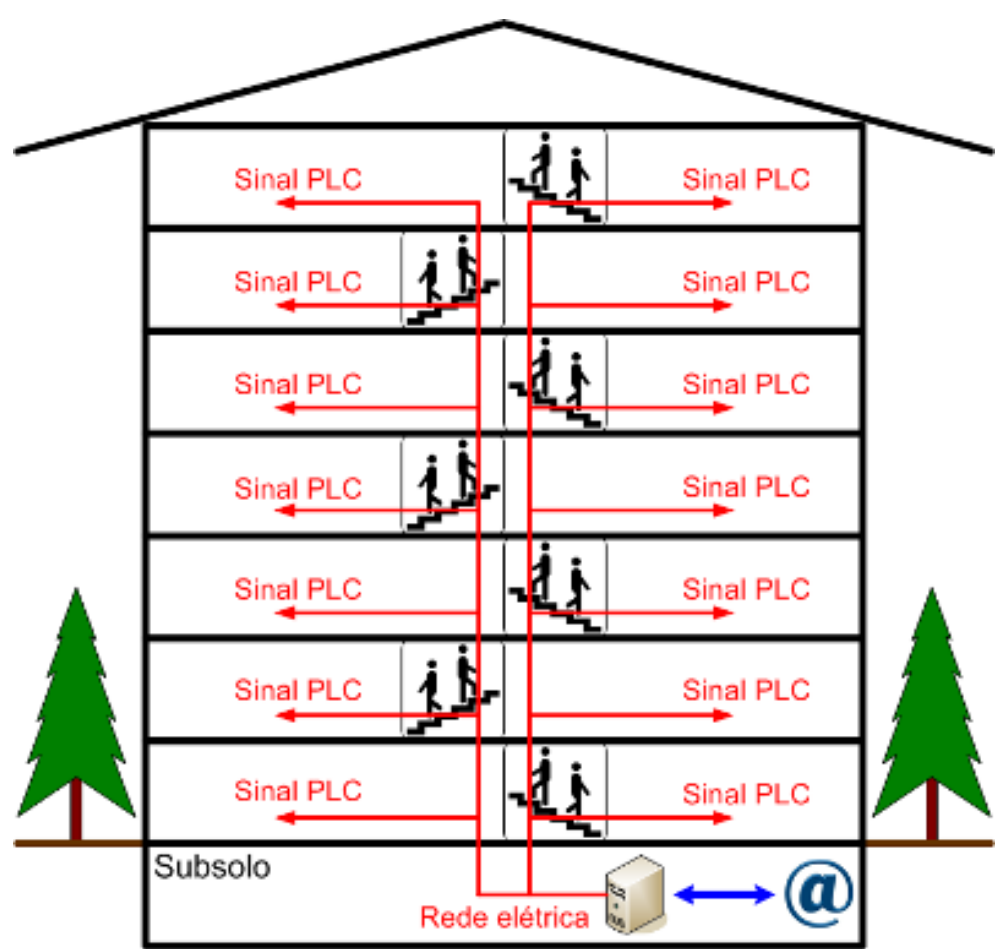

Figura 4 - Exemplo de aplicação interna.

Sinal PLC

$-\infty-0-\infty$

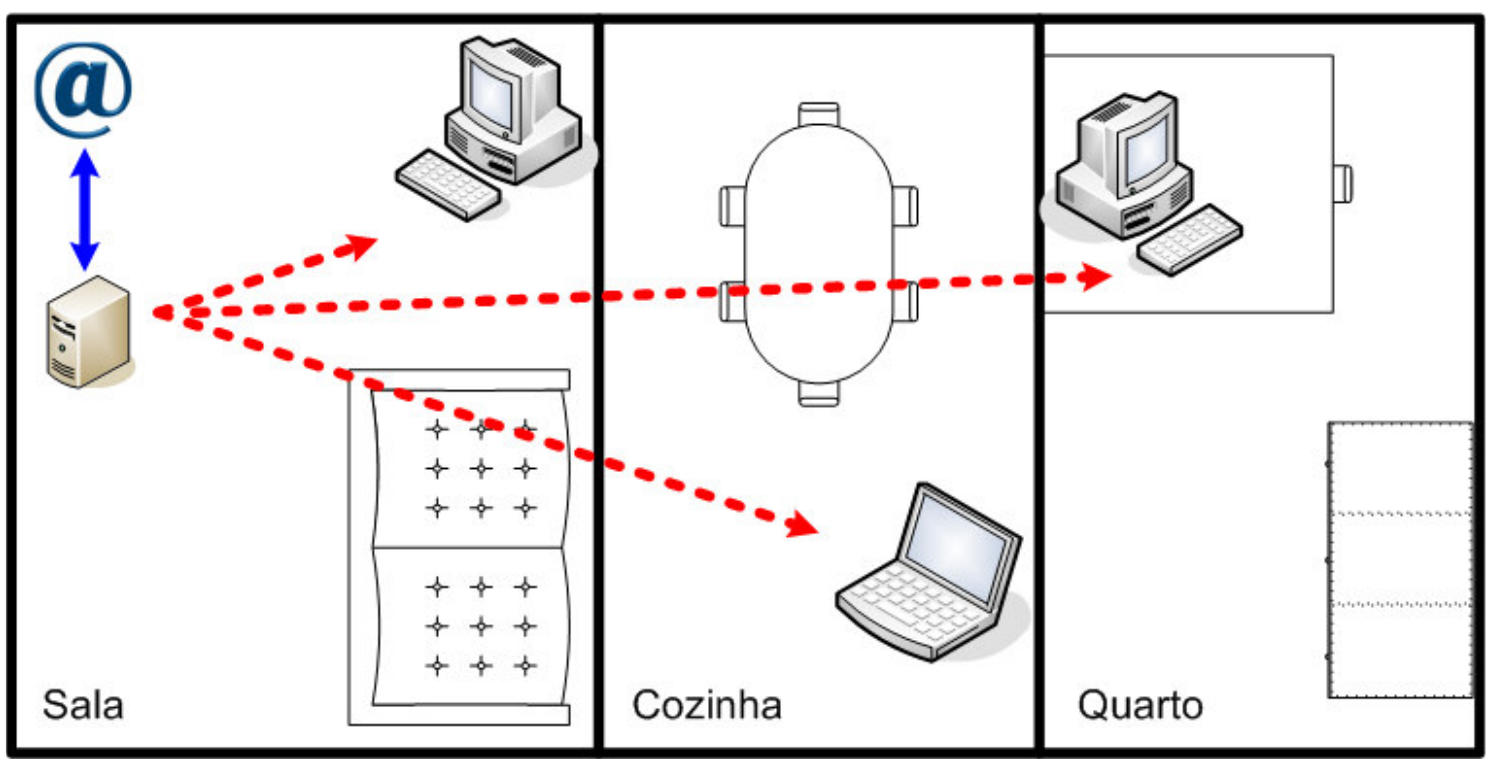

Figura 5 - Exemplo de aplicação doméstica.

Finalmente, a Figura 5 apresenta um exemplo de aplicação em um ambiente doméstico. Neste caso, o sinal de conectividade com a internet já está disponível dentro da área privativa do usuário final. Assim, a presente tecnologia é utilizada para distribuir os sinais pelos cômodos 
do local oferecendo conectividade, virtualmente, em todas as tomadas do mesmo. Como deverá ficar claro ao término deste trabalho, nem sempre essa é a situação verificada na prática.

As aplicações da tecnologia PLC na área de Energia são muitas. Todos os acessórios da rede elétrica que possuam interface de comunicação podem ser beneficiados pela sua utilização. Assim, religadoras, chaves, disjuntores e medidores diversos podem utilizar a mesma estrutura elétrica que alimenta seus circuitos de comando como meio físico de comunicação com seu respectivo centro de operação. Resumindo, a tecnologia é muito útil para transmitir sinais supervisórios, de monitoramento e controle das redes elétricas.

Além disso, [39] sugere que algumas das variáveis passíveis de serem monitoradas nos equipamentos PLC podem dar pistas de eventos que ocorrem na rede de potência. Em particular, grandes variações na relação sinal ruído em um dado trecho da rede podem indicar desgaste mecânico nos condutores e até mesmo indicar uma possível ruptura do mesmo.

A referência [38] apresenta como a tecnologia PLC pode ser útil em redes que tenham abundância de fontes de geração distribuídas. São destacados os aspectos de controle e monitoramento das fontes ativas na rede, fluxo de potência e proteção elétrica. Já a referência [40] apresenta a aplicação da tecnologia no controle da iluminação pública e os ganhos diretos e indiretos de tal implantação.

Como exemplo prático, pode-se citar a rede PLC/BPL que foi implantada, entre outros, pelo presente autor, no bairro da Restinga, na cidade de Porto Alegre no RS. Trata-se de uma rede PLC/BPL de média tensão, a qual, entre outras finalidades, serviu para realizar a comunicação com a religadora do alimentador onde foi construída a rede de comunicação. A Figura 6 (a) apresenta uma imagem de uma câmera IP, que utilizava a rede PLC, onde é mostrada a religadora que também utilizava a rede de comunicação para permitir seu telecomando. Já a Figura 6 (b) apresenta a equipe de linha viva da concessionária local realizando a instalação dos acopladores na rede de média tensão. 


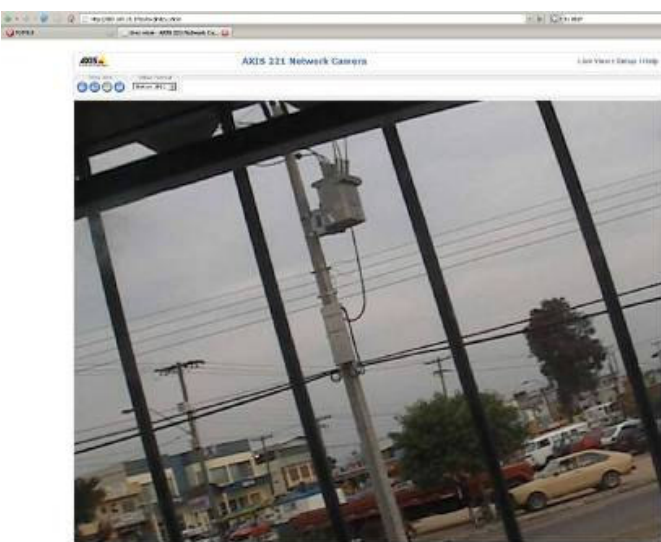

(a)

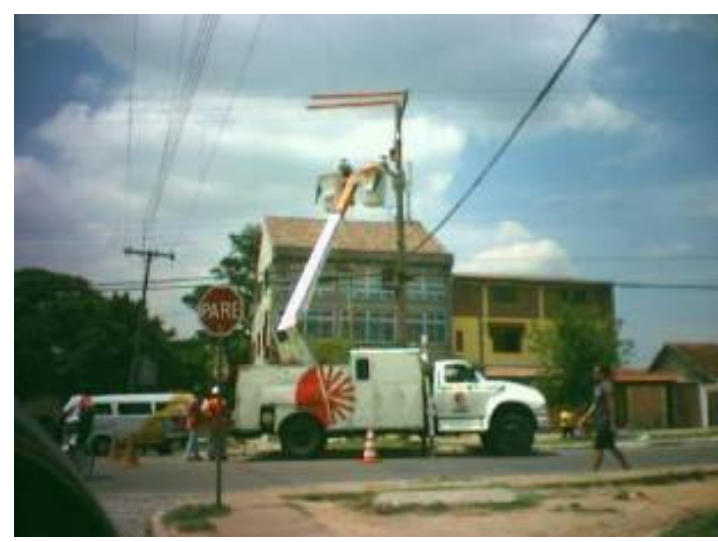

(b)

Figura 6 - (a) Foto da religadora utilizando o PLC como meio de comunicação. (b) Equipe de linha viva da concessionária local instalando os acopladores na rede de média tensão. 


\section{O sinal PLC/BPL}

\subsection{Modulação}

A presente tecnologia de comunicação, a exemplo de inúmeras outras, utiliza o esquema de modulação conhecido como orthogonal frequency-division multiplexing (OFDM).

A técnica baseia-se na multiplexação por divisão de freqüência (FDM) onde múltiplos sinais são enviados em diferentes freqüências. Como exemplo da técnica FDM pode-se citar os aparelhos de rádio e televisão onde normalmente cada estação está associada a uma determinada frequiência, a qual é utilizada para a realização das transmissões. Assim, a técnica OFDM parte de tal princípio e adicionalmente consegue uma melhor ocupação espectral, através de uma particular sobreposição espectral das subportadoras. Além disso, com a utilização de técnicas adicionais, resulta que os sinais possuem grande resistência a interferências.

Como exemplo comparativo (qualitativo) do aproveitamento espectral entre a técnica FDM convencional e o OFDM, apresenta-se a Figura 7 [51]. Quando são comparadas as larguras das faixas de freqüência necessárias, em ambos os sistemas de modulação, para uma mesma capacidade de transmissão, verifica-se a utilização de uma menor faixa de freqüências no sistema OFDM, e, portanto, um melhor aproveitamento espectral.

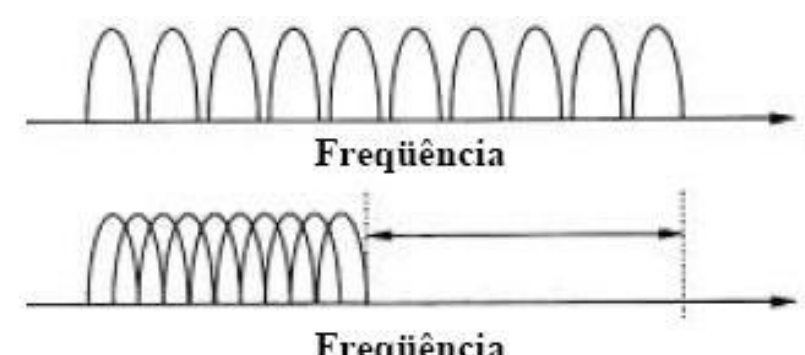

Figura 7 - Comparativo entre FDM convencional e OFDM [51].

Assim, o OFDM é amplamente utilizado em telecomunicações, sendo que a codificação e a decodificação dos sinais são auxiliadas pelo uso de sistemas digitais de processamento. 
Tipicamente, sua utilização ocorre em tecnologias de broadcasting ${ }^{7}$, como é o caso da tecnologia PLC/BPL, ADSL, redes sem fio, entre outras.

Como característica adicional, tal modulação apresenta boa imunidade a trechos multipercursos, facilidade de implementação através da Transformada Rápida de Fourier (FFT) ${ }^{8}$ e é adaptável a condições severas do canal de comunicação. De acordo com as características acima citadas e considerando a rede elétrica como meio físico para propagação dos sinais PLC, verifica-se que tal modulação é bastante adequada para compor tais sinais.

Na sequiência é apresentado um exemplo de espectro de um sinal PLC banda larga operando na faixa de $19 \mathrm{MHz}$ a $22,8 \mathrm{MHz}$.

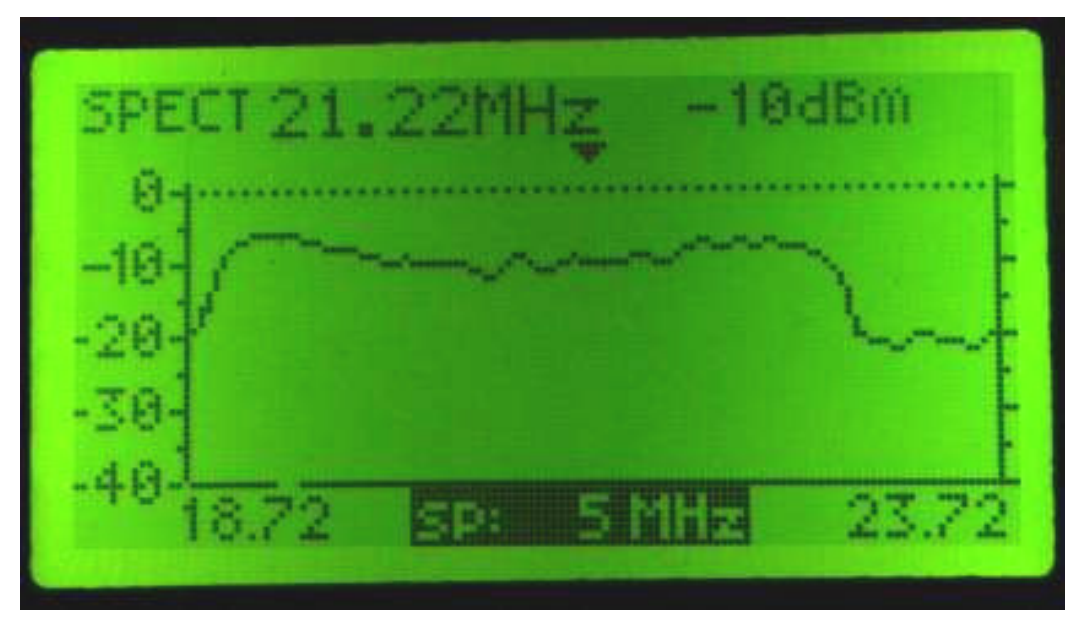

Figura 8 - Exemplo de espectro de um sinal PLC banda larga.

Destaca-se que não é objetivo deste trabalho esgotar o assunto, mas apenas descrever sucintamente a modulação utilizada na tecnologia PLC/BPL. Maiores detalhes sobre a modulação OFDM podem ser encontrados em [52] [53].

\footnotetext{
${ }^{7}$ A palavra é comumente utilizada para se referir a sistemas que emitem sinais que poderão ser recebidos por todos os dispositivos do sistema em questão.

${ }^{8}$ Existem fabricantes que utilizam Wavelets ao invés da FFT na implementação dos sinais PLC [44].
} 


\subsection{Capacidade de adaptação}

Como já citado, a utilização da técnica de modulação OFDM permite a adaptação da transmissão às condições do canal de transmissão. Desta forma, é possível realizar o controle de cada uma das portadoras do sistema de forma independente. Para a tecnologia PLC/BPL trata-se de um aspecto fundamental, uma vez que o canal de comunicação é a rede elétrica, cujos parâmetros são variantes no tempo.

Considerando que cada uma das portadoras presente no sinal PLC é responsável pelo transporte de certo número de bits, verifica-se na prática que o sistema é capaz de analisar a quantidade de bits que cada uma das portadoras está efetivamente transportando e então otimizar, em tempo real, quais portadoras estão contribuindo de forma efetiva para a transmissão. Assim, o sistema utiliza as portadoras com maior capacidade de transmissão em detrimento daquelas com menor ou nenhuma capacidade.

É importante destacar que o fato de uma determinada portadora não estar sendo utilizada na transmissão de dados não implica que ela seja desligada pelo sistema. Na prática, a portadora continua presente no espectro do sinal, porém apenas não transporta informações.

Na seqüência são apresentadas algumas fontes interferentes no sinal PLC, as quais prejudicam minimamente o sistema devido à capacidade de adaptação dinâmica aqui descrita.

\subsection{Interferência eletromagnética externa}

Pelo fato da tecnologia PLC/BPL utilizar a rede elétrica como meio de propagação dos sinais, verifica-se que a mesma está sujeita a todo tipo de sinais provenientes de cargas elétricas, assim como sinais que se acoplam magneticamente à rede. Nestes casos, o sistema PLC/BPL é considerado como interferido.

Como exemplo de interferências prejudiciais ao sistema PLC pode-se citar o conteúdo harmônico gerado por cargas elétricas não lineares. Tais harmônicos são gerados 
principalmente por retificadores, inversores, lâmpadas fluorescentes e motores universais, cargas estas comumente encontradas nas residências.

Sempre que tais harmônicos estão presentes na rede e interagem com os sinais PLC, geralmente verificam-se alterações no desempenho da rede de comunicação, porém cabe destacar que, conforme já citado, o sistema possui uma capacidade de adaptação permitindo com que a comunicação continue e a transmissão se adapte às novas condições do meio físico. Maiores detalhes sobre harmônicos são apresentados no Anexo A.

Além disso, o sistema PLC/BPL pode ser considerado interferente quando as emissões não intencionais do mesmo vierem a prejudicar outros sistemas, sejam eles de comunicação ou não. Caso esta situação seja verificada na prática, pode-se recorrer a um recurso presente na tecnologia, a máscara de potência, a qual será apresentada na sequiência.

\subsection{Máscara de potência}

Um recurso muito importante presente na tecnologia PLC/BPL é a máscara de potência. Tal recurso permite controlar a intensidade de cada uma das portadoras de forma individual, sendo possível, inclusive, zerar suas intensidades. Tais ajustes podem ser realizados através da interface administrativa dos próprios equipamentos. Cabe ressaltar que nem todos os equipamentos disponíveis comercialmente possuem tal recurso.

$\mathrm{Na}$ prática, sua utilização é de extrema importância na ocorrência de interferência eletromagnética com outros sistemas. Como exemplo, imagine uma situação onde as emissões não intencionais do sistema PLC interfiram em um dado sistema de comunicação que opere em uma determinada faixa de freqüência. Neste caso, é possível configurar o equipamento PLC de forma a minimizar a potência da portadora interferente no referido sistema de comunicação. Desta forma, objetiva-se obter a compatibilidade eletromagnética entre os dois sistemas.

Obviamente existem limites para a inclinação das atenuações introduzidas, sendo que a Figura 9 apresenta o mesmo espectro da Figura 8, porém com a atenuação de uma dada faixa de freqüências através do uso da máscara de potência. 


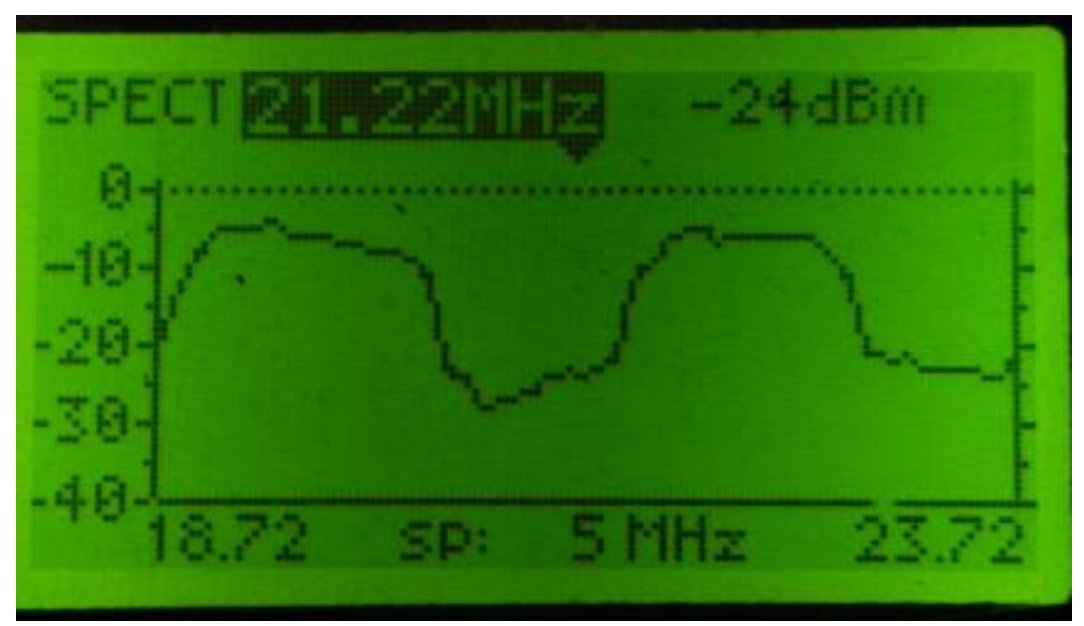

Figura 9 - Espectro de um sinal PLC banda larga utilizando a máscara de potência.

Adicionalmente, verifica-se que o uso da máscara de potência é necessário para atender a legislação vigente no que se refere ao uso do espectro, uma vez que existem limites para as emissões não intencionais emitidas pelo sistema [1] além de ser uma ferramenta útil que auxilia no desenvolvimento de projetos de redes PLC/BPL.

\subsection{Freqüências de trabalho}

Já foi mencionado que a tecnologia PLC/BPL de banda larga opera, tipicamente, de $1 \mathrm{MHz}$ a 35MHz. Porém, na tecnologia PLC banda larga de $1^{\text {a }}$ geração [39], toda essa faixa do espectro foi dividida em 13 diferentes faixas de trabalho [54], conforme apresenta a Tabela 1.

Através da análise da Tabela 1, verifica-se que existem faixas de freqüência separadas para o download e para o upload, caracterizando uma comunicação do tipo full-duplex. Cada par de faixas de frequiências (download mais upload) constitui o que é chamado de link. Assim existem 13 links disponíveis nos equipamentos de $1^{\text {a }}$ geração para o desenvolvimento dos projetos de redes PLC/BPL. Como a taxa máxima de transmissão destes equipamentos é de $45 \mathrm{Mbps}$ tem-se que a faixa de download é capaz de transmitir dados a uma taxa de $27 \mathrm{Mbps}$ e a de upload a $18 \mathrm{Mbps}$, totalizando os $45 \mathrm{Mbps}$. Estes valores se referem às taxas na camada física [50]. A Figura 10 apresenta uma ilustração de um link. 
Tabela 1 - Divisão do espectro em faixas de trabalho.

\begin{tabular}{ccccc}
\hline \multirow{2}{*}{ Link } & \multicolumn{3}{c}{ Upload } & \multicolumn{2}{c}{ Download } \\
& Início $(\mathrm{MHz})$ & Fim $(\mathrm{MHz})$ & Início $(\mathrm{MHz})$ & Fim $(\mathrm{MHz})$ \\
\hline 1 & 2,460 & 4,960 & 7,925 & 11,725 \\
2 & 13,800 & 16,300 & 19,000 & 22,800 \\
3 & 26,700 & 29,200 & 34,200 & 38,000 \\
4 & 8,575 & 11,075 & 2,460 & 6,260 \\
5 & 5,236 & 7,736 & 11,250 & 13,750 \\
6 & 11,250 & 13,750 & 5,236 & 7,736 \\
7 & 6,492 & 8,992 & 11,250 & 13,750 \\
8 & 11,250 & 13,750 & 6,492 & 13,750 \\
9 & 5,236 & 8,986 & 11,250 & 26,490 \\
10 & 16,311 & 18,811 & 22,740 & 18,811 \\
11 & 22,750 & 25,250 & 16,311 & 8,030 \\
12 & 2,015 & 4,515 & 5,530 & 4,515 \\
13 & 5,530 & 8,030 & 2,015 & \\
\hline
\end{tabular}

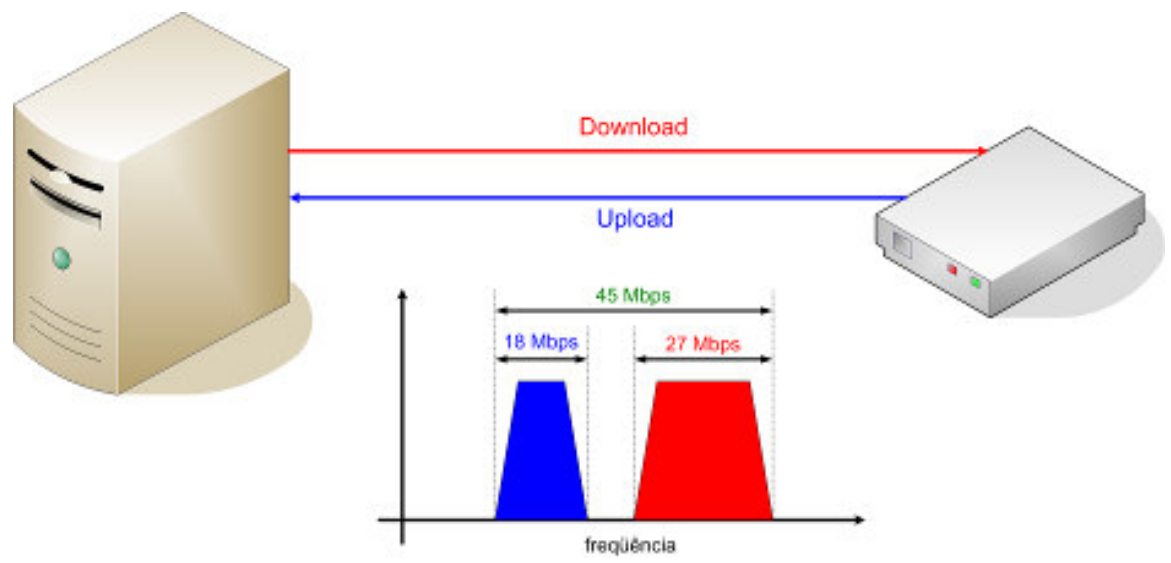

Figura 10 - Ilustração de um link.

Pode-se observar que existe intersecção de freqüências entre os diversos links apresentados. Desta forma, pode-se utilizar o recurso da máscara de potência para atenuar determinadas faixas de freqüência e eliminar tais intersecções. Este recurso permite que várias faixas de freqüência distintas sejam utilizadas no projeto de redes PLC/BPL. 


\section{Equipamentos PLC/BPL}

\subsection{Conceitos}

Atualmente, existem vários tipos de equipamentos PLC/BPL disponíveis no mercado. Cabe ressaltar que os fabricantes da tecnologia podem ser divididos em dois grupos: os fabricantes dos chips e os fabricantes dos equipamentos. Com relação aos fabricantes dos chips pode-se destacar a DS2 [39], Home Plug [55], Panasonic [44], entre outros. Cada fabricante desenvolveu sua tecnologia para aplicações diversas. Pode-se dizer que a tecnologia DS2 se aplica tanto no ambiente externo, assim como nos ambientes internos e domésticos, enquanto que os demais são mais apropriados para a utilização doméstica. Assim cada chip oferece recursos diferentes em termos de gerenciamento da rede PLC/BPL.

Uma vez que os chips estejam disponíveis, entram em cena os fabricantes dos equipamentos. Pode-se destacar inúmeras empresas que já produziram equipamentos PLC/BPL como, por exemplo, Mitisubishi Electric [56], Schneider Electric [57], Corinex [58], Panasonic [44], entre outros. Cada fabricante utiliza um chip de sua opção e então desenvolve os equipamentos, cada um com suas facilidades. No que se refere aos chips de tecnologia DS2, eles são classificados em tecnologia de $1^{a}$ geração, onde as taxas de transferência são da ordem de $45 \mathrm{Mbps}$, e em tecnologia de $2^{\mathrm{a}}$ geração, onde as taxas chegam a 200Mbps [39].

Independentemente do chip utilizado ou do fabricante considerado, todos os equipamentos seguem uma topologia de conexão radial, conforme ilustra a Figura 11. Assim, as próximas seções descreverão os tipos de equipamentos existentes em uma rede PLC/BPL, assim como suas funções. 


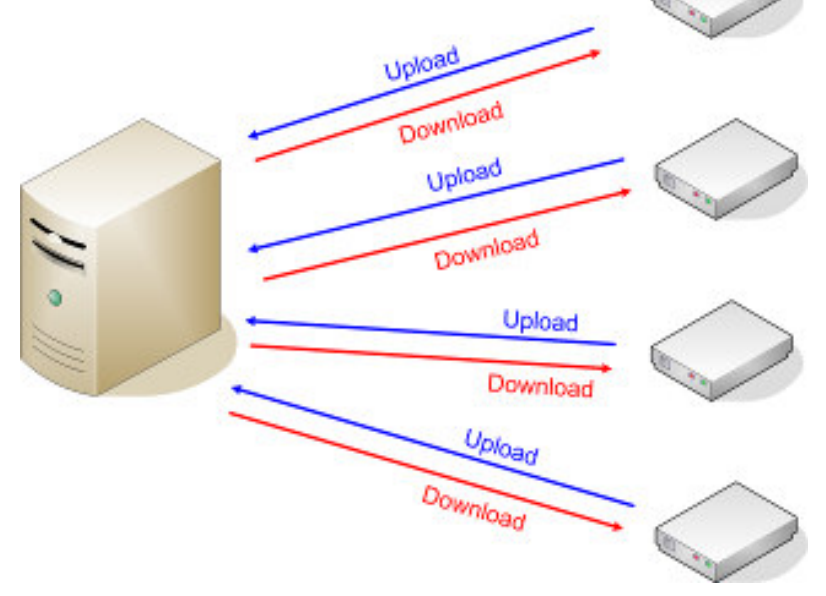

Figura 11 - Esquema da topologia radial da rede PLC/BPL.

\subsection{Master}

$\mathrm{O}$ primeiro equipamento de qualquer rede PLC/BPL é chamado de master. Ele é o responsável pela interface entre os sinais provenientes de uma rede cabeada, padrão ethernet, e os sinais PLC propriamente ditos. Desta forma este é o equipamento que injeta os sinais PLC/BPL na rede elétrica, além de ser o responsável pelo gerenciamento dos demais equipamentos que se conectarão a ele, uma vez que a topologia é radial.

A Figura 12 apresenta um equipamento master do fabricante Mitsubishi Electric, o qual utiliza o chip de $1^{\text {a }}$ geração da DS2. 


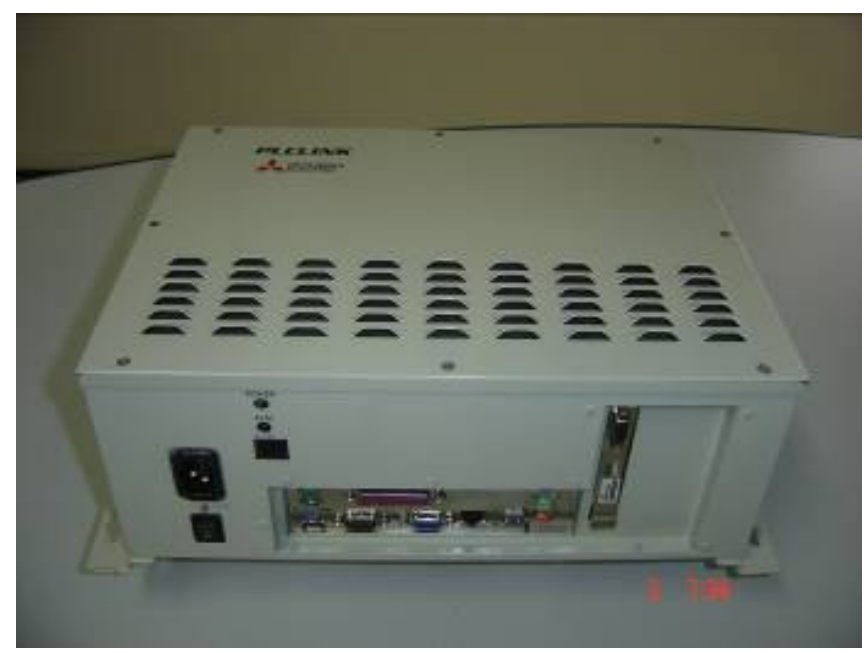

Figura 12 - Equipamento master de $1^{\text {a }}$ geração.

No que se refere à concepção física do equipamento, verifica-se que o mesmo é gerenciado por um Sistema Operacional Linux (SO). O SO coordena as atividades dos periféricos, como placa de rede, placa PLC, etc. Além disso, o sistema é parametrizado através de inúmeros arquivos de configuração, os quais são carregados durante a inicialização do sistema operacional. Outra característica importante é que os equipamentos PLC/BPL são capazes de operar na camada 2 [50], o que implica que não é necessário os equipamentos terem um endereçamento IP configurado. Virtualmente, o que se tem na prática, é uma comunicação irrestrita entre as interfaces ethernet e PLC.

Especificamente sobre a interface de comunicação PLC, observa-se que o referido equipamento possui uma placa com interface de comunicação do tipo DB-9, localizada do lado direito do mesmo. É por ali que os sinais PLC são acessíveis e passíveis de serem injetados na rede elétrica. Como será apresentado na seção 6.5, essa tarefa é realizada com o auxílio de acopladores externos, do tipo capacitivo ou indutivo.

Cada placa de comunicação é capaz de gerar sinais em faixas de freqüência diferentes, conforme a Tabela 1, assim a utilização de uma ou outra placa dependerá dos requisitos de projeto. 


\subsection{Repeater}

O próximo equipamento existente em uma rede PLC/BPL é o chamado repeater que, como o próprio nome sugere, é o responsável pela regeneração dos sinais de uma rede. Obviamente sua aplicação dependerá das necessidades da rede a ser implantada, ou seja, sua utilização só será necessária caso o alcance dos sinais provenientes do master não sejam satisfatórios para o projeto em questão.

A Figura 13 apresenta um equipamento do tipo repeater do fabricante Mitsubishi Electric, o qual utiliza o chip de $1^{\text {a }}$ geração da DS2 ao lado de um equipamento do tipo master para facilitar a comparação.

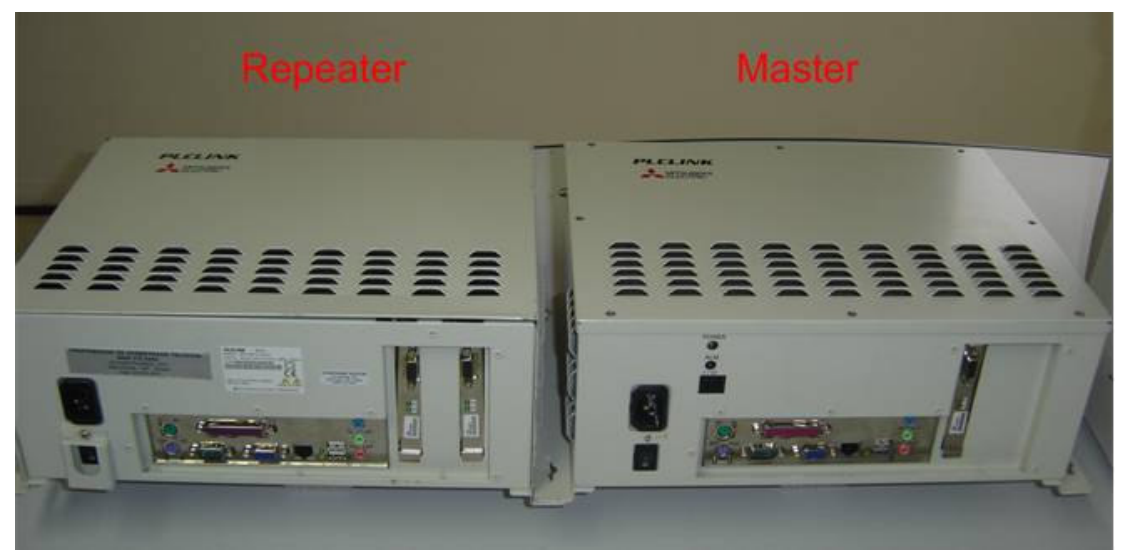

Figura 13 - Equipamento do tipo repeater (lado esquerdo da foto).

Observa-se que existem poucas diferenças entre os equipamentos, sendo a principal delas a existência de 2 slots para inserção de placas de link no equipamento do tipo repeater. Com 2 placas de link, o equipamento tem a capacidade de receber sinais em uma dada faixa de freqüência de outros equipamentos já existentes na rede, os quais muitas vezes possuirão baixa intensidade ou estarão minimamente já degradados. Com a outra placa o equipamento tem a capacidade de injetar novamente os sinais na rede elétrica com potência nominal e assim expandir a rede de comunicação. 


\subsection{CPE}

Na parte final da rede de comunicação está presente o equipamento conhecido por Customer Premises Equipment (CPE). Este é responsável por converter os sinais provenientes da rede elétrica para a interface do tipo ethernet. Desta forma, este equipamento é passível de ser conectado à placa de rede de um micro computador. Neste ponto o micro computador que estiver conectado com o CPE, virtualmente, terá conectividade com o ponto de conexão da rede ethernet ao master, no início da rede.

A Figura 14 apresenta um equipamento do tipo CPE do fabricante Mitsubishi Electric, o qual utiliza o chip de $1^{\text {a }}$ geração da DS2.

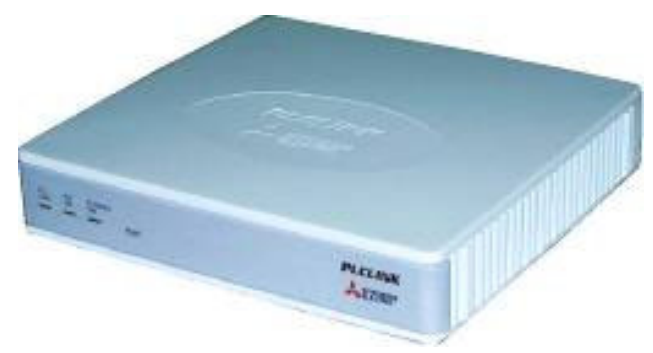

Figura 14 - Equipamento do tipo CPE.

Vale destacar que este equipamento realiza o acoplamento pelo próprio cabo de alimentação, ou seja, os sinais PLC adentram o equipamento pelo mesmo condutor de alimentação, assim não é necessária a utilização de acopladores externos.

Sua instalação é bastante simples, bastando conectá-lo à tomada onde existe sinal PLC disponível.

\subsection{Acopladores}

Conforme citado, existe a necessidade de utilização de acopladores externos para injetar os sinais PLC/BPL na rede elétrica. 
Considerando o equipamento apresentado na seção 6.2 verifica-se que a interface de saída dos sinais PLC/BPL é do tipo DB-9, assim pode-se utilizar um acoplador do tipo capacitivo para intermediar a conexão com a rede elétrica. A Figura 15 apresenta um esquema de ligação de um acoplador capacitivo entre a interface DB-9 e a rede elétrica.

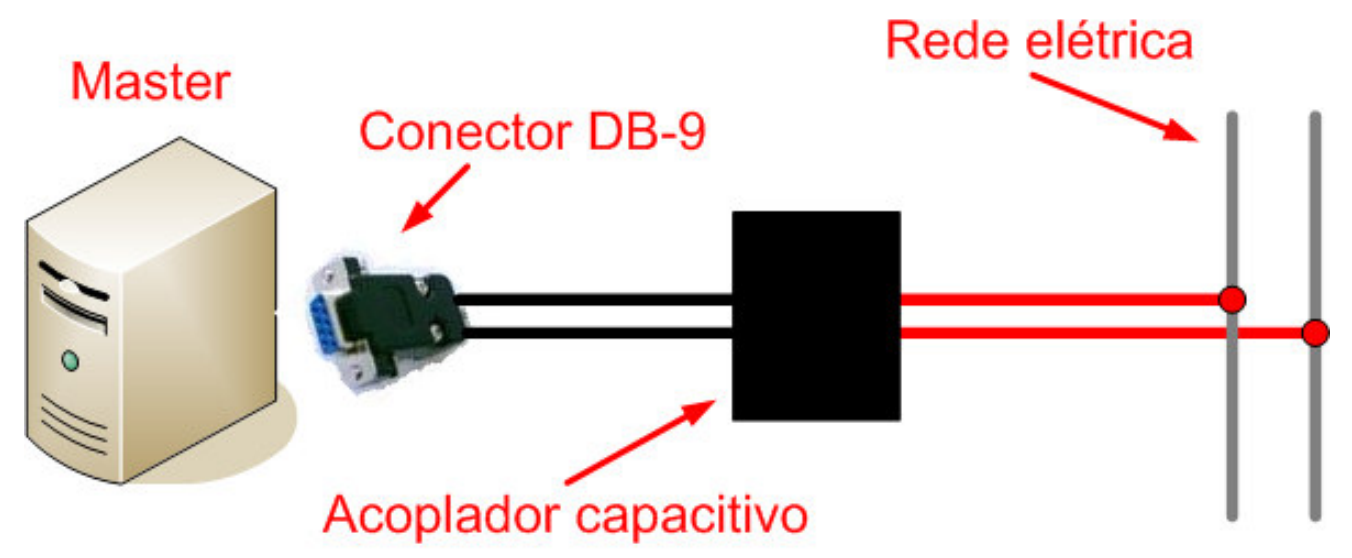

Figura 15 - Esquema de ligação de acoplador capacitivo.

Neste momento, fica claro que, na verdade, o acoplador nada mais é que um filtro com características do tipo passa alta, ou seja, ele permite o trânsito dos sinais PLC/BPL (MHz) e impede que os sinais de potência $(60 \mathrm{~Hz})$ cheguem até o equipamento PLC, pois caso isso ocorra a porta de saída do equipamento master sofrerá sérios danos.

A Figura 16 apresenta um modelo de acoplador capacitivo de baixa tensão de fabricação nacional [59].

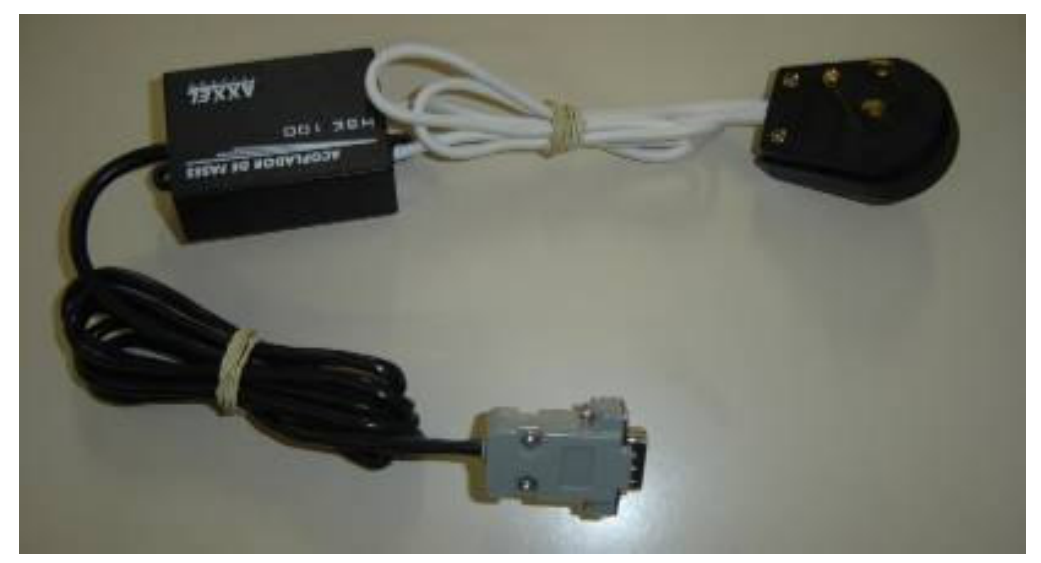

Figura 16 - Acoplador capacitivo para redes de baixa tensão.

Observa-se que uma das extremidades do acoplador possui um conector do tipo DB-9, enquanto a outra extremidade possui uma tomada macho para conexão direta à rede elétrica. 
Obviamente, a tomada é substituída de acordo com o local de instalação, por exemplo, conectando os condutores diretamente a um barramento em um quadro de distribuição.

Assim como existe o acoplador capacitivo de baixa tensão, existe também o mesmo tipo de acoplador para redes de média tensão. Como a capacidade de isolamento, neste caso, deve ser muito maior é de se esperar que tal acoplador possua maiores dimensões que o anterior. A Figura 17 apresenta um modelo de acoplador capacitivo para redes de média tensão de fabricação espanhola [60].

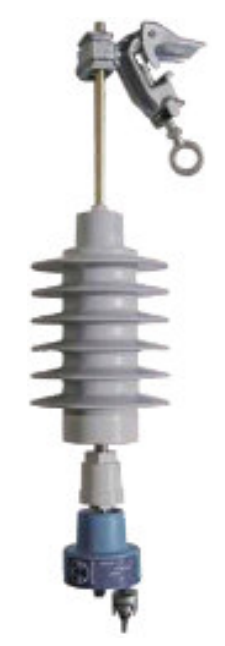

Figura 17 - Acoplador capacitivo para redes de média tensão.

O conjunto apresentado na Figura 17 é passível de ser instalado nas redes de média tensão sem a necessidade de desligamento da rede, bastando para sua instalação um técnico que possua habilidade com a vara de manobra. Este conjunto, quando instalado, fica pendurado no condutor e preso por uma trava existente no próprio acoplador. Suas aplicações vão desde redes com tensões da ordem de $13,8 \mathrm{kV}$ até $34,5 \mathrm{kV}$. Além do modelo apresentado acima, existem outros, os quais podem ser fixados no poste ou ainda substituindo o próprio isolador da linha [60]. 


\subsection{Filtros de linha}

Outro acessório bastante utilizado nas implantações de redes PLC/BPL é uma régua contendo cerca de 3 tomadas. A Figura 18 apresenta um modelo de régua comumente utilizada.

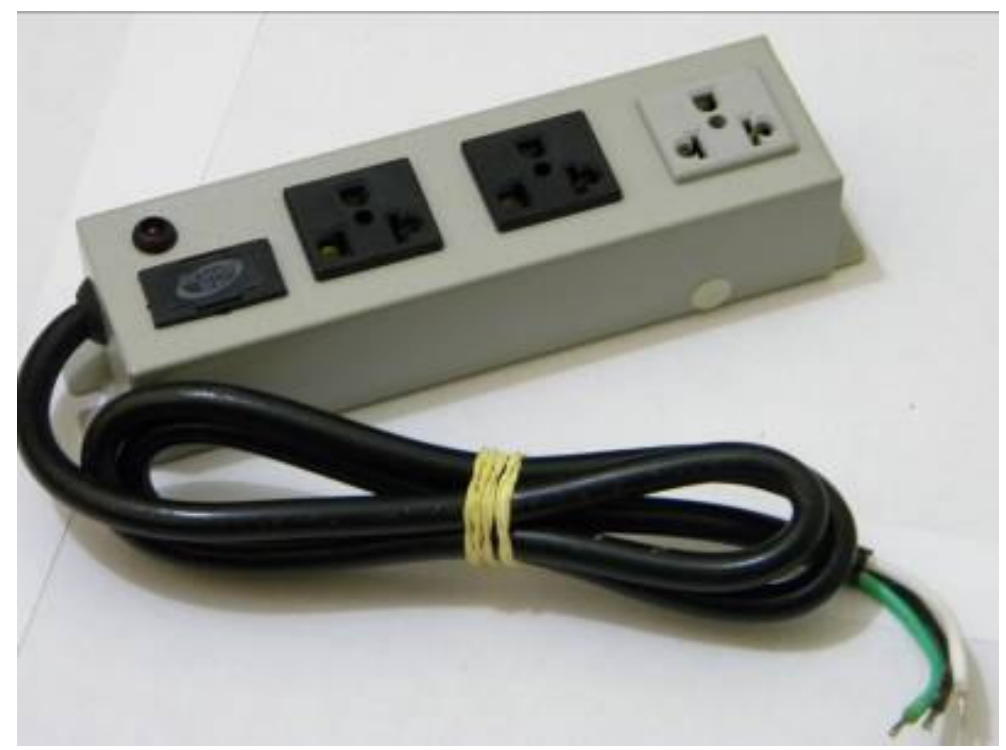

Figura 18 - Régua comumente utilizada em instalações PLC/BPL.

Tal acessório contribui de inúmeras formas nas instalações de redes PLC/BPL. Inicialmente, sua utilização permite ao usuário não inutilizar a tomada onde será conectado o equipamento CPE. Além disso, as 2 tomadas pretas que aparecem na Figura 18 estão acopladas a um filtro do tipo passa baixa. Desta forma, as demais cargas elétricas do usuário devem ser conectadas às mesmas, a fim de evitar que eventuais harmônicos gerados por elas sejam injetados na rede elétrica. Já a tomada branca está conectada diretamente à rede elétrica e, portanto o CPE deve ser ligado à mesma. A Figura 19 apresenta o esquema de ligação das tomadas dentro da régua. Ressalta-se que a utilização de tal acessório é extremamente recomendada, constituindo-se em uma das contribuições deste trabalho. 


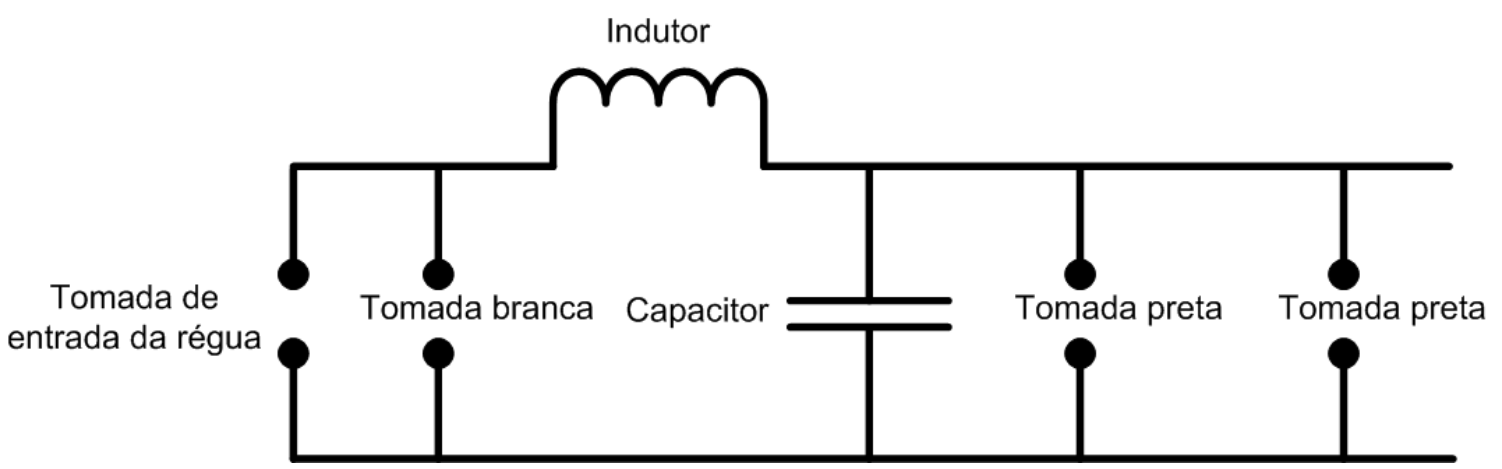

Figura 19 - Esquema de ligação da régua.

\subsection{Ferramentas}

Pelo fato da atividade de instalação de redes PLC/BPL ser bastante particular, existem algumas ferramentas específicas que auxiliam muito no desenvolvimento dos trabalhos, as quais serão apresentados na seqüência. Ressalta-se que a utilização de tais ferramentas é extremamente recomendada, constituindo-se em uma das contribuições deste trabalho.

\subsubsection{Analisador de espectro portátil}

$\mathrm{O}$ analisador de espectro constitui-se numa ferramenta essencial a qualquer equipe de instalação de redes PLC/BPL para operação comercial. Com tal ferramenta, é possível detectar os harmônicos presentes na rede elétrica onde será implantada a rede de comunicação e subsidiar a escolha das freqüências de trabalho de modo a minimizar a ocorrência de IEM que possam reduzir o desempenho da rede PLC/BPL. Além disso, a ferramenta permite avaliar o nível dos sinais PLC/BPL em cada um dos pontos de conexão (tomadas) definidos no projeto. Assim, é uma ferramenta essencial para o comissionamento das redes, conforme será discutido na seção 7.8 . 
A Figura 20 apresenta o analisador de espectro portátil do fabricante espanhol Promax [61].

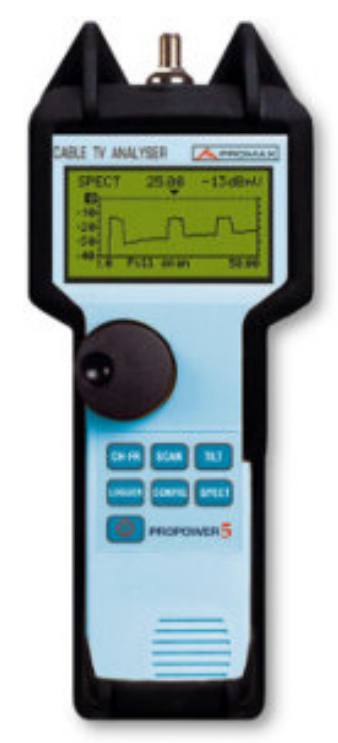

Figura 20 - Analisador de espectro portátil.

Obviamente, o referido equipamento não apresenta precisão equivalente à de um analisador de espectro de bancada, porém, para os propósitos de projeto e comissionamento de redes PLC/BPL, ele cumpre muito bem sua função. Como o equipamento é portátil, pode ser levado pelas equipes, em princípio, para qualquer local.

Cabe ressaltar que sua faixa de frequiência de operação é na faixa de operação da tecnologia PLC/BPL de banda larga, ou seja, de $1 \mathrm{MHz}$ a $50 \mathrm{MHz}$.

\subsubsection{Gerador de sinais portátil}

Outra ferramenta bastante útil é o gerador de sinais na faixa de $1 \mathrm{MHz}$ a $50 \mathrm{MHz}$. Tal ferramenta possui dimensões bastante reduzidas o que a torna útil para atividades de campo. Sua principal utilização é na avaliação da resposta em freqüência das redes elétricas. Esta atividade é realizada de forma qualitativa, quando se trata de instalações comerciais. Isso se deve ao tempo restrito para implantação da rede de comunicação. Comumente a ferramenta é conectada ao ponto onde se deseja injetar os sinais e, então, com o analisador de espectro 
portátil (descrito na seção 6.7.1), verifica-se a intensidade dos sinais na outra extremidade da rede de comunicação que se deseja construir.

A Figura 21 apresenta o gerador de sinais do fabricante espanhol Promax [61].

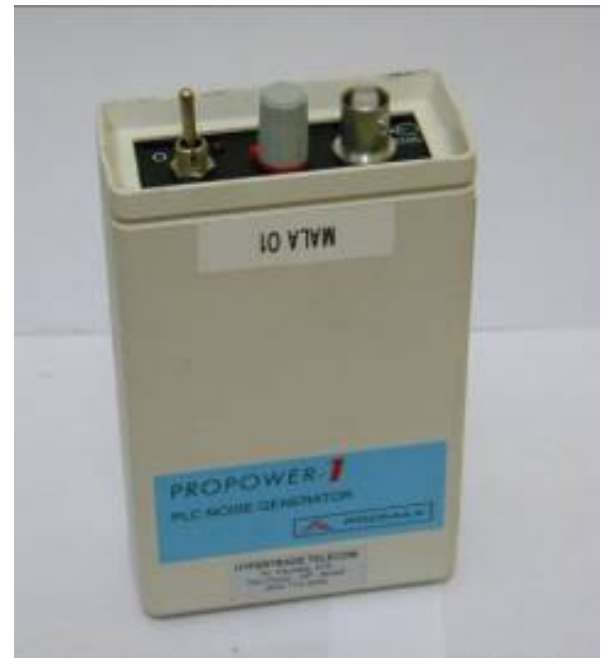

Figura 21 - Gerador de sinais PLC portátil.

Destaca-se que, na ausência de tal ferramenta, é perfeitamente possível utilizar o próprio equipamento master para injetar os sinais PLC na rede elétrica e permitir a avaliação do comportamento dos sinais na mesma.

\subsubsection{Tracejador de cabos}

Finalmente, tem-se o tracejador de cabos, o qual permite que determinados condutores elétricos sejam identificados em meio a outros cabos.

A ferramenta consiste, inicialmente, em um dispositivo que deve ser ligado na tomada (ou circuito) que contém o condutor a ser identificado. Tal dispositivo realiza a injeção de sinais de baixa freqüência (de $30 \mathrm{~Hz}$ a $70 \mathrm{~Hz}$ ) na rede elétrica, os quais se propagam por todo o local. Além disso, existe um identificador propriamente dito. Com ele pode-se detectar os sinais produzidos pela fonte de alimentação que foi conectada ao condutor (circuito) que se quer identificar. 
Tal identificador consiste de uma bobina com núcleo ferromagnético móvel, portanto pode-se variar a indutância da bobina e calibrar o dispositivo em tempo real de forma a identificar o condutor procurado.

Sempre que o identificador detecta sinais gerados pelo dispositivo conectado à tomada, ele emite sinais audíveis, sendo que sua intensidade e frequiência estão associadas à intensidade do sinal detectado.

Para isso, deve-se aproximar o identificador, sempre que possível, dos condutores, como em uma prumada de um prédio, e então variar a indutância da bobina de forma a encontrar o limiar mínimo que produz sinais audíveis. Uma vez encontrado um condutor, deve-se repetir o processo até que o condutor identificado esteja associado ao menor limiar que produza sinais audíveis (condição de menor indutância da bobina que identifica os sinais e maior densidade de fluxo magnético detectado).

Essa ferramenta é de extrema utilidade quando se deseja encontrar condutores em prumadas de edifícios, os quais, muitas vezes, estarão associados à instalação de equipamentos do tipo repeater.

A Figura 22 apresenta o tracejador de cabos do fabricante espanhol Promax [61].

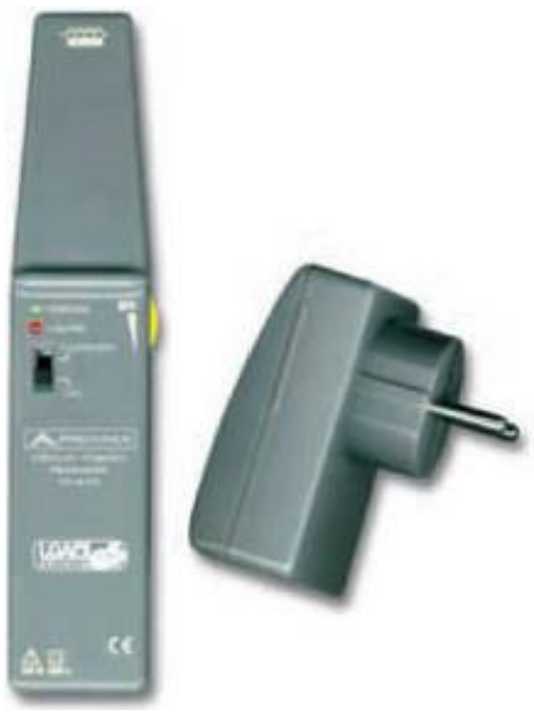

Figura 22 - Tracejador de cabos.

Concluindo, as ferramentas apresentadas constituem material essencial para uma equipe de instalação de redes PLC/BPL, uma vez que elas permitem que as atividades realizadas sejam confiáveis e cumpridas no menor tempo possível. 
Cabe destacar que as atividades comerciais de instalação de redes de comunicação desta natureza implicam em custos elevados, uma vez que existe a necessidade de mão de obra especializada. Assim, a redução do tempo de instalação é algo essencial para a viabilização econômica dos projetos. A Figura 23 apresenta uma foto da mala comumente utilizada em campo pelas equipes de implantação.

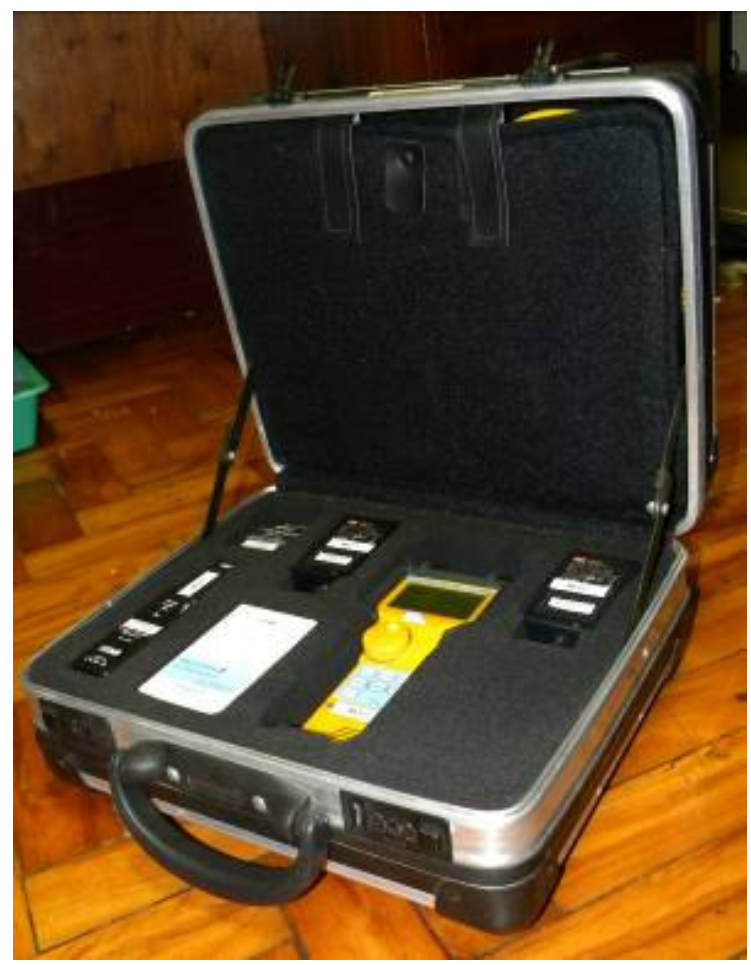

Figura 23 - Mala de ferramenta comumente utilizada por equipes de campo. 


\section{Projetos de redes PLC/BPL}

\subsection{Introdução}

O desenvolvimento de projetos e a posterior implantação de redes PLC/BPL possuem uma série de características inerentes à tecnologia. Durante o desenvolvimento deste trabalho, foram projetadas e implantadas cerca de 23 redes de comunicação comerciais no Brasil, sendo que cerca de 5 delas possuem certa similaridade, uma vez que tratam-se de redes com características domésticas.

Desta forma, verifica-se que, na grande maioria dos casos, as redes de comunicação possuem características bastante diferentes. Isso pode ocorrer devido a inúmeros fatores, por exemplo, localização dos medidores na edificação, disposição dos condutores na prumada, dielétrico existente entre os condutores (água, lama, ar, etc.), entre outros.

Assim, verifica-se que, na prática, é bastante razoável delimitar uma série de variáveis a serem observadas e definidas para cada um dos projetos a serem desenvolvidos. Isso implica no fato de que, até o presente momento, não existe uma regra fixa para implantação de redes PLC/BPL, ou seja, regras que funcionem para todos os casos. Logo, o que será apresentado na seqüência se constitui nas diretrizes básicas para o desenvolvimento de projetos e implantação de redes PLC/BPL, sejam elas de baixa ou média tensão, sendo que todo o conteúdo apresentado neste capítulo representa outra contribuição deste trabalho.

\subsection{Planejamento físico e lógico}

Como qualquer outro tipo de projeto, a primeira atividade a ser realizada é a definição dos requisitos e as premissas da rede de comunicação que será implantada. Assim, deve-se 
descrever a estrutura destacando-se os aspectos de interesse do ponto de vista da tecnologia PLC/BPL. Como exemplo, pode-se citar detalhes da estrutura, como a localização dos medidores do local, distribuição geométrica da prumada, locais de acessos aos condutores ao longo da edificação e esquema de ligação das unidades consumidoras.

Além disso, deve-se documentar a estrutura abordada do ponto de vista dos pontos de conexão, a qual, não necessariamente, é constituída de todas as tomadas. Cabe destacar que, do ponto de vista de telecomunicações, basta um ponto de acesso para que o usuário final seja atendido. Assim, deve-se definir a capacidade de transmissão desejada para cada trecho da rede PLC/BPL, sendo que a identificação clara dos pontos de interesse guiará as injeções e medições dos sinais PLC/BPL. Adicionalmente, pode-se citar o registro das informações de onde a rede PLC/BPL terá início, localização de eventuais servidores e outros acessórios de rede e identificação de cada ponto de acesso. Finalmente, deve-se verificar a necessidade de interferências físicas no local, como instalação de caixas abrigo, disponibilidade de alimentação elétrica e lançamento de cabos para energização ou acoplamento.

Além dos aspectos relacionados à parte física da rede de comunicação, devem-se definir os aspectos lógicos da rede. Assim, é importante definir o endereçamento que será implementado nos equipamentos, como endereçamento IP, máscara de rede, gateway, VLAN, QoS e CoS. Apesar dos equipamentos operarem na camada 2, o endereçamento se faz necessário para permitir o gerenciamento dos equipamentos que fazem parte da rede de comunicação. Além disso, as configurações de QoS e CoS possibilitam a priorização de pacotes, como os de voz, assim como restrições na capacidade de transmissão de cada equipamento, de forma individual.

\subsection{Detecção de harmônicos}

A detecção dos harmônicos presentes na rede elétrica onde será instalada uma rede PLC/BPL é um dos primeiros passos a ser executado em um projeto. 
Inicialmente, pode-se realizar uma inspeção visual no local onde será instalada a rede, com o objetivo de identificar as cargas elétricas existentes que potencialmente causarão problemas à rede de comunicação, como por exemplo, as mencionadas no Anexo A.

Para realizar tal atividade, pode-se utilizar um analisador de espectro portátil, o qual é bastante adequado para atuação em campo.

Uma vez que o espectro do local seja obtido com o analisador de espectro, deve-se realizar sua análise a fim de determinar a existência de sinais na mesma faixa de operação da tecnologia PLC, sendo que os sinais detectados no local balizarão a escolha das freqüências de trabalho que serão utilizadas na implantação da rede de comunicação. Além disso, sabe-se que as cargas elétricas conectadas ao sistema mudam a todo instante, portanto é importante considerar a sazonalidade das cargas do local a fim de determinar os sinais que estarão eventualmente presentes.

\subsection{Planejamento de links}

Conforme citado na seção 5.5, existem 13 faixas de freqüência distintas que podem ser utilizadas para realizar os enlaces de comunicação dentro de uma rede PLC/BPL.

De posse das informações sobre os harmônicos existentes na rede elétrica de interesse, podese realizar a escolha da melhor faixa de operação, porém essa escolha também deve levar em consideração as informações definidas na seção 7.2. Adicionalmente, de acordo com o modelo de LT apresentado no Anexo A, verifica-se que quanto maior a freqüência de trabalho maior será a atenuação do sinal e, conseqüentemente, menor será a distância coberta pelo sinal PLC. Assim, quando existe a necessidade de cobertura de grandes extensões, recomenda-se a utilização das menores faixas de frequiência, como o link 1. Entende-se por grandes extensões comprimentos superiores a 30m em ambientes internos (prédios, por exemplo) e comprimentos superiores a $250 \mathrm{~m}$ em ambientes externos (redes primárias, por exemplo). Destaca-se que tais valores são baseados nas experiências vivenciadas em campo.

Sempre que a rede de comunicação possuir extensões, tais que exijam a instalação de um equipamento do tipo repeater, deve-se observar a adequada utilização das faixas de 
freqüência na mesma, uma vez que trechos adjacentes devem operar em links diferentes, o que evita interferência nos diversos trechos de comunicação.

A Figura 24 apresenta um exemplo correto de planejamento de links.

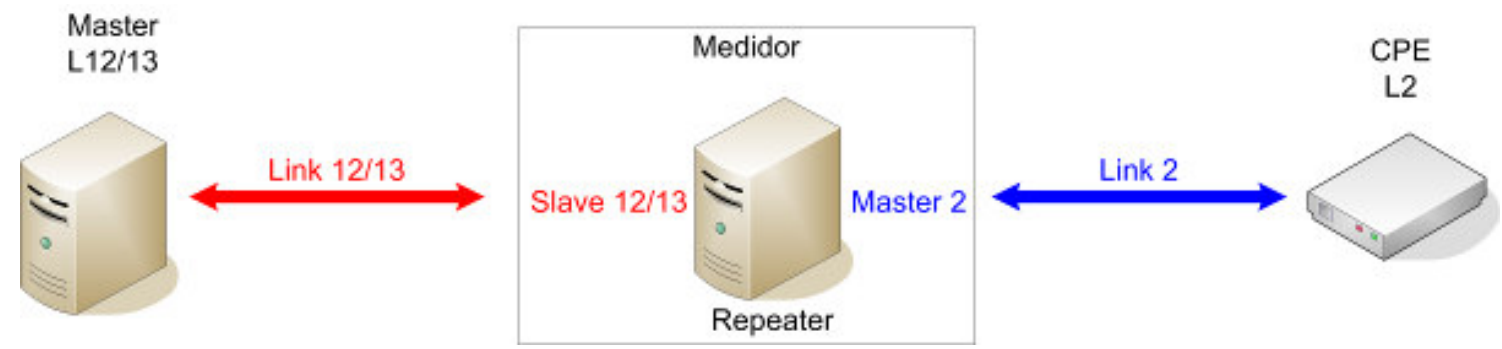

Figura 24 - Exemplo de planejamento de links.

Destaca-se que os equipamentos CPE de $1^{\text {a }}$ geração apenas se comunicam através do link 2, conforme apresenta a Figura 24. Assim, qualquer que seja a rede de comunicação, o último trecho da mesma sempre deverá operar em tal faixa de freqüência.

Caso o planejamento de links desenvolvido, de acordo com os requisitos de projeto, seja prejudicado por harmônicos existentes no local, pode-se recorrer a técnicas de mitigação de IEM, as quais são apresentadas na próxima seção.

\subsection{Técnicas de mitigação de IEM}

Neste caso, as técnicas de mitigação têm como objetivo evitar que os harmônicos provenientes das cargas elétricas se propaguem indiscriminadamente por toda a rede, assim como evitar que estes estejam presentes, em intensidades elevadas, no mesmo ambiente eletromagnético que os sinais PLC/BPL.

Basicamente, existem quatro recursos que podem ser utilizados para mitigar potenciais ocorrências de degradação no desempenho das redes de comunicação.

Inicialmente, pode-se citar o desenvolvimento do projeto considerando a presença de tais harmônicos e, portanto, desenvolver uma rede PLC cujas freqüências de operação não coincidam com a faixa de freqüência dos harmônicos existentes. Na seqüência, pode-se citar 
modificações na topologia da rede PLC, as quais consistem, por exemplo, em modificar o meio de propagação dos sinais a fim de evitar os harmônicos. Isso é realizável, geralmente, em prédios onde pode existir mais de uma maneira de levar os sinais a um mesmo local.

Como terceiro recurso, pode-se utilizar o acessório apresentado na seção 6.6 (régua de tomadas com filtro), o qual pode auxiliar de forma a minimizar o conteúdo harmônico, originado nas cargas, que se propagam pela rede elétrica onde está instalada uma determinada rede de comunicação PLC.

Finalmente, tem-se a utilização de ferrites como acessório de auxílio à mitigação de IEM. A Figura 25 apresenta um ferrite comumente utilizado nas instalações de redes PLC/BPL do tipo banda larga.
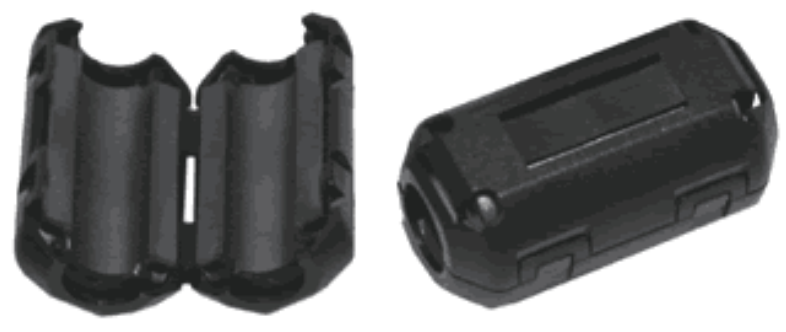

Figura 25 - Foto de um ferrite comumente utilizado em redes banda larga.

Sua utilização é extensiva, uma vez que seu custo é extremamente baixo face aos resultados que podem ser alcançados.

Seu emprego é realizado através de uma ligação em série com os condutores da rede, tipicamente junto à carga geradora de harmônicos. Como o ferrite apresenta uma carcaça plástica apropriada para a montagem de uma bobina, onde ele é o núcleo da mesma, verificase que seu efeito, do ponto de vista da rede elétrica, é uma impedância com características indutivas. Como tal, seu módulo será tão maior quanto maior for a freqüência dos sinais, impedindo assim a passagem de sinais de alta freqüência, sejam eles PLC ou não.

Como exemplo de aplicação, considere-se uma lâmpada fluorescente acionada por um reator eletrônico. Considere-se ainda que a mesma seja uma potencial fonte de harmônicos.

A Figura 26 apresenta um esquema de ligação onde a utilização dos ferrites se mostra eficiente, ou seja, minimiza consideravelmente a intensidade dos harmônicos que se propagam até outros locais da mesma rede elétrica que fazem parte da rede de comunicação. 


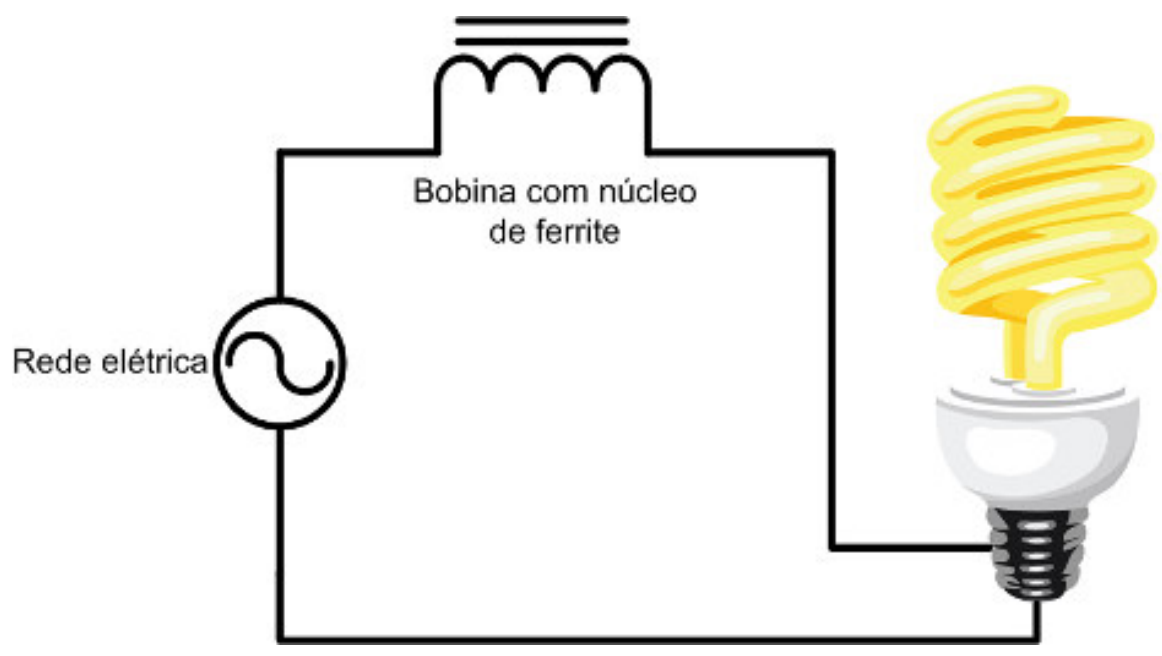

Figura 26 - Esquema de aplicação de ferrite.

Cabe ressaltar que o ferrite a ser utilizado deve ser montado de tal forma a garantir que não ocorrerá sua saturação pela corrente que circulará através da bobina. Tal corrente é a corrente absorvida pela carga e, portanto, pode assumir valores elevados. Caso ocorra a saturação do núcleo de ferrite, potencialmente os sinais de $60 \mathrm{~Hz}$ serão distorcidos agravando o problema e não contribuindo em nada para sua minimização. Desta forma, é importante conhecer a curva de magnetização BxH do núcleo de ferrite a ser utilizado.

A Figura 27 apresenta um núcleo de ferrite utilizado para a montagem de uma bobina, que pode ser facilmente ligada em série com as cargas elétricas geradoras de harmônicos.

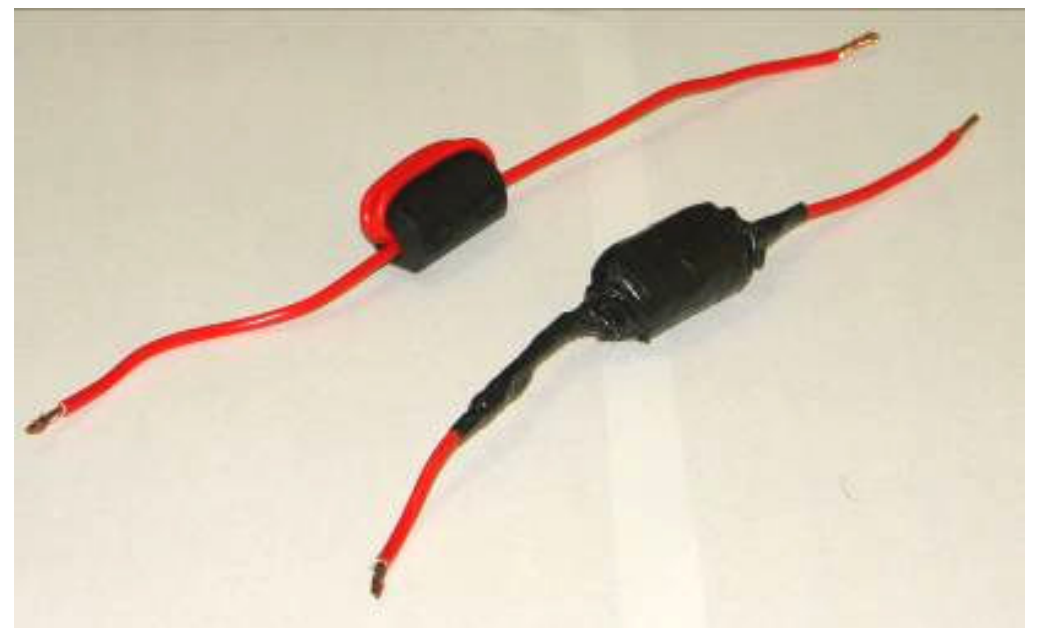

Figura 27 - Foto de uma bobina pronta para ser utilizada.

Adicionalmente, pode-se citar uma técnica de mitigação de EMI que consiste em garantir um sinal PLC com intensidade superior à intensidade dos harmônicos existentes. 
O exemplo a seguir ilustra tal técnica de mitigação, sendo que a rede de comunicação e o local apresentado constituem uma implantação comercial realizada.

Trata-se de uma sala de informática alimentada por um ramal secundário exclusivo que vem diretamente do transformador de distribuição, o qual está localizado do lado de fora de tal sala a uma distância aproximada de 60m. A Figura 28 ilustra a estrutura do local.

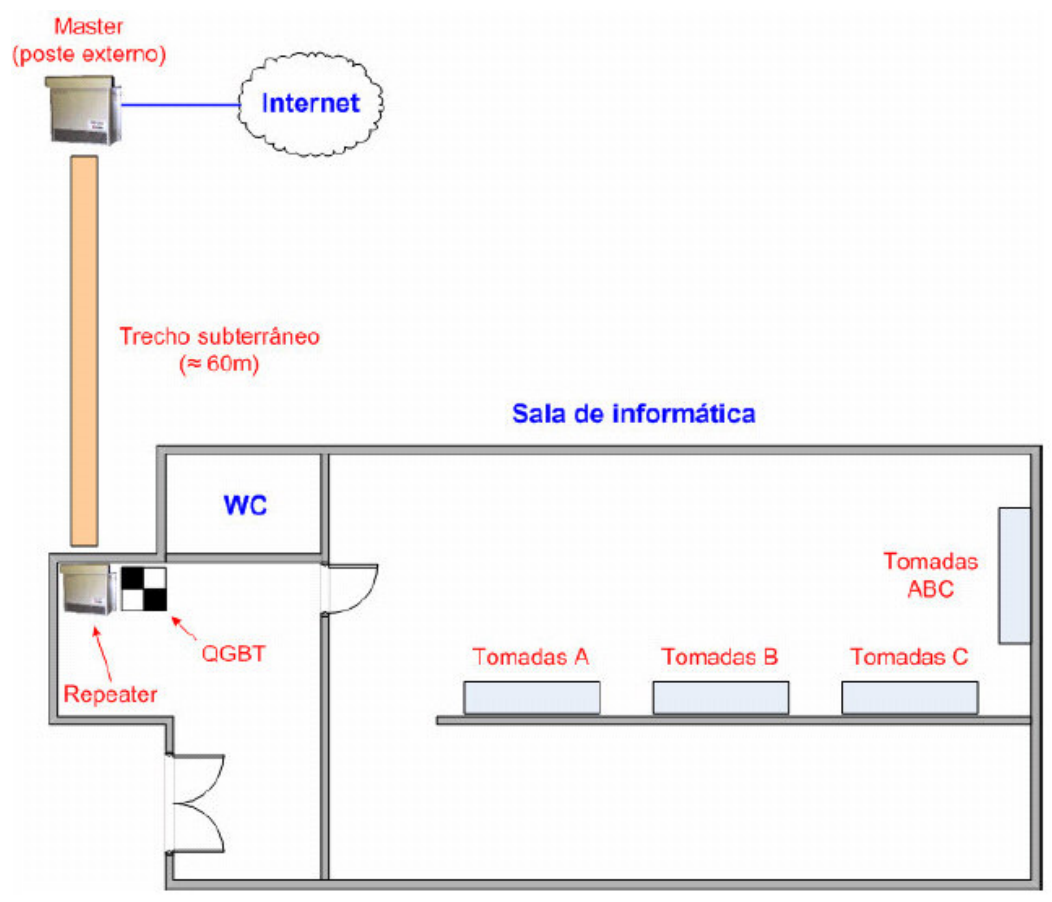

Figura 28 - Estrutura física da rede comercial implantada.

Inicialmente, instalou-se um equipamento do tipo master no poste externo, junto ao transformador, operando com link 2. Porém, verificou-se que o sinal era fortemente atenuado pelo trecho subterrâneo, o qual estava completamente inundado com água e lama. Desta forma, quando as lâmpadas internas da sala eram ligadas, verificava-se queda do enlace de comunicação da rede PLC. Assim, optou-se pela instalação de um equipamento do tipo repeater junto ao quadro de distribuição interno da sala de informática. A Figura 29 apresenta o planejamento de links utilizado. 


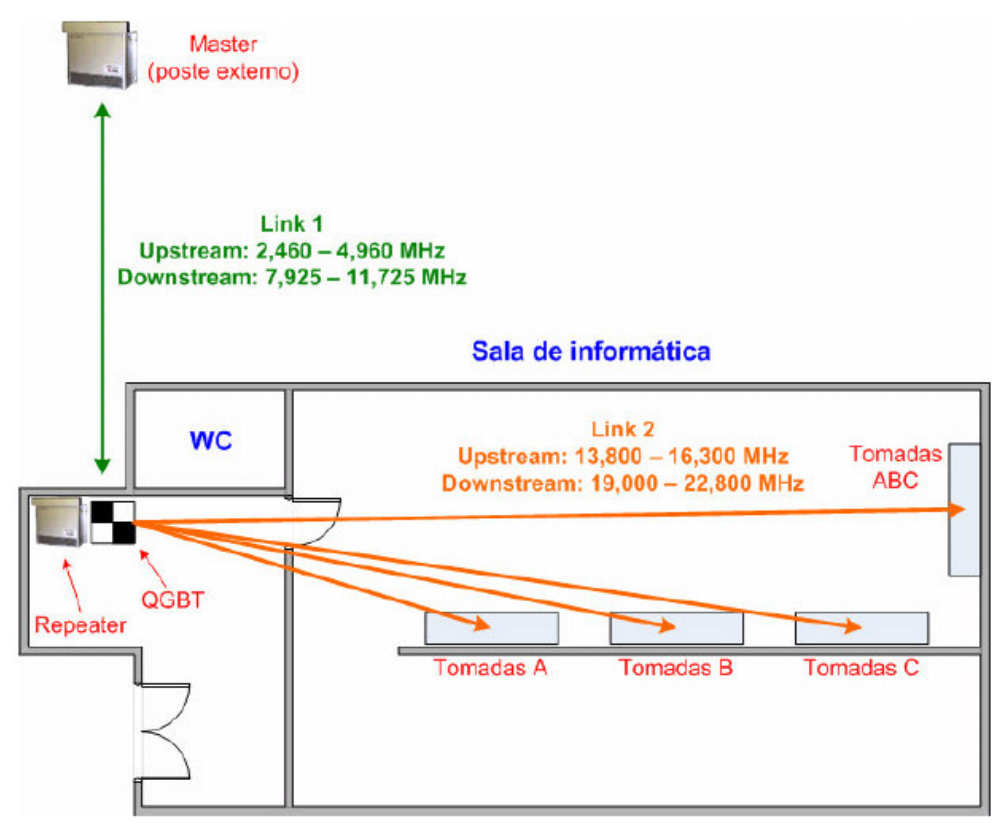

Figura 29 - Planejamento de links da rede comercial implantada.

Desta forma, optou-se por um link de mais baixa freqüência no trecho externo, onde a atenuação é maior, e na parte interna da sala de informática utilizou-se, necessariamente, o link 2 para a comunicação com os equipamentos CPEs. Nesta situação, mesmo quando as lâmpadas eram acionadas, não se observou degradação no desempenho da rede de comunicação.

A Figura 30 apresenta algumas fotos do local aqui descrito.

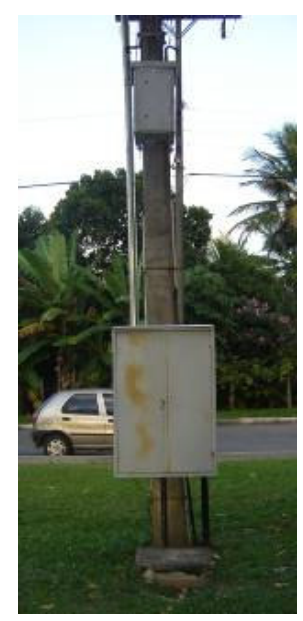

(a)

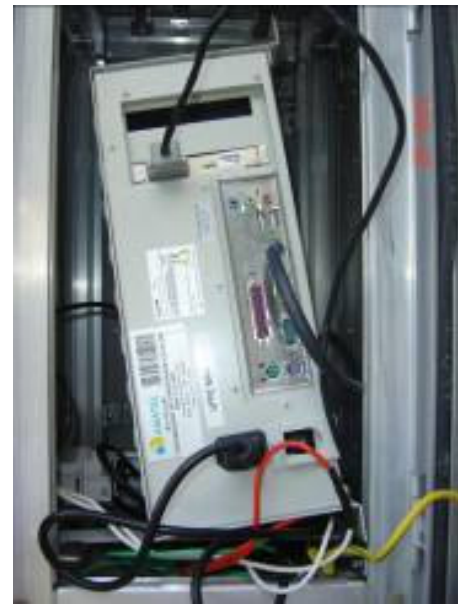

(b)

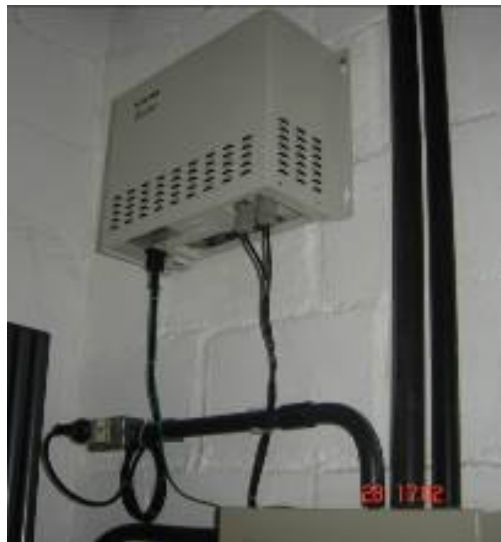

(c)

Figura 30 - (a) Caixa abrigo (superior) para o equipamento master; (b) Detalhe do master dentro da caixa abrigo; (c) Equipamento repeater instalado dentro da sala de informática. 


\subsection{Alocação dos equipamentos, acoplamento e medições}

A partir de todas as considerações tratadas nas seções anteriores, já devem ser conhecidos os locais onde os condutores são acessíveis dentro da estrutura onde será implantada a rede PLC. Como exemplo, considere-se uma edificação onde o centro de medição está localizado no subsolo do mesmo, ou seja, todos os medidores das unidades consumidoras estão localizados em uma única sala. Assim, potencialmente, os equipamentos PLC serão alocados neste mesmo local. Nestas situações, não existem grandes preocupações com relação à alocação dos equipamentos, uma vez que o local não é sujeito a intempéries. O mesmo não ocorre caso o local a ser abordado constitua-se de um ambiente externo. Nesta situação, muitas vezes é necessária a utilização de caixas abrigo, como a que é mostrada na Figura 30 (a) e (b).

Enfatiza-se que o equipamento do tipo master ou repeater deve, sempre, ser instalado o mais próximo possível dos pontos de conexão dos usuários finais. Isso garante um melhor aproveitamento dos equipamentos em termos de número de CPEs por master/repeater, assim como aumenta a confiabilidade da rede, uma vez que os níveis dos sinais PLC/BPL junto aos usuários finais serão tão maiores quanto possíveis.

Uma vez definidos os locais de instalação dos equipamentos do tipo master, deve-se iniciar os acoplamentos dos sinais PLC à rede elétrica. De acordo com os pontos de acesso previamente definidos, deve-se realizar a injeção dos sinais, através dos acopladores, preferencialmente no mesmo condutor onde se encontra o referido ponto de acesso. Na prática, essa tarefa não é das mais simples, uma vez que, tipicamente, são muitos os pontos de acesso. Nestes casos, devese considerar o efeito de indução que ocorre entre os diversos condutores e circuitos do local, o qual é extremamente significativo e contribui muito para a distribuição dos sinais pela edificação.

Desta forma, a atividade de injeção dos sinais é acompanhada simultaneamente pela atividade de medição dos níveis de sinal nos diversos pontos de acesso. Assim, pode-se realizar uma determinada injeção de sinal, dentre as várias possíveis (vide Tabela 2), e então verificar o nível do sinal PLC nos pontos de acesso. Como valor de referência, o CPE ainda consegue se comunicar com seu respectivo master quando o sinal PLC disponível possuir uma intensidade mínima de $-50 \mathrm{dBm}$. 
Tabela 2 - Diversos tipos de injeção de sinal.

\begin{tabular}{c}
\hline Tipo de injeção \\
\hline Fase A + Neutro \\
Fase B + Neutro \\
Fase C + Neutro \\
Fase A + Fase B \\
Fase A + Fase C \\
Fase B + Fase C \\
Múltiplas injeções \\
\hline
\end{tabular}

Destaca-se que, mesmo para sistemas trifásicos, muitas vezes não é necessário realizar a injeção dos sinais nas múltiplas fases, bastando, por exemplo, apenas uma simples injeção do tipo fase-neutro e então o efeito de indução permitirá que o sinal esteja disponível nas demais fases. Cabe ao responsável pelas injeções interpretar as medições realizadas e então aperfeiçoar as injeções de sinal para obter uma melhor distribuição dos sinais pela edificação.

Assim, recomenda-se que para cada uma das injeções realizadas seja efetuado o registro dos níveis de sinal em todos os pontos da edificação. Desta forma, comparando-se os dados obtidos, pode-se detectar qual a melhor topologia de injeção dos sinais para a referida estrutura.

As diversas técnicas de abordagem, principalmente em edificações, serão apresentadas no capítulo 8 deste trabalho. Além disso, o Anexo A apresenta inúmeras considerações sobre a distribuição dos sinais PLC nas edificações através do uso do modelo de Linha de Transmissão.

\subsection{Avaliação dos enlaces}

Uma vez que os sinais medidos atendem aos requisitos de conectividade dos equipamentos PLC/BPL, deve-se proceder com a análise quantitativa da qualidade dos canais de comunicação.

O primeiro passo a ser executado consiste em verificar se o enlace realmente pode ser estabelecido. Para isso, pode-se utilizar o comando ping, o qual é nativo tanto em sistemas 
operacionais do tipo Windows quanto Linux. O comando ping é utilizado, justamente, para testar a conectividade entre equipamentos. O funcionamento baseia-se no envio de pacotes para o equipamento destino, assim como na escuta da resposta a estes pacotes. Se o equipamento destino estiver ativo ele enviará uma resposta ao equipamento solicitante.

$\mathrm{Na}$ prática, pode-se conectar um computador junto ao equipamento master e outro computador junto ao CPE conectado ao ponto elétrico onde se deseja realizar a avaliação do enlace.

Uma vez que o resultado do teste com o comando ping seja positivo, ou seja, o ponto elétrico em questão realmente oferece conectividade, deve-se passar à segunda etapa dos testes.

A segunda etapa consiste na avaliação quantitativa do canal de comunicação, ou seja, consiste na determinação da capacidade de transmissão do referido canal de comunicação. Os testes podem ser realizados com o aplicativo iperf [62], sendo que deve ser avaliado o desempenho dos trechos em ambos os sentidos, ou seja, do master para o CPE e do CPE para o master. Isso se deve ao fato da capacidade de ambos os trechos serem diferentes.

O iperf é uma ferramenta de domínio público (licença GNU), a qual é utilizada para medir o desempenho de redes no que se refere aos protocolos TCP e UDP. Assim, o aplicativo gera tráfego TCP/UDP medindo a capacidade máxima de transmissão do canal de comunicação, além de fornecer informações sobre atrasos e datagramas perdidos. Sua interface é bastante simples e a ferramenta extremamente versátil.

Nos testes de desempenho, é recomendável que seja avaliada a qualidade do canal por, no mínimo, 5 minutos. A aplicação deve ser executada em ambas as extremidades do canal de comunicação que se deseja avaliar. Assim, a estrutura para execução do aplicativo é do tipo cliente servidor. A Tabela 3 apresenta os comandos para iniciar a aplicação em ambos os modos de operação, os quais podem ser executados diretamente na linha de comando do sistema operacional em uso, uma vez que o aplicativo esteja disponível.

Tabela 3 - Comandos para iniciar o aplicativo iperf em seus diversos modos de operação.

\begin{tabular}{cc}
\hline Modo de operação do iperf & Comando \\
\hline Servidor iperf - TCP & iperf $-\mathrm{s}-\mathrm{i} 1-\mathrm{fm}$ \\
Servidor iperf - UDP & iperf $-\mathrm{s}-\mathrm{u}-\mathrm{i} 1-\mathrm{fm}$ \\
Cliente iperf - TCP & iperf $-\mathrm{c}<\mathrm{hos}>-\mathrm{i} 1-\mathrm{fm}-\mathrm{t} 300$ \\
Cliente iperf - UDP & iperf $-\mathrm{c}<\mathrm{hos}>-\mathrm{u}-\mathrm{i} 1-\mathrm{fm}-\mathrm{t} 300-\mathrm{b} 120$ \\
\hline
\end{tabular}


Obviamente, os parâmetros indicados nos comandos da Tabela 3 poderão sofrer alterações de acordo com as características específicas de cada rede ou teste a ser realizado. Desta maneira, se houver dúvida, recomenda-se a leitura da ajuda do aplicativo ou do site do desenvolvedor [62].

Uma vez realizada a análise quantitativa de todos os trechos da rede PLC/BPL, deve-se verificar se eles atendem os requisitos de projeto da rede. Caso algum trecho não atenda às especificações, deve-se voltar às atividades apresentadas na seção 7.6 no sentido de alterar as injeções realizadas e aumentar o nível de sinal dos trechos que não atenderem as especificações. Com o aumento do nível de sinal, espera-se aumentar o número de bits por portadora e, portanto, aumentar a capacidade de transmissão do canal. Caso tal medida não seja suficiente, deve-se estudar a instalação de um equipamento do tipo repeater.

Além das medidas quantitativas, realizadas com o iperf, pode-se realizar medidas qualitativas com outros aplicativos, como, por exemplo, o VLC [63]. Tal aplicativo faz o papel de um servidor de vídeo, sendo que é capaz de reproduzir vídeos controlando sua taxa de transferência (streaming server). Através de uma estrutura cliente servidor, é possível trafegar vídeos através de uma rede PLC/BPL e avaliar o resultado de forma qualitativa, ou seja, bom ou ruim.

\subsection{Comissionamento}

Com base no aumento do número de redes PLC/BPL instaladas comercialmente, cresceu a importância do processo de comissionamento de tais redes, uma vez que o ponto de conexão entregue ao cliente deve estar em perfeitas condições de uso. Além disso, a documentação eficiente das redes instaladas tem papel fundamental na atividade de manutenção das mesmas, seja esta preventiva ou corretiva. Adicionalmente, a documentação da rede é fundamental para o atendimento da regulamentação brasileira [1], a qual exige que informações mínimas sobre o projeto sejam documentadas e disponibilizadas para a Agência, além de auxiliar na resolução de eventuais problemas relacionados à Compatibilidade Eletromagnética. 
Enfatiza-se, assim, que a estrutura de comissionamento aqui apresentada pode ser aplicada a qualquer rede PLC/BPL instalada, seja esta de uso comercial ou não, facilitando assim o bom desempenho do projeto executado, as atividades de manutenção e o atendimento à regulamentação vigente. Assim, são apresentados na seqüência os itens constituintes do modelo de comissionamento proposto, sendo que o mesmo foi empregado na rede PLC/BPL desenvolvida para o projeto SAMBA, na cidade de Barreirinhas, estado do Maranhão, e posteriormente bem aceito pelo projeto Opera, sigla para Open PLC European Research Alliance [64].

O primeiro item que compõe o relatório de comissionamento de uma rede PLC/BPL é a "estrutura física". Tal item segue as diretrizes apresentadas na seção 7.2 e consiste na documentação detalhada de toda a estrutura física do local, assim como dos requisitos da rede de comunicação e o planejamento de links associado.

O segundo item a compor o relatório está relacionado às "medições realizadas", as quais constituem outro aspecto essencial das redes PLC/BPL. Todas as informações coletadas a respeito da distribuição dos sinais dentro da edificação em questão devem ser registradas, uma vez que estas dependem fortemente das características elétricas da rede, assim como das cargas conectadas à mesma e que, portanto, mudam muito de um local para outro. Como exemplo, pode-se citar a documentação de todas as injeções realizadas, assim como dos valores de sinal PLC/BPL medidos em cada ponto de interesse, para cada uma das injeções efetuadas. De posse de tais informações pode-se obter a melhor topologia de injeção dos sinais a ser utilizada no local para que o desempenho da rede seja o melhor possível, atendendo os requisitos do projeto.

O terceiro item integrante do relatório trata dos "testes de desempenho" e está intimamente relacionado aos aspectos apresentados na seção 7.7. Deve-se realizar o registro de todos os testes realizados para que toda e qualquer atividade de manutenção seja facilitada, além do fato de garantir para o cliente (no caso de redes comerciais) que as capacidades de transmissão de cada trecho da rede PLC/BPL estão de acordo com os requisitos definidos no projeto da rede.

O quarto item verificado em um relatório de comissionamento consiste na documentação das configurações dos equipamentos da rede. De acordo com a complexidade de cada rede PLC/BPL instalada, deve-se configurar os equipamentos para que eles se adaptem às características dessas redes. Desta forma, deve-se documentar de forma adequada todas as configurações de cada um dos equipamentos PLC/BPL que forem integrados às redes. 
Como exemplo, pode-se citar o endereçamento IP de cada equipamento, máscara de rede, gateway, método de autenticação, VLAN, QoS, CoS, Watchdog, STP, NTP, entre outros.

Tais informações são de extrema importância, principalmente para as atividades de manutenção das redes instaladas.

O quinto item consiste no registro fotográfico da instalação realizada. Quando uma rede PLC/BPL está instalada é muito importante realizar o registro fotográfico da mesma, uma vez que, muitas vezes, não existe padrão nas instalações elétricas (realidade brasileira) o que acaba dificultando enormemente o registro adequado de algumas informações particulares da rede elétrica abordada. Desta forma, o registro fotográfico é uma forma bastante simples de documentar inúmeros aspectos das redes, além de servir de base para a documentação de todo o projeto da rede PLC/BPL instalada.

Na seqüência, o sexto item do relatório de comissionamento está relacionado ao inventário da rede instalada. Do ponto de vista corporativo, a documentação detalhada de todos os equipamentos utilizados nas redes PLC/BPL é fundamental para o controle dos ativos comercializados, assim como para evitar problemas futuros com relação ao projeto desenvolvido. É essencial documentar a localização exata (latitude / longitude) de cada um dos equipamentos do tipo master presentes nas redes, uma vez que se trata de um requisito legal da regulamentação em vigor no Brasil [1]. Recomenda-se o registro explícito, no relatório de comissionamento da rede PLC/BPL, do MAC Address de cada interface de comunicação (interface PLC/BPL e interface ethernet) de todos os equipamentos, assim como dos números seriais dos mesmos.

Finalmente, o sétimo item do relatório trata das considerações gerais e conclusão do mesmo. Este item deve conter um resumo dos principais aspectos do projeto desenvolvido, assim como recomendações para o cliente acerca de filtros que por ventura foram utilizados no projeto. Desta forma, evitam-se problemas de instabilidade na rede PLC/BPL através de orientações simples que podem ficar registradas no relatório entregue ao cliente para consulta posterior. 


\subsection{Exemplos de rede}

Do ponto de vista didático, são apresentados na seqüência dois exemplos de redes PLC/BPL, os quais constituem os exemplos mais simples possíveis, dentre todas as topologias passíveis de serem implantadas.

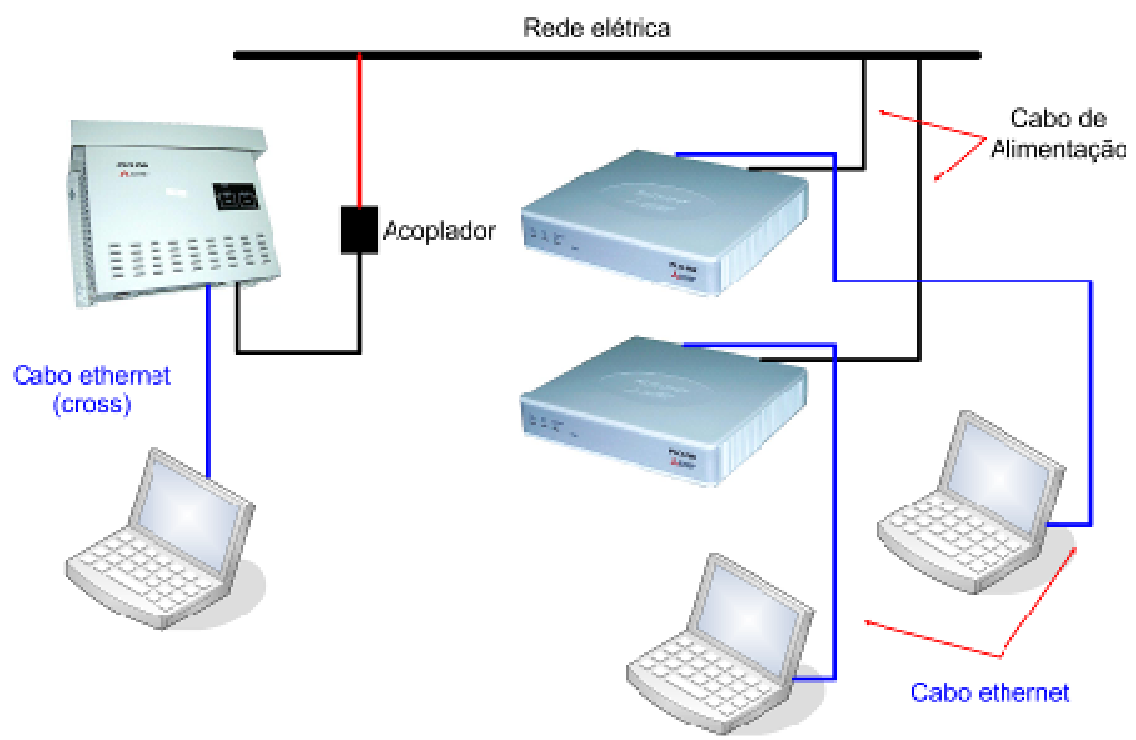

Figura 31 - Exemplo 1 de uma rede PLC/BPL simples.

O objetivo da rede apresentada na Figura 31 é conectar os 3 notebooks que aparecem na mesma. A rede PLC/BPL oferecerá conectividade às máquinas de forma que elas possam se comunicar. Observa-se que são utilizados 1 equipamento do tipo master, 2 equipamentos do tipo CPE, além de 1 acoplador capacitivo de baixa tensão. Caso não seja necessário que os equipamentos PLC sejam gerenciados, pode-se deixá-los operar diretamente na camada 2 e portanto a instalação se torna praticamente plug \& play.

Uma extensão deste exemplo é realizar a conexão dos 2 notebooks à internet, sendo que a Figura 32 apresenta este exemplo. 


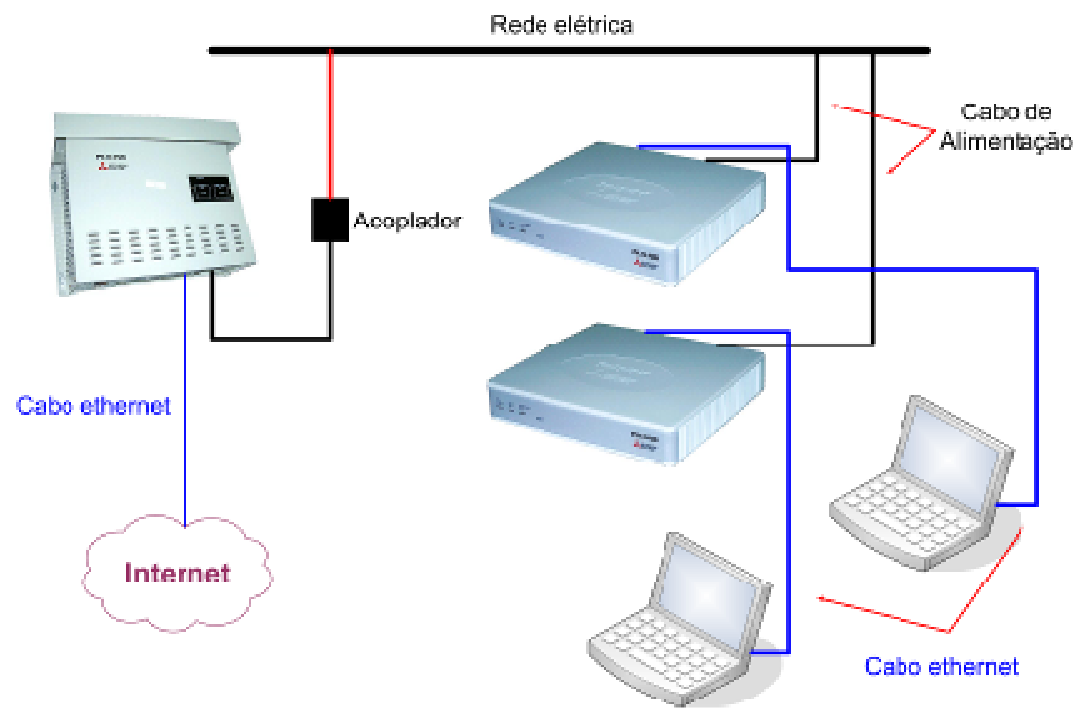

Figura 32 - Exemplo 2 de uma simples rede PLC/BPL.

Observa-se que a única diferença entre a Figura 31 e a Figura 32 é a presença de um ponto de conexão com a internet. Desta forma, a estrutura da Figura 32 efetivamente permite oferecer conexão com a internet para os 2 notebooks conectados aos CPEs. 


\section{Técnicas de abordagem de redes reais}

Conforme exposto, são muitas as variáveis a serem consideradas na implantação de uma rede

PLC/BPL. Desta forma, serão apresentadas, na seqüência, as diretrizes básicas para realizar a abordagem das edificações em suas várias formas estruturais.

Destaca-se que as metodologias de abordagem aqui propostas constituem-se em contribuições deste trabalho.

\subsection{Ambiente doméstico}

Conforme já apresentado, o ambiente doméstico pode ser dividido em dois segmentos. O primeiro deles consiste na abordagem de um ambiente residencial com o objetivo de interligar os diversos cômodos do local. Como este tipo de aplicação não possui interesse comercial, a metodologia aqui proposta será apresentada utilizando-se exemplos do segundo segmento doméstico, ou seja, ambientes corporativos. Entende-se por ambientes corporativos escritórios de empresas, sendo que muitas vezes a similaridade com ambientes residenciais é grande. Desta forma, este é o tipo de ambiente que não apresenta grandes complicadores para a implantação da tecnologia pelo fato dos comprimentos dos circuitos elétricos envolvidos serem relativamente pequenos.

A Figura 33 ilustra o ambiente de uma pousada onde a tecnologia PLC foi utilizada para oferecer conectividade dentro de cada um dos quartos do local.

A estrutura é constituída de 6 conjuntos, onde os quartos estão distribuídos ao longo de 5 destes. As linhas azuis da figura correspondem ao cabeamento de rede convencional. Desta forma, cada prédio é integrado à rede de comunicação através de cabeamento convencional e então a tecnologia PLC é responsável por levar os sinais até os quartos, a partir do quadro de distribuição de cada conjunto. 


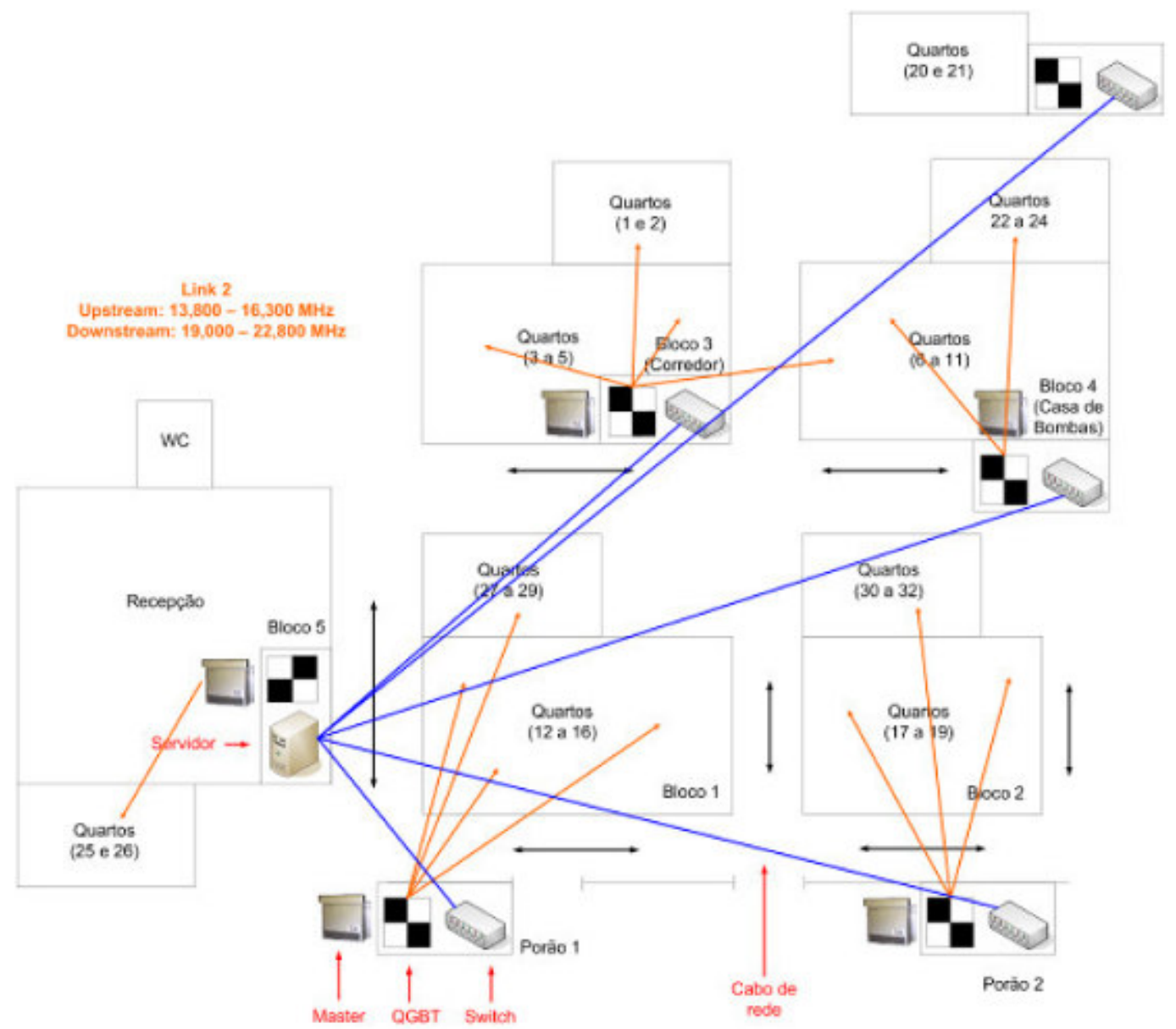

Figura 33 - Estrutura da rede PLC dentro da pousada.

Como o ambiente é relativamente pequeno do ponto de vista elétrico ${ }^{9}$, a opção natural é injetar os sinais PLC no quadro de distribuição de cada conjunto. Desta forma, como não existem grandes complicadores em termos de distribuição do sinal PLC, basta seguir os procedimentos descritos no capítulo 7 deste trabalho a fim de garantir que os níveis de sinal observados atendam aos requisitos de projeto.

A Figura 34 apresenta algumas fotos relevantes do local e da estrutura montada, sendo que as setas vermelhas indicam os equipamentos PLC/BPL e as verdes os acopladores capacitivos de baixa tensão.

Finalmente, cabe destacar que a potencialidade e a versatilidade da tecnologia foram bem exploradas neste projeto, uma vez que as atividades foram desenvolvidas sem nenhum desligamento no local, assim como nenhuma paralisação dos quartos.

\footnotetext{
${ }^{9}$ Para maiores detalhes consulte a seção 7.4.
} 


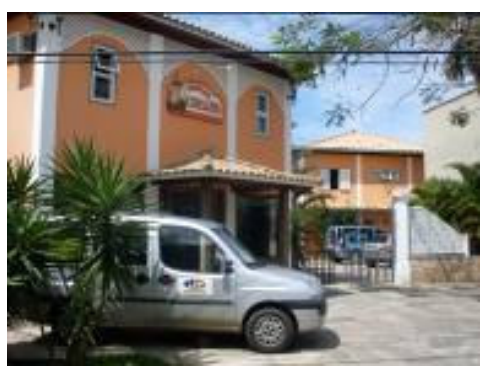

(a)

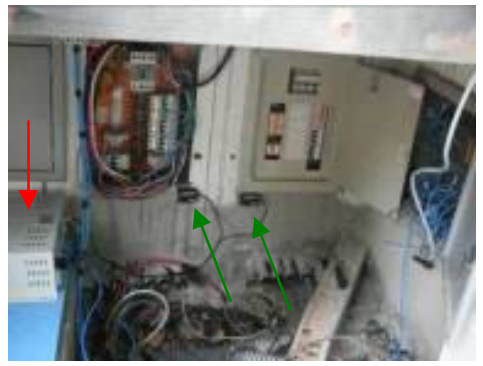

(b)

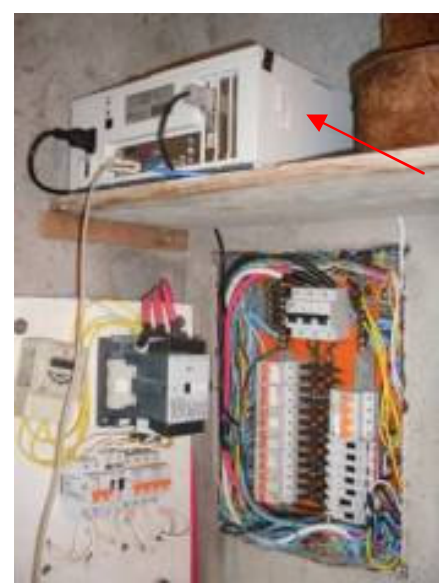

(c)

Figura 34 - Fotos da estrutura montada na pousada.

\subsection{Ambiente interno}

Dependendo da estrutura da edificação, a implantação da tecnologia dentro de um ambiente interno pode ser extremamente complexa. Entende-se por ambiente interno a utilização da tecnologia no interior de edifícios.

Considere uma estrutura onde todos os medidores estão concentrados no subsolo da edificação, ou seja, o centro de medição é centralizado. Além disso, considere que os condutores elétricos que alimentam as unidades, de baixo para cima, estão alocados da periferia da prumada para o centro da mesma, ou seja, os condutores que alimentam o primeiro andar estão localizados na borda da prumada, enquanto que os condutores que alimentam as unidades do último andar estão alocados no centro da mesma. Destaca-se que esta distribuição dos condutores dentro da prumada é encontrada na prática na maioria dos edifícios. A Figura 35 ilustra a topologia acima descrita. 


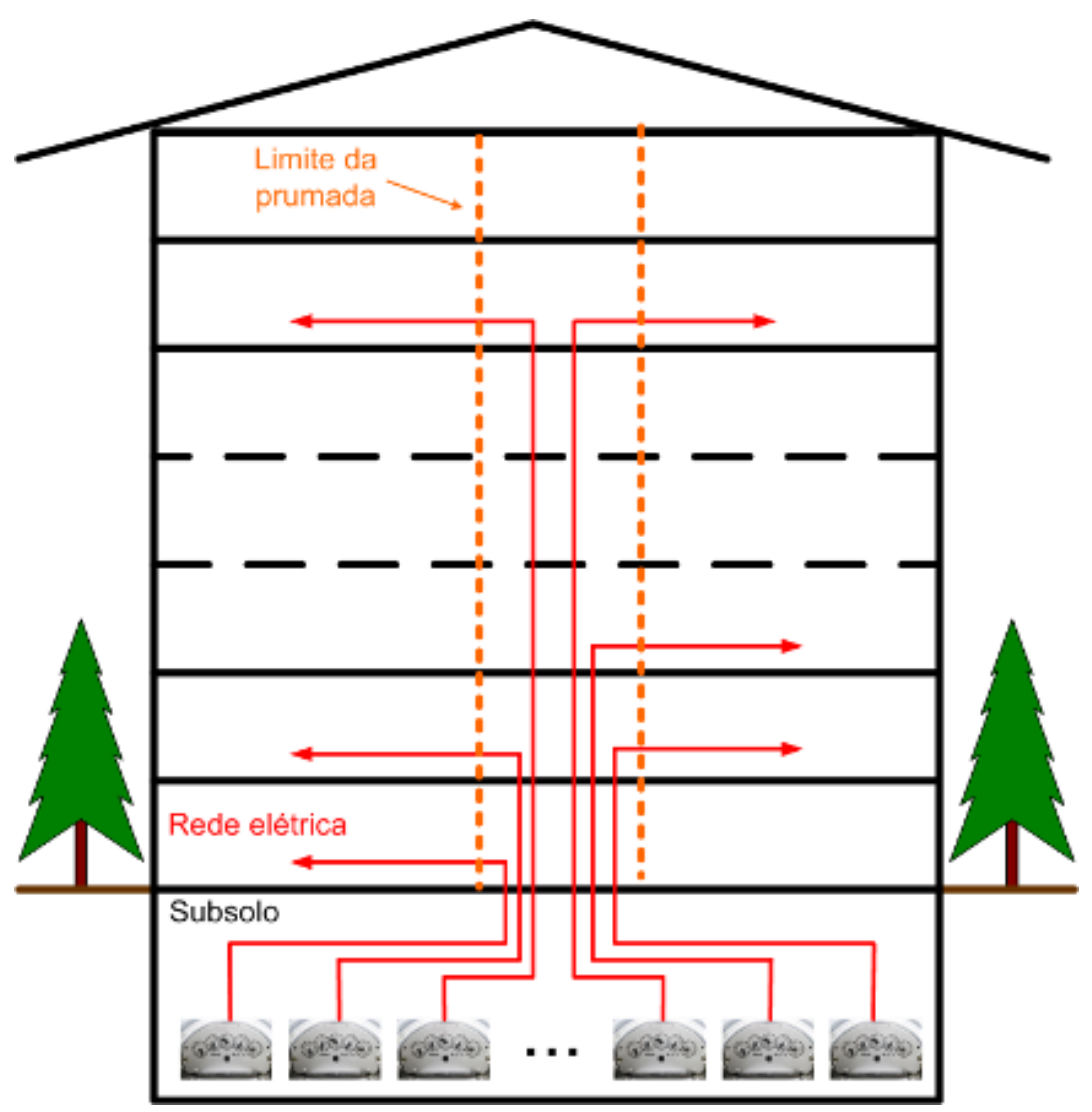

Figura 35 - Distribuição dos medidores e esquema da prumada do edifício.

Diante de tal estrutura de distribuição, pode-se realizar a abordagem da edificação utilizando para isso o conceito de grupo de andares. Tal conceito consiste em injetar os sinais PLC em um dado andar e verificar o nível de indução de sinais nas unidades do mesmo andar, assim como nos andares adjacentes, com o objetivo de detectar qual é o número de andares onde a injeção efetuada pode produzir níveis de sinal PLC satisfatórios para oferecer conectividade, segundo as necessidades do projeto.

A Figura 36 ilustra um exemplo onde o sinal PLC é injetado no penúltimo andar e 1 andar acima e 1 andar abaixo apresentam sinal PLC com intensidade satisfatória. Para facilitar a nomenclatura este grupo será chamado de "grupo \pm 1 ”. 


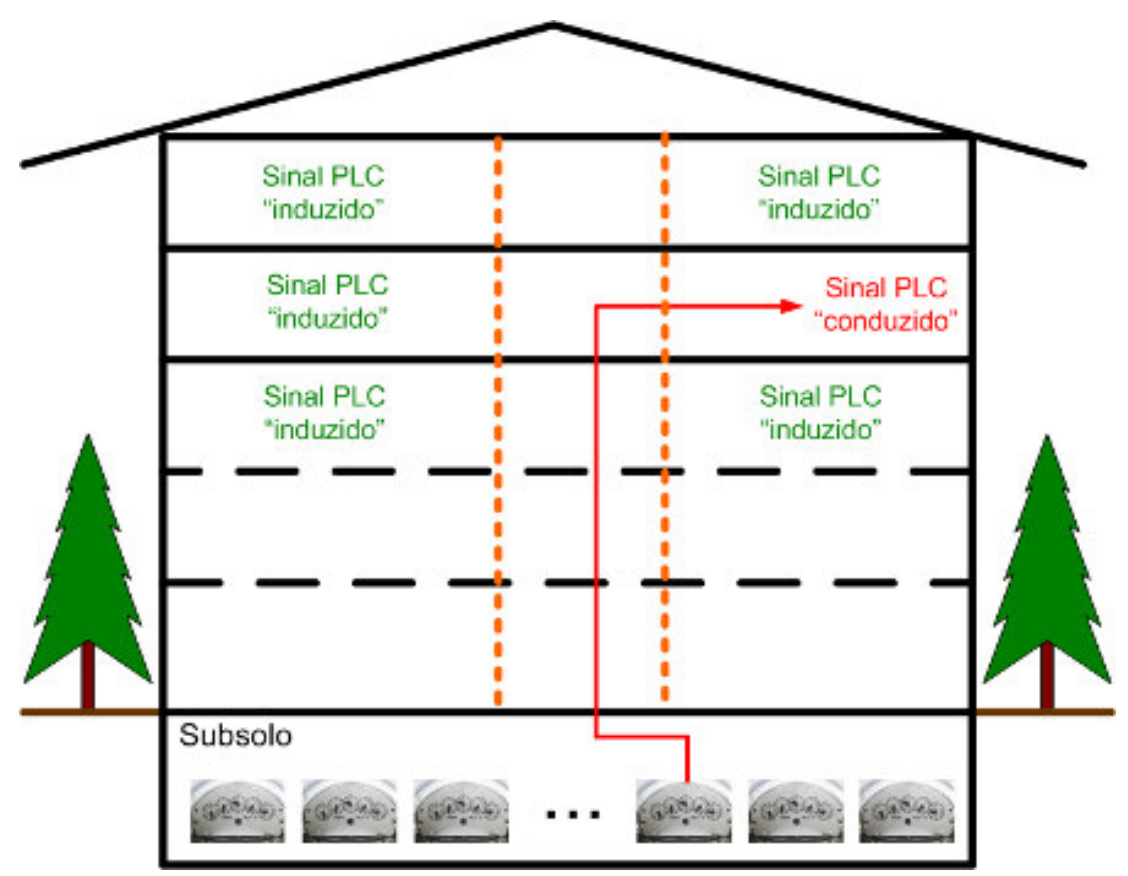

Figura 36 - Ilustração de um “grupo \pm 1 ”.

Aconselha-se iniciar as injeções de sinal no penúltimo andar da edificação, conforme exemplo anterior, para se detectar qual o grupo que será criado. Esta escolha se deve ao fato de que, na maioria dos prédios abordados durante o desenvolvimento deste trabalho, os grupos criados eram do tipo "grupo \pm 1 ".

Já a Figura 37 ilustra um exemplo onde o sinal PLC é injetado no ante penúltimo andar e 2 andares acima e 2 andares abaixo apresentam sinal PLC com intensidade satisfatória. Assim, analogamente ao caso anterior, este grupo será chamado de "grupo \pm 2 ".

Não foram observados, em campo, casos onde existia assimetria nas induções, por exemplo, sinais presentes em até 2 andares acima e apenas 1 abaixo do andar de injeção. Apesar disso, recomenda-se atenção durante a determinação do grupo criado, pois não foram feitos testes exaustivos para garantir que realmente não ocorra assimetria nas induções.

Um fato relevante é que, caso a edificação possua muitos andares e o sinal PLC seja fortemente atenuado, será necessária a instalação de um equipamento do tipo repetidor ao longo da estrutura. Alternativamente, pode-se estudar a alteração da faixa de frequiência de trabalho. Para isso, será necessário determinar o andar onde os sinais ainda possuem intensidade satisfatória para então alocar o referido equipamento.

Outra recomendação, que é conseqüência do fato citado, é a de que, uma vez que o sinal PLC seja injetado em um determinado andar com o objetivo de determinar o grupo a ser criado, 
deve-se primeiro realizar a medição da intensidade do sinal PLC na unidade consumidora onde o sinal foi injetado.

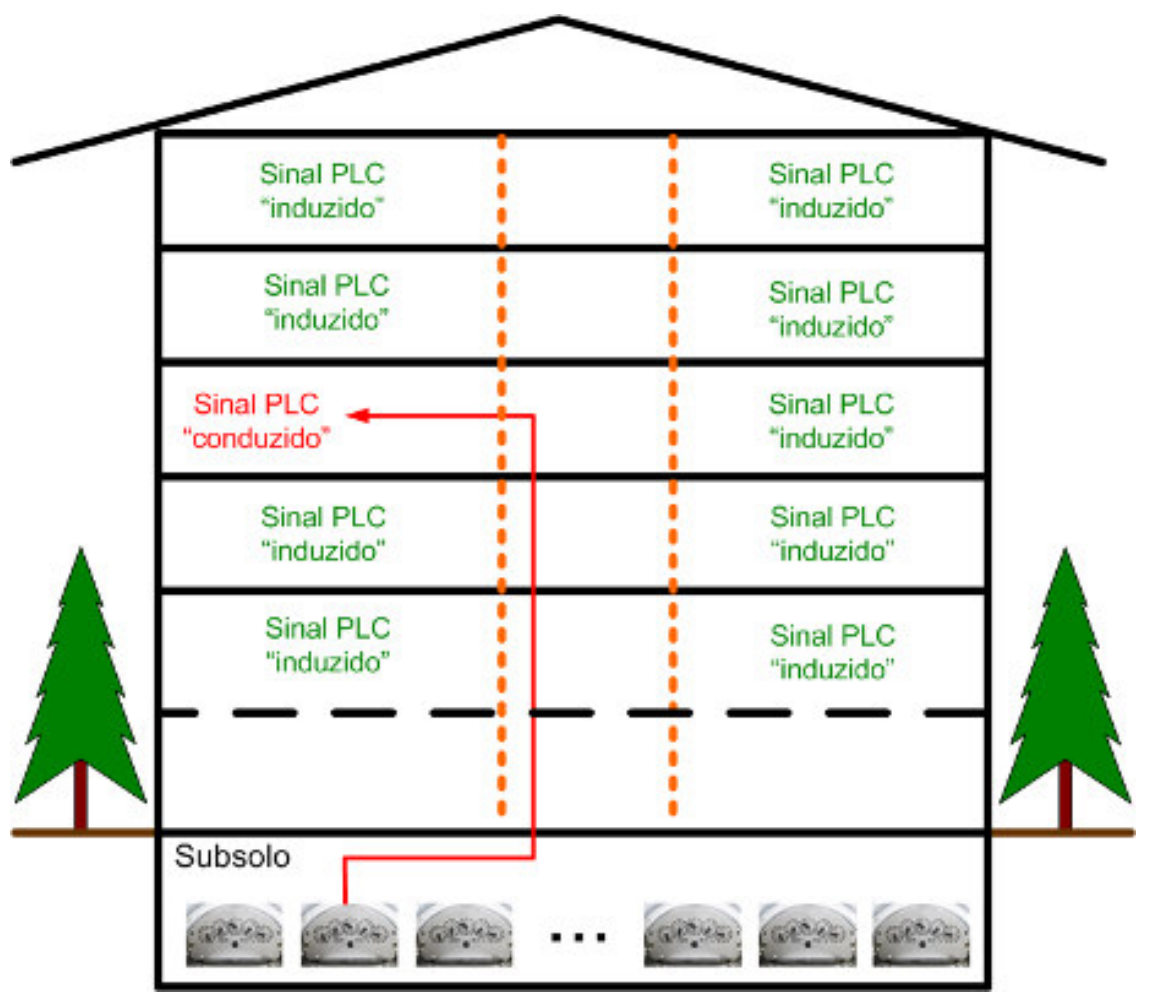

Figura 37 - Ilustração de um "grupo \pm 2 ”.

Uma vez definido o grupo que é possível de ser criado com uma única injeção de sinal, devese proceder com novas injeções a fim de levar os sinais PLC às demais unidades consumidoras. Para isso, pode-se utilizar um novo acoplador e realizar uma simples emenda no cabo entre o acoplador e o equipamento master. A nova injeção deverá ser realizada no $\operatorname{andar}\left(A_{\text {NOVA_INJ }}\right)$ resultante da equação (1).

$$
A_{N O V A_{-} I N J}=A_{A N T_{-} I N J}-2 n_{\text {GRUPO }}
$$

onde:

- $A_{A N T_{-} I N J}$ : corresponde ao andar onde foi realizada a última injeção;

- $n_{\text {GRUPO }}$ : corresponde ao número de andares, acima e abaixo, que a injeção anterior produziu. 
Destaca-se que não foram verificadas as intensidades de sinal produzidas caso fosse alterado o local de injeção do sinal para outra unidade consumidora dentro do mesmo andar. Desta forma, trata-se de algo ainda a ser investigado futuramente.

Cabe ressaltar que os grupos podem variar desde o "grupo \pm 0 " até uma situação onde uma única injeção de sinal produza intensidades que atendam todas as unidades consumidoras da edificação. Obviamente, isso vai depender da forma como os sinais PLC se distribuem pela mesma.

Finalmente, caso a indução de sinal PLC nas unidades consumidoras adjacentes ao ponto de injeção (no mesmo andar), assim como nos andares adjacentes, não seja favorável à produção de sinais com intensidade satisfatória, poder-se-ia, no limite, utilizar 1 equipamento do tipo master para injetar os sinais em cada uma das unidades consumidoras da edificação. Obviamente este tipo de solução não é financeiramente viável e, portanto, pode-se recorrer às estratégias que serão apresentadas no capítulo 9 deste trabalho.

Como exemplo prático, pode-se citar uma edificação que foi abordada na cidade de São Paulo, no bairro de Moema, a qual continha 12 andares, sendo 1 apartamento por andar. No local existia um centro de medição centralizado localizado no subsolo da edificação. Foi realizada apenas 1 injeção de sinal no apartamento do último andar e então foi verificado que os níveis de sinal presentes nos demais andares eram todos superiores a $-40 \mathrm{dBm}$. Do ponto de vista comercial, pode-se dizer que este tipo de edificação é muito interessante, uma vez que a quantidade de "horas·homem" aplicadas é a menor possível.

Outro exemplo de abordagem de uma edificação é a de um edifício comercial de 18 andares, localizado também na cidade de São Paulo. O local possui um centro de medição centralizado e localizado no subsolo da estrutura. No local existem 3 geradores, para o caso de falta de energia da concessionária e conseqüentemente uma chave de transferência (na verdade são duas chaves) para interligar as duas formas de alimentação.

O objetivo era transportar os sinais PLC do subsolo da edificação para 3 salas comerciais específicas, sendo uma localizada no $1^{\circ}$ andar, outra no $3^{\circ}$ andar e a última no $11^{\circ}$ andar.

Quando os sinais foram injetados logo após os medidores, que é muitas vezes o local naturalmente escolhido, nenhum sinal era medido nas referidas salas comerciais. Como existiam chaves de transferência no local as injeções foram realizadas nos condutores que voltavam de tal chave e, então, sinais satisfatórios foram observados nos pontos de acesso. 
Neste caso, foi necessário utilizar 2 faixas de freqüência distintas para atender a edificação, conforme ilustra a Figura 38.

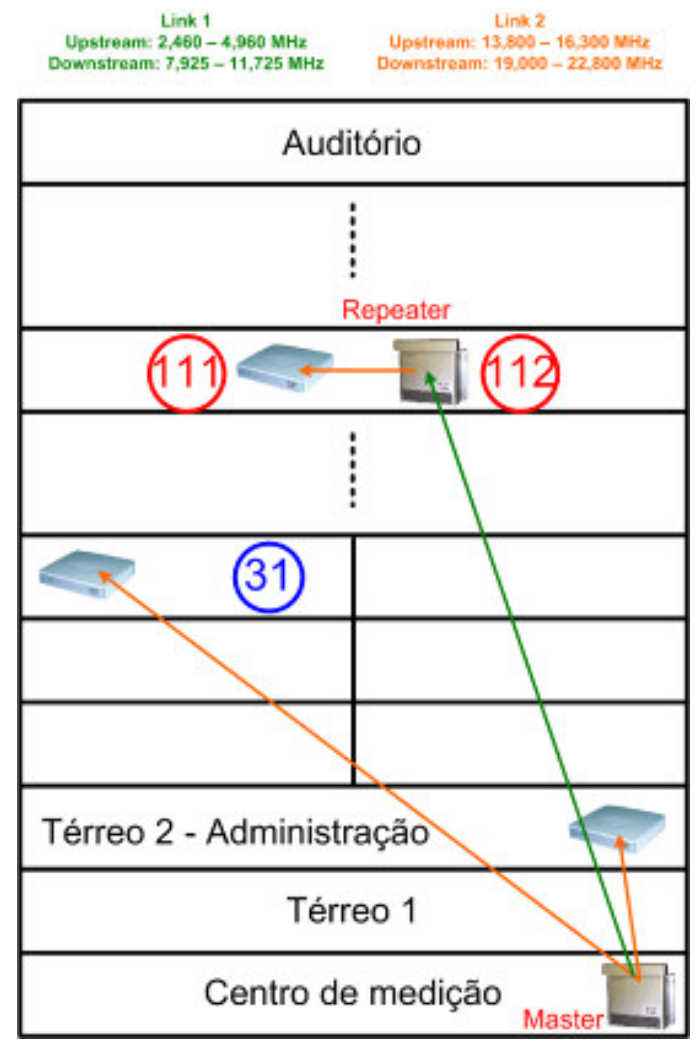

Figura 38 - Estrutura construída para abordagem do edifício comercial.

A utilização de um equipamento repetidor no andar 11 foi necessária, pois os sinais na faixa de $20 \mathrm{MHz}$ (link 2) eram fortemente atenuados até o referido andar, chegando com intensidades não satisfatórias. Desta forma, optou-se pela utilização de um link de mais baixa freqüência, cerca de $2 \mathrm{MHz}$ (link 1), o qual chegava no $11^{\circ}$ andar com intensidades bastante satisfatórias.

Os outros dois pontos de acesso, localizados nos andares inferiores, foram atendidos com 1 injeção em seus respectivos condutores, a partir de um único equipamento do tipo master, ou seja, foi realizada uma injeção múltipla. As distâncias e estrutura envolvidas eram tais que sinais na faixa de $20 \mathrm{MHz}$ (link 2) chegavam nos pontos de acesso com intensidades satisfatórias para as necessidades do projeto.

Do ponto de vista comercial, este é um prédio "complicado", pois foram muitos os contra tempos encontrados no que se refere ao acesso aos locais, ausência de documentação elétrica do local, informações desencontradas fornecidas pelos funcionários do local, além da 
distribuição dos sinais PLC não serem integralmente favoráveis. Tudo isso implicou em várias "horas·homem" para a implantação de simples 3 pontos de acesso. O maior número de horas foi utilizado para compreender a estrutura elétrica do local.

Na seqüência, são apresentadas fotos do centro de medição do referido edifício comercial abordado, onde é possível visualizar os medidores das unidades consumidoras (a), assim como os condutores que ficam em cima de uma esteira metálica localizada acima dos medidores (b) e (c).

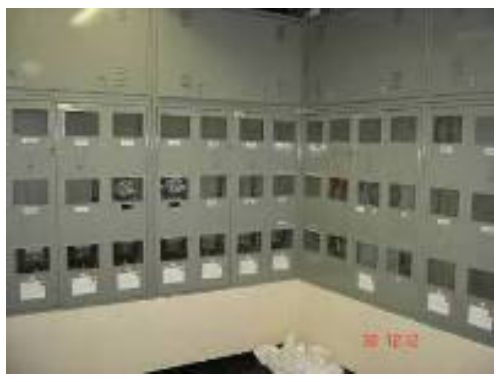

(a)

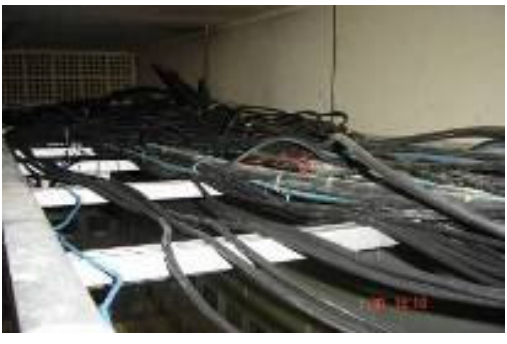

(b)

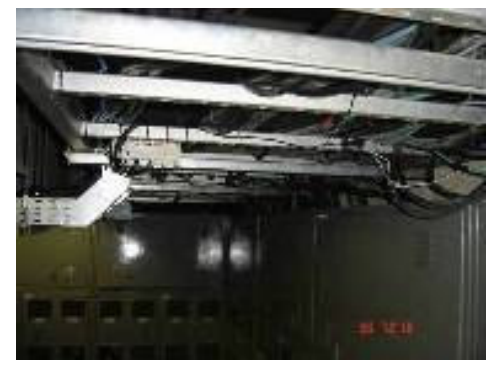

(c)

Figura 39 - Fotos do centro de medição do edifício comercial abordado.

\subsection{Ambiente externo}

Com relação ao ambiente externo, é possível definir dois tipos de abordagem distintas. O primeiro deles é a utilização da tecnologia na rede primária, ou seja, na rede de média tensão. Como este tipo de estrutura é praticamente inexistente no Brasil, assim como ainda não possui interesse comercial, esta não será aqui abordada. O segundo tipo de abordagem em ambientes externos está relacionado à utilização do ramal secundário, ou rede de baixa tensão.

Desta forma, será apresentado o esquema utilizado para implantação da tecnologia PLC/BPL em um dado ramal secundário.

Como premissa considere um ramal com cerca de $400 \mathrm{~m}$ de comprimento e cerca de 50 unidades consumidoras associadas ao ramal, e, portanto, a um mesmo transformador. Estes dados são representativos de grande parte das redes secundárias existentes no Brasil. 
A abordagem inicial consiste em criar regiões que operem em faixas de freqüência distintas, sendo que a Figura 40 ilustra tal situação.

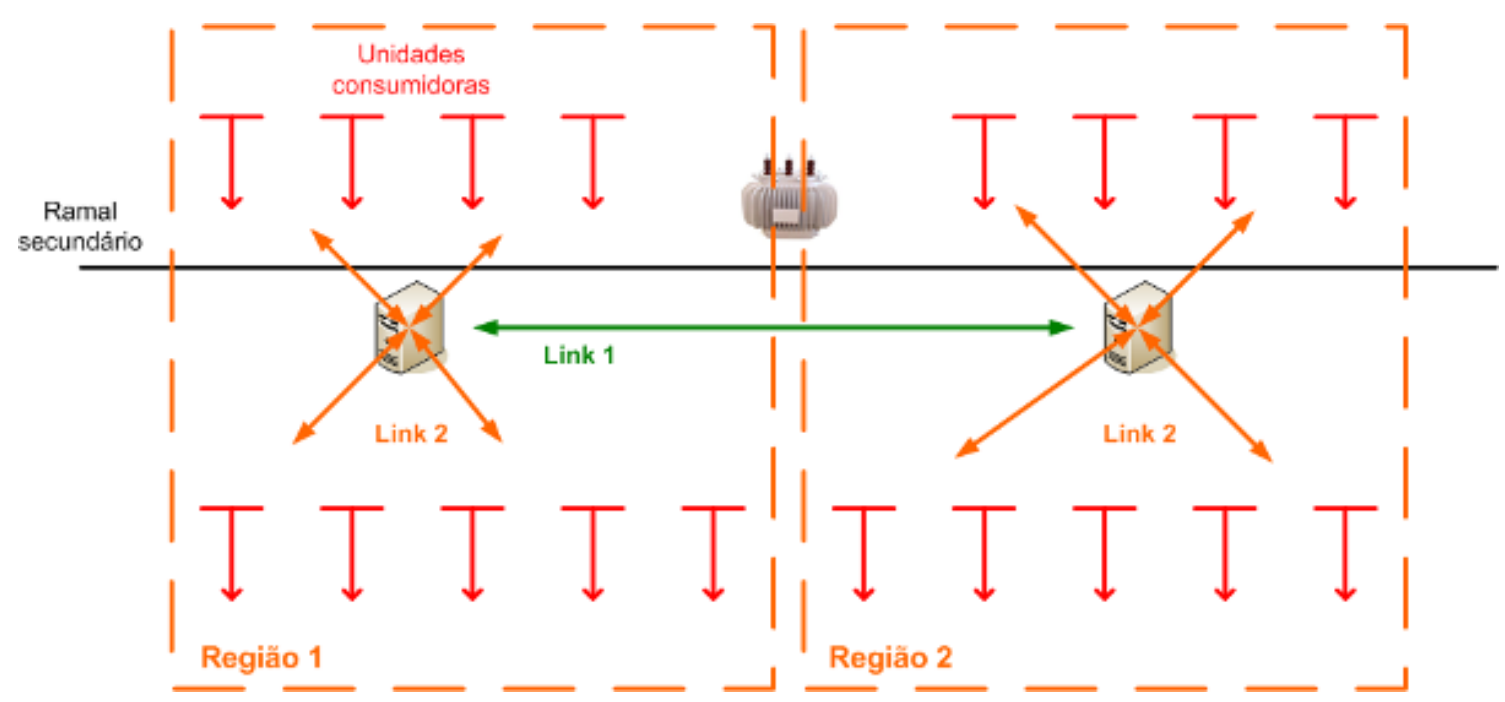

Figura 40 - Divisão de um ramal secundário em 2 regiões.

De acordo com a análise da Figura 40, verifica-se que uma das primeiras formas de abordagem é dividir o ramal secundário em 2 regiões. Nesta situação, ambos os equipamentos operam como repetidores, uma vez que utilizam 2 faixas de frequiência distintas para realizar a comunicação. Observe que, necessariamente, um deles deverá estar conectado à outra rede através de uma interface padrão ethernet. A princípio, neste caso, não importa qual deles faz tal conexão.

Para realizar a injeção dos sinais PLC/BPL no ramal, devem-se escolher os condutores que proporcionem os maiores níveis de sinal dentro das residências a serem abordadas. Desta forma, o primeiro critério para a escolha dos condutores onde os sinais deverão ser injetados está associado ao esquema de ligação das unidades consumidoras. Deve-se verificar em qual das fases as residências de interesse estão conectadas e então injetar os sinais, inicialmente, na fase onde exista um maior número de residências de interesse. Obviamente, os sinais estarão presentes nas outras fases, devido à indução de tensão que potencialmente ocorrerá, sendo que os detalhes de tal fenômeno podem ser encontrados no Anexo A.

Uma vez que os sinais são injetados, devem-se realizar os procedimentos descritos no capítulo 7 deste trabalho.

Caso exista uma distribuição uniforme das residências de interesse entre as fases do ramal secundário, e, portanto, não seja possível adotar o critério anteriormente proposto, pode-se 
proceder com a escolha inicial para injeção dos sinais de um esquema fase-neutro e então realizar os procedimentos descritos no capítulo 7 deste trabalho. Adicionalmente, pode-se instalar ferrites, devidamente dimensionados, nas entradas das unidades consumidoras onde não se deseja a presença de sinais PLC. Isso permite um maior aproveitamento dos sinais nas unidades consumidoras de interesse.

Se ainda assim a distribuição dos sinais PLC não for satisfatória, ou se os níveis de sinal obtidos dentro das residências de interesse não atenderem os requisitos de projeto, pode-se proceder com uma nova divisão da região de abordagem. Um exemplo de 3 regiões operando em faixas de freqüência distintas em um dado ramal secundário é ilustrado na Figura 41.

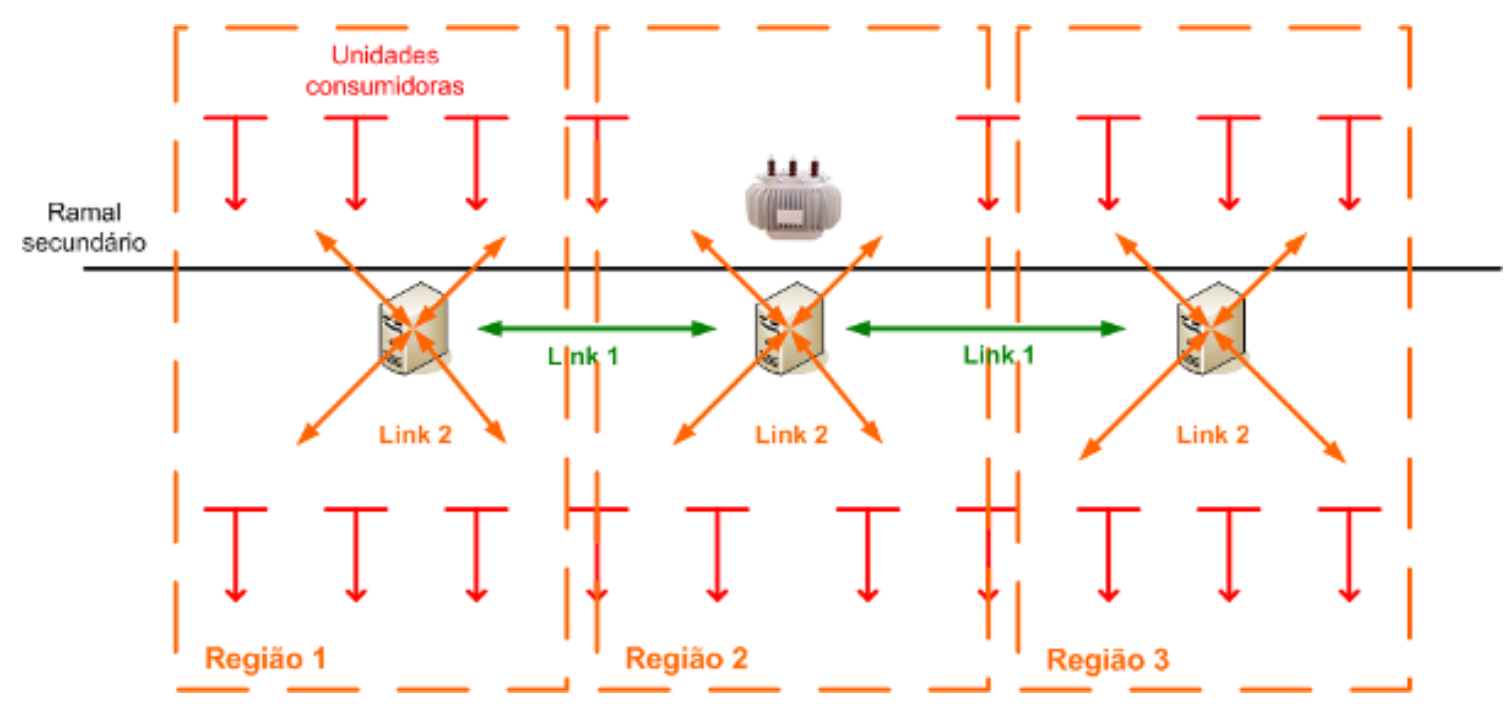

Figura 41 - Divisão de um ramal secundário em 3 regiões.

$\mathrm{Na}$ situação ilustrada na Figura 41, o equipamento central (região 2) passa a ser o equipamento que se conectará à outra rede de comunicação externa.

Observe que, tanto no caso de 2 regiões quanto no caso de 3 regiões, existe a possibilidade da ocorrência de interferência entre redes PLC. Isso potencialmente pode ocorrer na interface entre as regiões. A ocorrência ou não de tal fenômeno está associada à distribuição dos sinais PLC no local e, caso ocorra, a realocação dos equipamentos deverá ser considerada.

Caso a divisão em 3 regiões ainda não produza níveis de sinal satisfatórios, deve-se considerar a criação de mais regiões seguindo o padrão apresentado na Figura 40 e Figura 41.

Como exemplo real de uma abordagem de um ramal secundário, pode-se citar a rede PLC implantada na cidade de Barreirinhas, estado do Maranhão, onde a tecnologia foi utilizada como canal de retorno para a TV Digital. Dentro da referida cidade foram abordados 2 ramais 
secundários. Em tais ramais existiam cerca de 80 residências de interesse, ou seja, onde os sinais PLC deveriam oferecer conectividade.

A Figura 42 e Figura 43 ilustram a estrutura da rede PLC implantada na cidade de Barreirinhas.
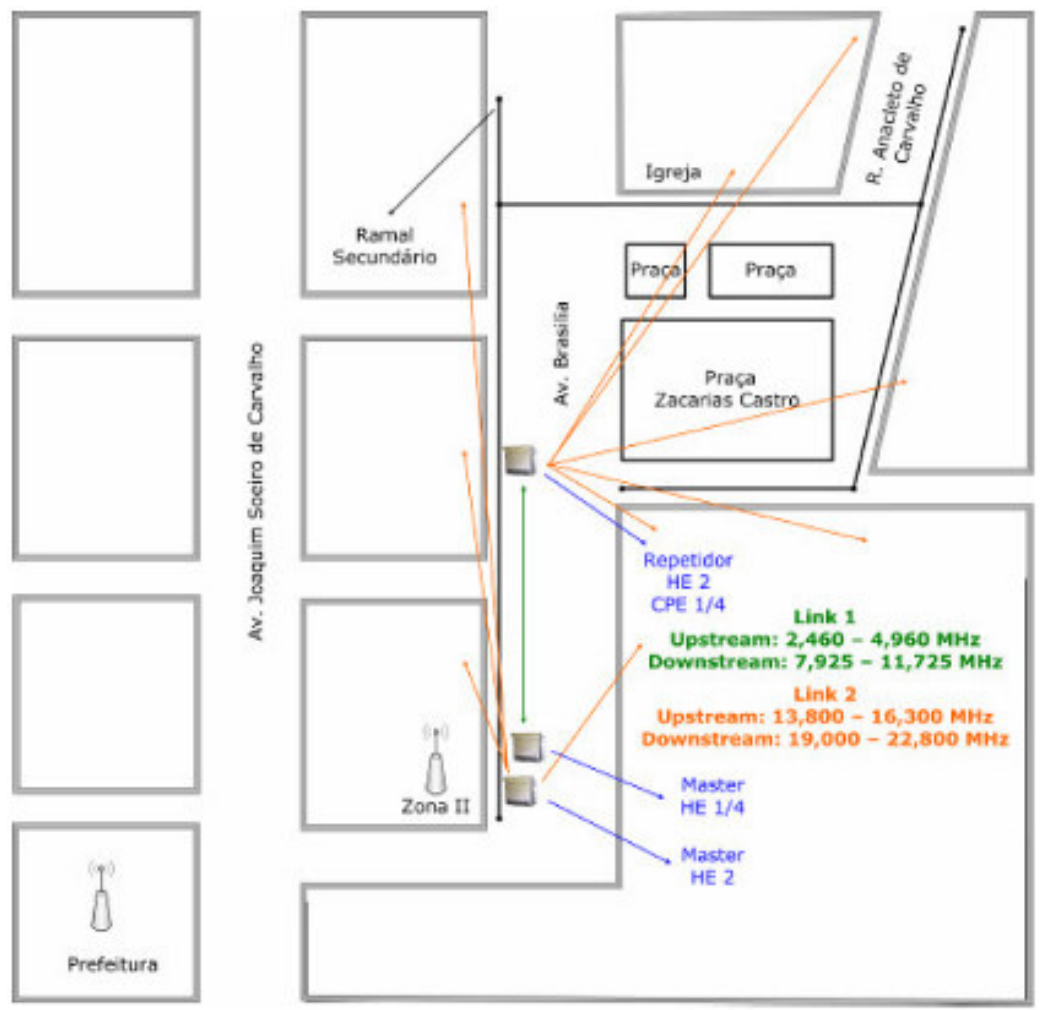

Figura 42 - Estrutura do primeiro ramal secundário abordado.

Observa-se que a rede de comunicação, conforme esperado, é híbrida, uma vez que existe um trecho da rede onde foram utilizados rádios.

Na seqüência, a Figura 44 (a) apresentada um equipamento do tipo master instalado dentro de uma caixa abrigo no poste, (b) a caixa abrigo montada sobre o poste e (c) o equipamento CPE dentro do ambiente do usuário final. 


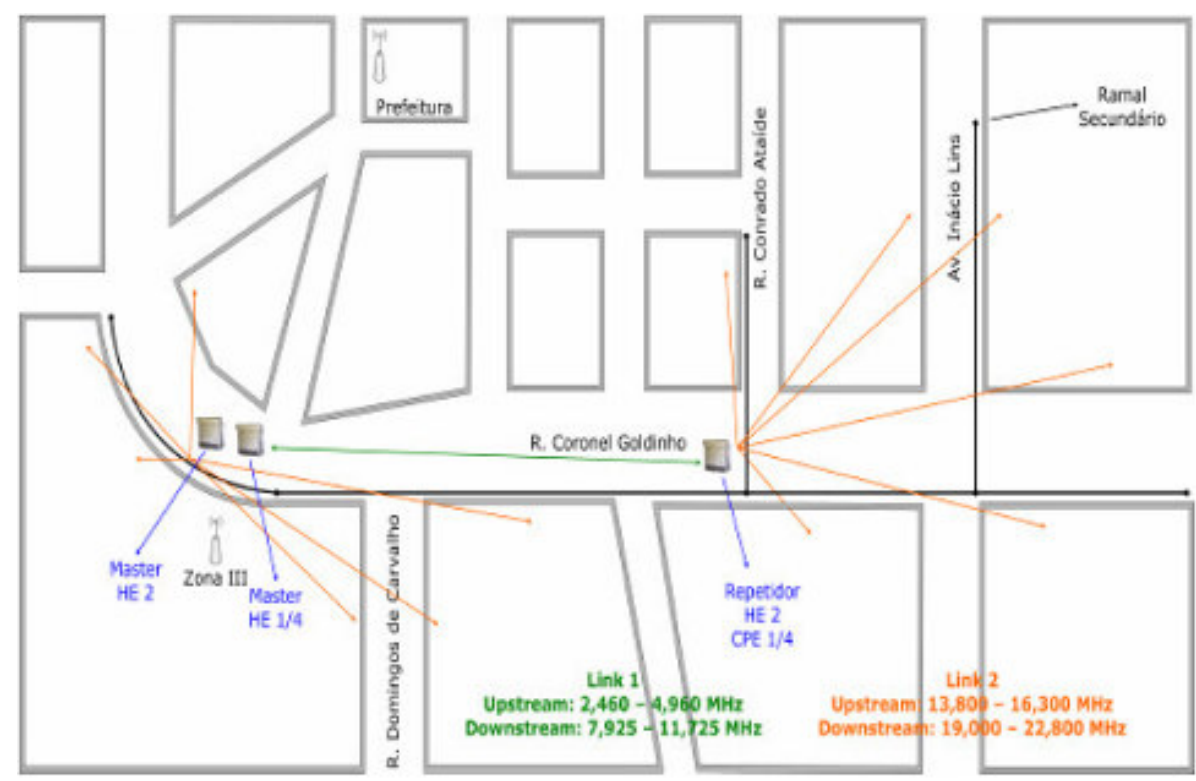

Figura 43 - Estrutura do segundo ramal secundário abordado.

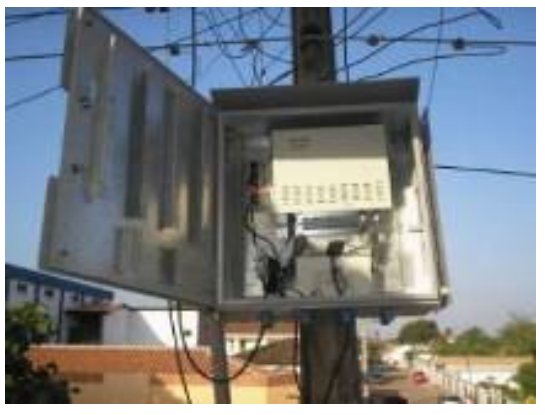

(a)

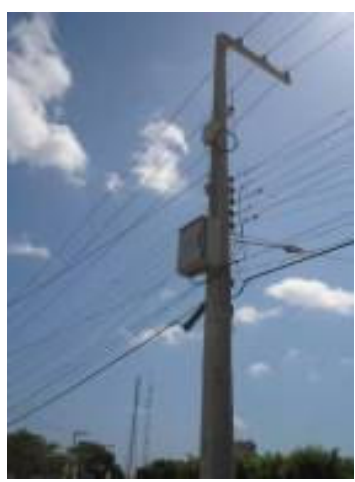

(b)

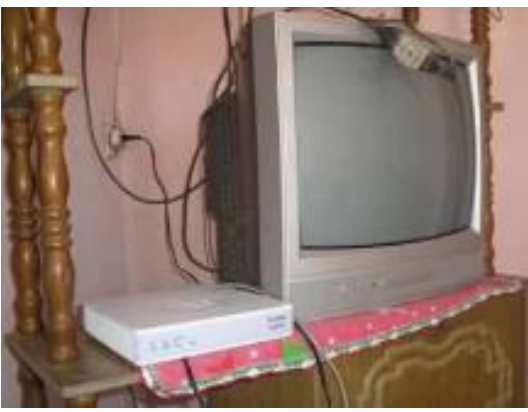

(c)

Figura 44 - Fotos da estrutura instalada na cidade de Barreirinhas.

Cabe ressaltar que, dependendo do tamanho das residências conectadas ao ramal secundário abordado, pode acontecer dos sinais PLC chegarem dentro da edificação muito degradados. Nestes casos, recomenda-se a utilização de um equipamento repetidor junto ao medidor da referida residência. Este repetidor terá a função de regenerar os sinais que adentram a edificação. Se mesmo assim os "novos" sinais não forem satisfatórios, a residência tem de ser abordada como sendo um novo projeto de rede PLC/BPL. 


\section{Outras técnicas de abordagem}

No item anterior foram apresentadas as técnicas básicas para realizar a abordagem das edificações, mas em alguns casos elas não são suficientes para proporcionar os níveis de sinal exigidos para atender os requisitos de projeto. Desta forma, são apresentadas na sequiência técnicas complementares de abordagem dos locais, as quais constituem-se em outra contribuição deste trabalho.

\subsection{Tronco de sinal}

Esta técnica consiste na utilização de estruturas auxiliares como meio físico para transporte dos sinais. Ela pode ser empregada em casos onde as técnicas apresentadas no capítulo 8 não são suficientes, ou seja, os níveis de sinal exigidos não são atendidos pelo fato de, muitas vezes, as atenuações introduzidas pela rede elétrica do local serem elevadas, ou ainda, devido aos harmônicos existentes.

Desta forma, podem-se utilizar cabos específicos para transportar os sinais PLC até um novo local de injeção, o qual deve ser mais próximo dos pontos de acesso de interesse do que as injeções realizadas inicialmente.

Considere uma estrutura vertical em que os sinais PLC injetados juntos aos medidores, no centro de medição, produzem, nos andares superiores, um nível de sinal de baixa intensidade (menor que $-50 \mathrm{dBm}$ ), ou seja, insatisfatórios. Em tal situação, pode-se lançar um cabo auxiliar, muitas vezes através do shaft da estrutura, e levá-lo até o ponto mais próximo dos pontos de acesso onde o nível de sinal era problemático. A Figura 45 ilustra tal procedimento de abordagem.

Como condutor auxiliar pode-se utilizar, a princípio, qualquer cabo que seja adequado para o transporte de sinais de alta freqüência, como por exemplo o cabo AFD 1p-22 da empresa 
RFS, assim como os cabos coaxiais. O objetivo é que o cabo auxiliar introduza a menor atenuação possível nos sinais PLC.

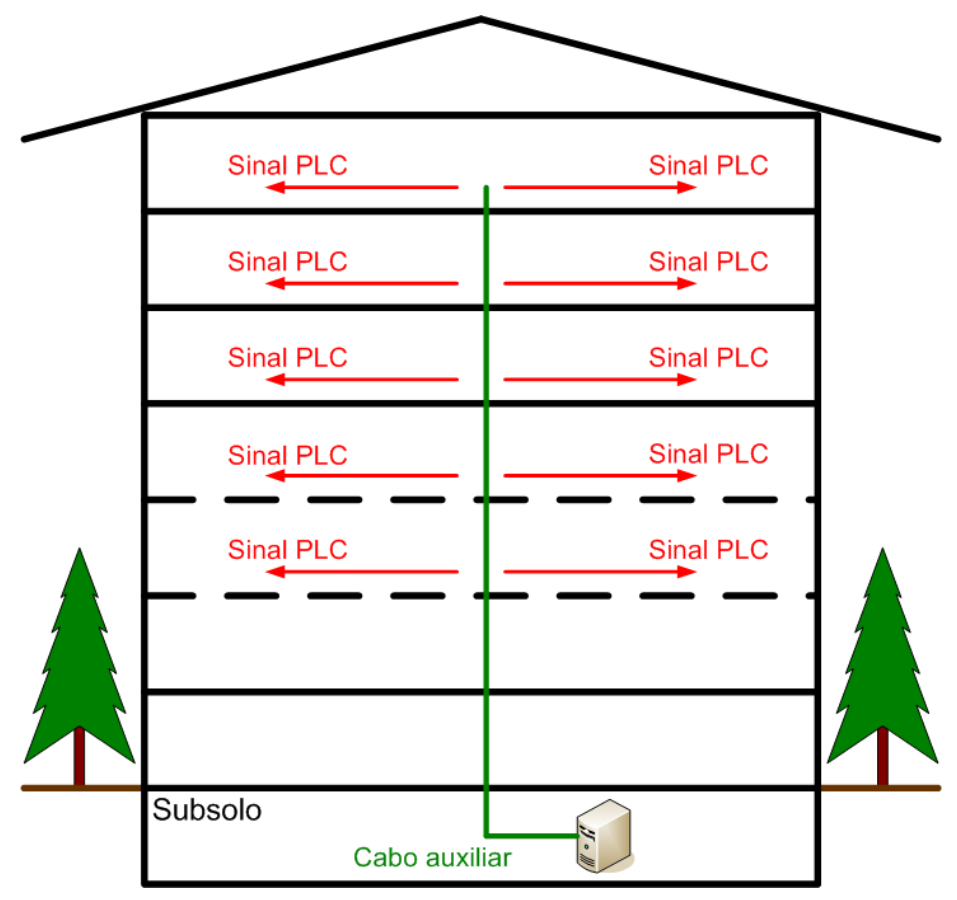

Figura 45 - Ilustração do esquema de abordagem com cabo auxiliar.

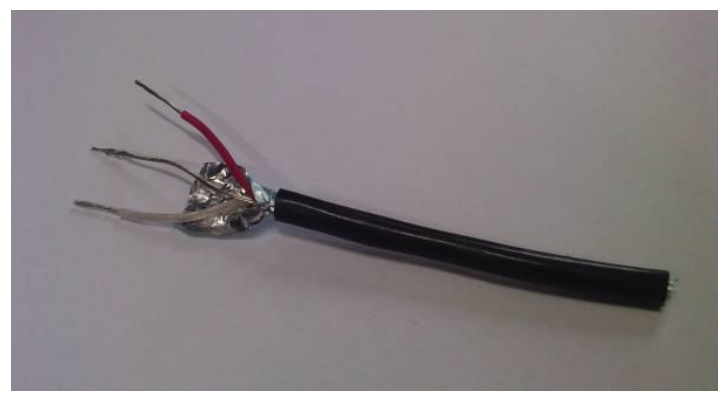

(a)

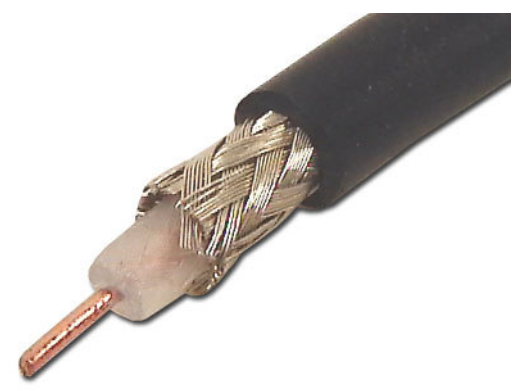

(b)

Figura 46 - Exemplo de cabos auxiliares. (a) cabo AFD 1p-22 da RFS e (b) cabo coaxial.

Observa-se que, uma vez que o sinal seja novamente injetado na rede elétrica, diretamente em um dado andar (novo local de injeção), devem-se aplicar os procedimentos descritos na seção 8.2. Desta forma, tem-se uma situação onde as injeções que criarão os grupos serão feitas diretamente em um dado andar, ao invés da injeção inicialmente realizada no centro de medição. Finalmente, ressalta-se que a forma de abordagem aqui apresentada pode ser 
utilizada em conjunto com a técnica apresentada na seção 8.2 , uma vez que ambas podem ser complementares e não mutuamente exclusivas.

Uma forma de abordagem similar à aqui apresentada pode ser encontrada em [34], porém os trabalhos foram conduzidos de forma totalmente independente.

\subsection{Priorização de pontos de acesso}

Esta técnica consiste em uma extensão da apresentada na seção anterior. Considere um local de grandes dimensões físicas, como por exemplo, da ordem de centenas de metros. Em um local como este as dimensões elétricas envolvidas são bastante extensas, o que diminui a possibilidade dos sinais PLC chegarem facilmente aos pontos de acesso.

Como exemplo prático pode-se citar um dos galpões da Companhia de Entrepostos e Armazéns Gerais de São Paulo (CEAGESP), o qual possui infra-estrutura PLC instalada para oferecimento de serviços de acesso aos permissionários que lá se encontram. Trata-se de um galpão com cerca de 600 permissionários e aproximadamente 200 metros de comprimento por 90 de largura.

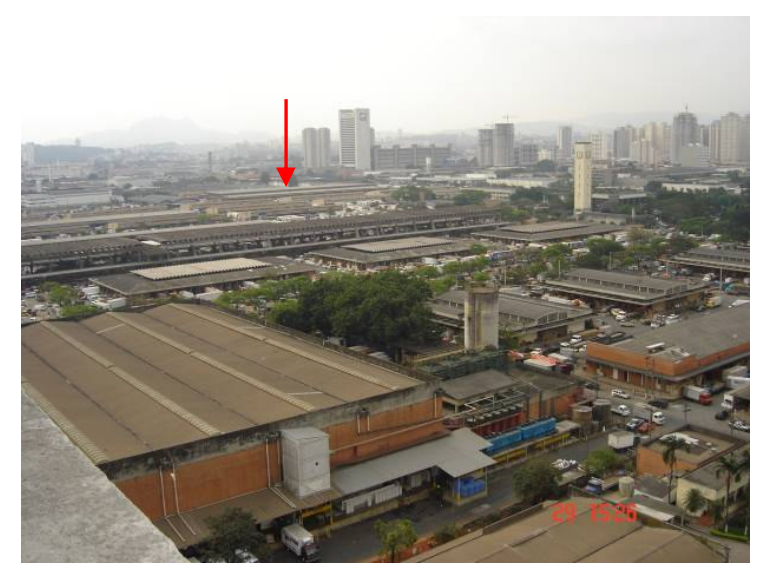

(a)

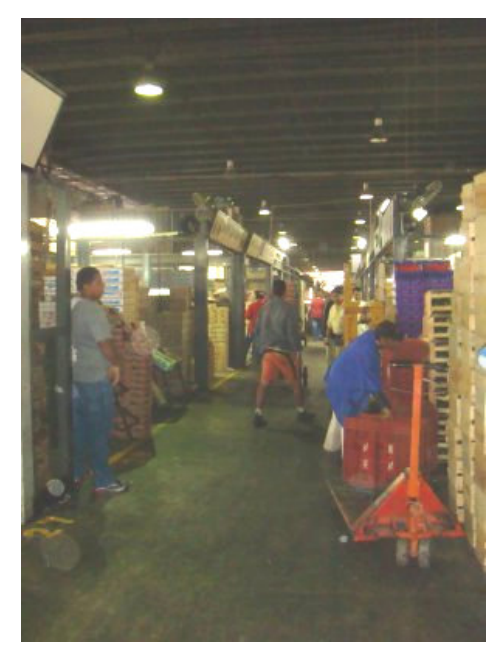

(b)

Figura 47 - Ceagesp. (a) Vista aérea com destaque para o pavilhão MFE-B e (b) vista interna do pavilhão. 
Neste tipo de estrutura, é bastante inconveniente construir uma rede cabeada convencional, uma vez que as distâncias envolvidas excedem o limite recomendado de $100 \mathrm{~m}$, além da necessidade de construção de cascatas de switchs, dificuldade de energização e alocação destes ao longo do pavilhão e grande quantidade de cabo a ser utilizada. Desta forma, pode-se utilizar a tecnologia PLC para distribuir os sinais internamente através de uma estrutura auxiliar de transporte dos sinais. Optou-se por utilizar tal técnica de abordagem, pois os sinais PLC que foram injetados nos 4 quadros de distribuição dentro do pavilhão não chegavam em praticamente nenhum dos boxes, e, mesmo nos que chegavam, o nível de sinal era muito insatisfatório.

Observe que, quando se utiliza uma rede auxiliar para o transporte dos sinais, é possível realizar derivações efetuando-se simples emendas nos cabos, o que é útil para a economia de material, uma vez que em uma rede cabeada todos os cabos devem, necessariamente, sair de um mesmo ponto. Destaca-se que os condutores foram alocados de forma a construir diversos circuitos distintos, os quais podem ser ligados a equipamentos master diferentes. Isso é importante, pois para cada acoplamento realizado espera-se, obviamente, uma redução no nível de sinal em todos os pontos de acesso associados a esta estrutura cabeada específica. Portanto, assim que os níveis de sinal associados a um dado circuito auxiliar se tornarem críticos pode-se utilizar um novo equipamento master e iniciar um novo circuito auxiliar.

Uma vez que a estrutura cabeada auxiliar está disponível junto aos boxes, pode-se realizar o acoplamento diretamente à rede elétrica do permissionário optante pelo serviço de acesso. Conforme citado anteriormente, do ponto de vista de telecomunicações, basta disponibilizar ao usuário final um único ponto de acesso, assim pode-se realizar a injeção dos sinais dentro do box e mais que isso, pode-se confinar o sinal PLC em uma única tomada. A Figura 48 ilustra o esquema elétrico necessário para injetar e confinar o sinal PLC em uma única tomada. 


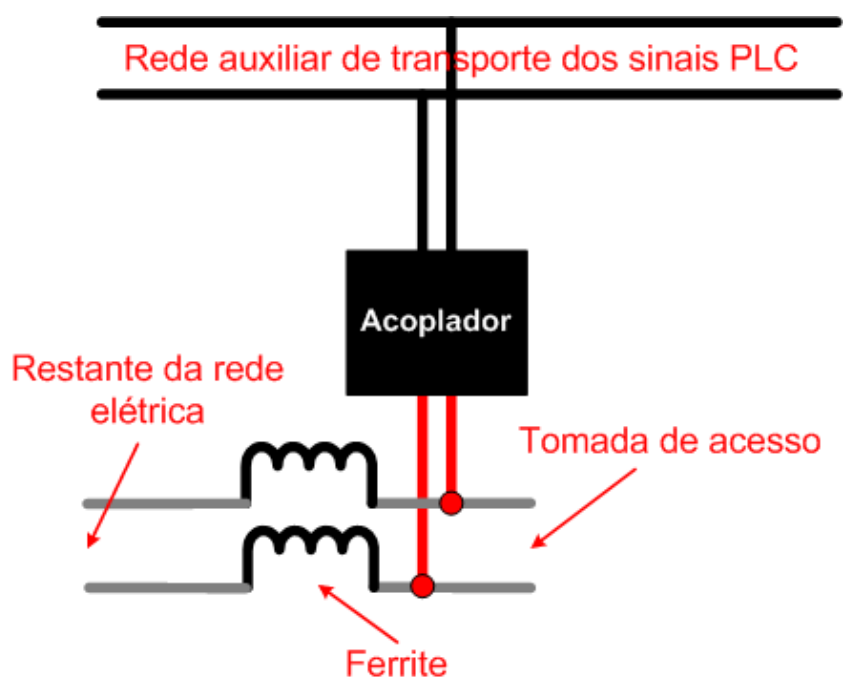

Figura 48 - Esquema para confinamento do sinal PLC em uma única tomada.

Através da análise da Figura 48, é possível verificar que se pode levar o cabo auxiliar até dentro da estrutura, especificamente na tomada que será o ponto de acesso, e então realizar a injeção dos sinais utilizando um acoplador capacitivo. Na sequiência, devem-se instalar os ferrites imediatamente antes do ponto de injeção e então apenas a referida tomada terá sinal PLC disponível. Uma vantagem deste tipo de estrutura de abordagem é que o sinal PLC não se distribui indiscriminadamente pela estrutura, principalmente em locais desnecessários, e então é possível conectar muito mais CPEs a um único master do que se o sinal fosse injetado de forma tradicional. Assim, pode-se reduzir o número de equipamentos do tipo master a serem utilizados, o que tem como conseqüência direta a redução do custo global do projeto.

Observe que se pode preparar previamente a estrutura apresentada na Figura 48, o que do ponto de vista corporativo é interessante, uma vez que isso permite reduzir o tempo de trabalho dentro da estrutura do cliente a ser ativado. A Figura 49 apresenta uma foto da estrutura montada pronta para ser instalada em campo. 


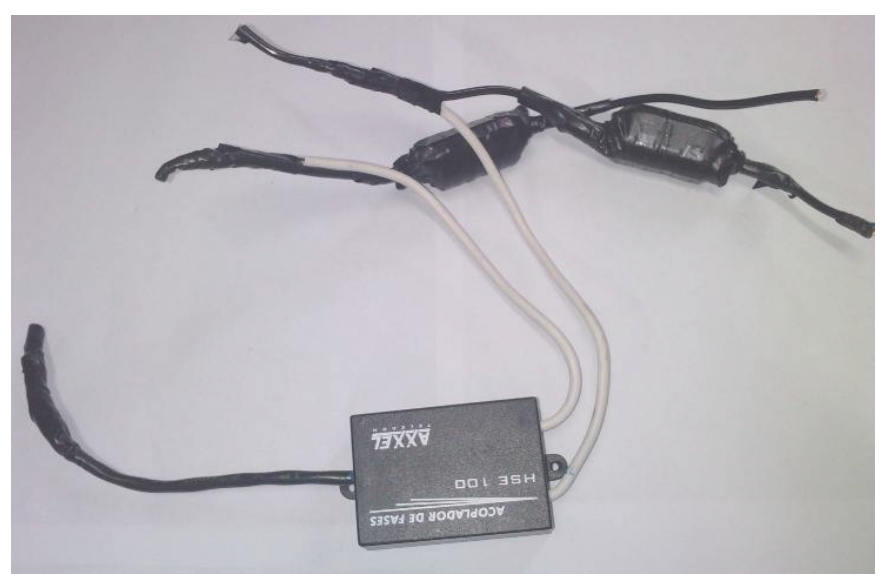

Figura 49 - Estrutura montada de um acoplador junto com ferrites.

Destaca-se que para utilizar tal estrutura basta desmontar a tomada de acesso, deixando acessíveis os condutores que a alimentavam e então realizar a emenda destes com os condutores pretos que aparecem a direita na Figura 49. Na seqüência, devem-se conectar os condutores brancos que aparecem à esquerda na Figura 49, na tomada que será o ponto de acesso.

\subsection{Priorização de circuitos elétricos}

Outra técnica útil na abordagem de estruturas onde se deseja disponibilizar mais de um ponto de acesso, ou seja, aproveitar a flexibilidade de layout que a tecnologia PLC oferece, pode-se recorrer à técnica de priorização de circuitos elétricos.

O objetivo desta forma de abordagem é aumentar a intensidade dos sinais nos circuitos elétricos de interesse, o que na prática, muitas vezes, corresponde ao circuito de tomadas de uso geral (TUG). Isso se deve ao fato de que, comumente, não é necessária a presença de sinais PLC, por exemplo, nos circuitos de iluminação, tomadas de uso específico (TUE) ou chuveiro.

Do ponto de vista prático, pode-se, novamente, recorrer ao uso dos ferrites para priorizar os circuitos elétricos de interesse. A Figura 50 apresenta uma ilustração de um quadro de distribuição com os ferrites alocados no mesmo. 


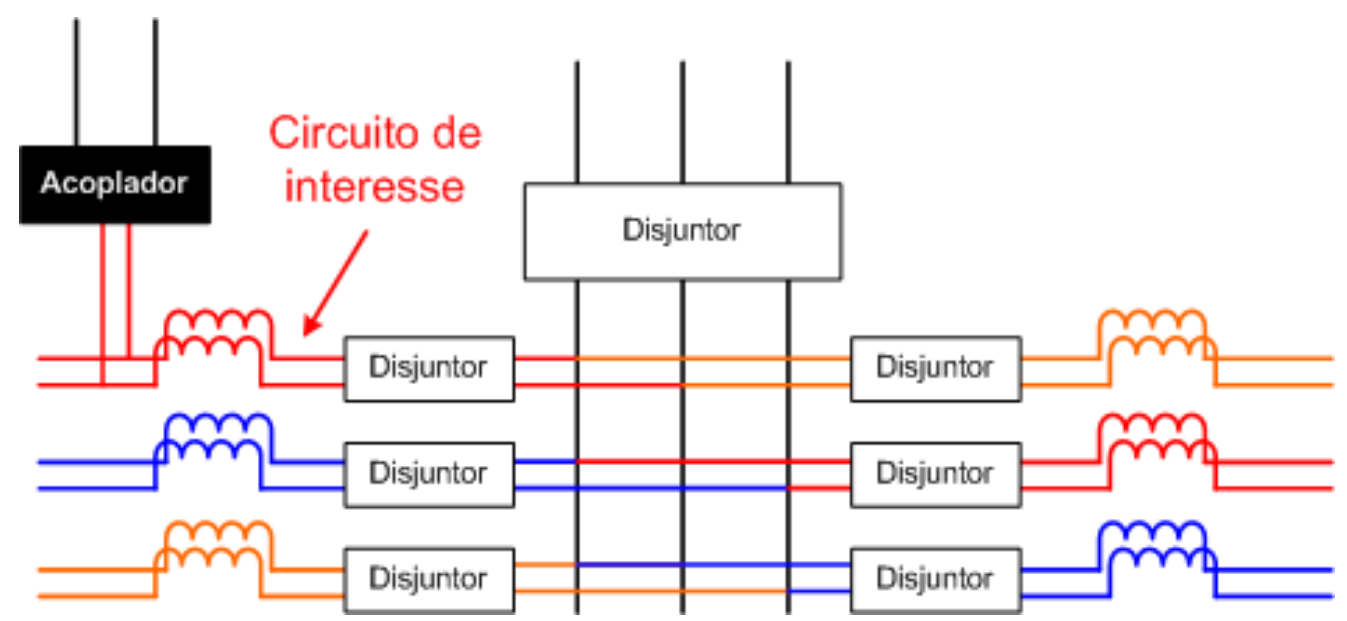

Figura 50 - Ilustração do esquema de priorização de circuitos elétricos.

Através da análise da Figura 50, verifica-se que o sinal PLC deve ser injetado no circuito de interesse, após o disjuntor do mesmo. Na seqüência, pode-se instalar ferrites entre o ponto de injeção e o disjuntor com o objetivo de minimizar, ou até mesmo impedir, que os sinais PLC cheguem ao barramento. Além disso, podem-se instalar outros ferrites após os disjuntores dos circuitos onde não se deseja a presença de sinais PLC.

Observa-se que, na prática, consegue-se melhorar o nível de sinal no circuito de interesse de forma considerável, porém o fato de instalar os ferrites no quadro de distribuição não garante que os demais circuitos não terão sinal PLC, uma vez que o fenômeno de indução ocorrerá caso a distribuição dos condutores pelo local seja favorável a tal. Maiores detalhes sobre a indução dos sinais podem ser encontrados no Anexo A.

Como caso prático, a Figura 51 apresenta uma foto de um quadro de distribuição do pavilhão EDSEDE II da CEAGESP onde tal técnica foi utilizada. Destaca-se que no local, após a instalação dos ferrites, houve um acréscimo (valor absoluto) de $10 \mathrm{dBm}$ na intensidade do sinal nos pontos de acesso de interesse. A Figura 51 (a) apresenta o quadro de distribuição do local, sendo que os ferrites e acoplador estão localizados na parte inferior esquerda da foto. É possível visualizar os condutores branco e azul dos mesmos. Já a Figura 51 (b) apresenta o detalhe desses acessórios. 


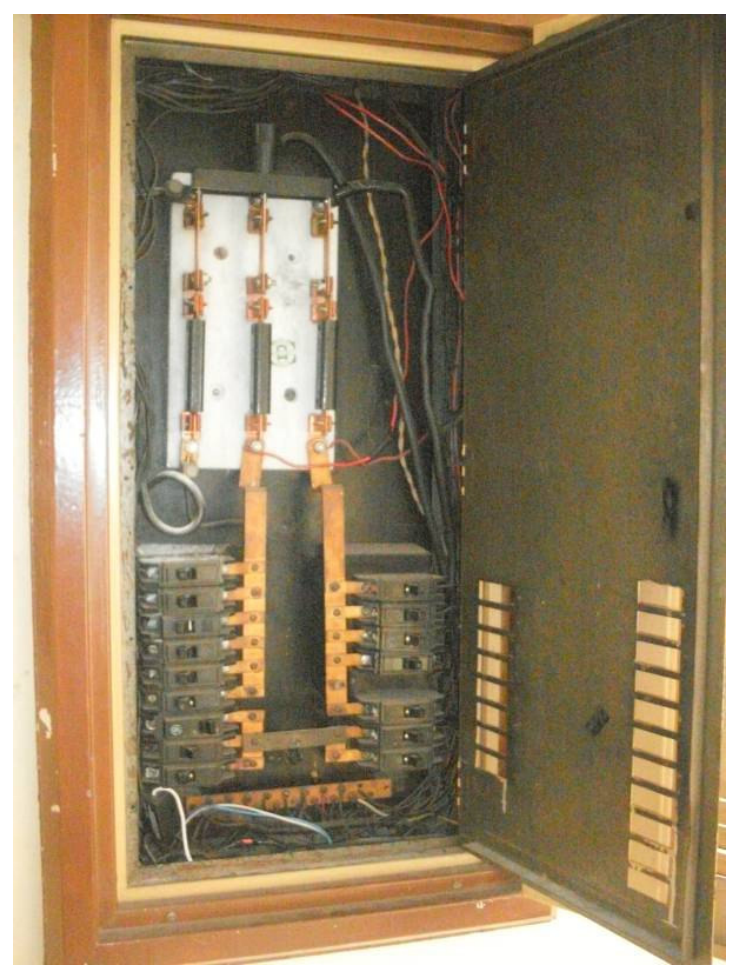

(a)

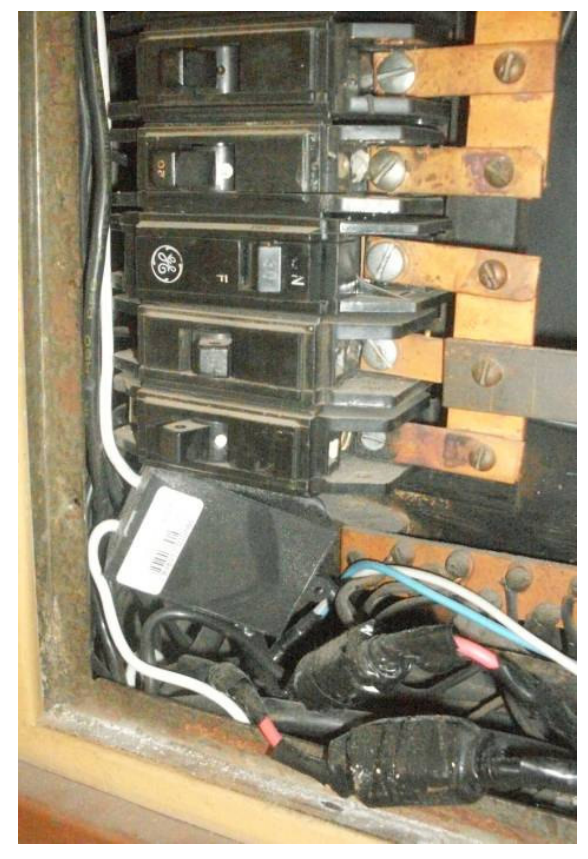

(b)

Figura 51 - Foto de quadro de distribuição contendo ferrites para priorização de circuitos elétricos.

\subsection{Utilização da rede telefônica}

A última técnica a ser apresentada neste trabalho consiste em utilizar a rede de telefonia como meio físico para transporte dos sinais. Conforme exposto na seção 4.2, o princípio de funcionamento da tecnologia baseia-se na sobreposição de um sinal de alta freqüência à rede elétrica existente. Desta forma, é possível utilizar, a princípio, qualquer tipo de estrutura conveniente para realizar o transporte dos sinais.

Assim como a rede elétrica sempre está presente nas edificações, muitas vezes ocorre o mesmo com a rede de telefonia. A abordagem pela rede telefônica é bastante útil nos casos onde é muito difícil proporcionar intensidades aceitáveis de sinal PLC nos pontos de acesso. Como o cabo telefônico é construído para transportar sinais na faixa de $\mathrm{kHz}$, observa-se que a atenuação dos sinais PLC no mesmo é muito menor do que na rede elétrica convencional. 
Assim, a abordagem da edificação se torna mais simples, o que tem como conseqüência a diminuição do tempo total de instalação, refletindo diretamente no custo do projeto, além de minimizar o potencial de ocorrência de IEM devido aos fenômenos que ocorrem nas redes elétricas.

A Figura 52 ilustra o esquema básico para realizar a injeção e extração dos sinais PLC na rede de telefonia.

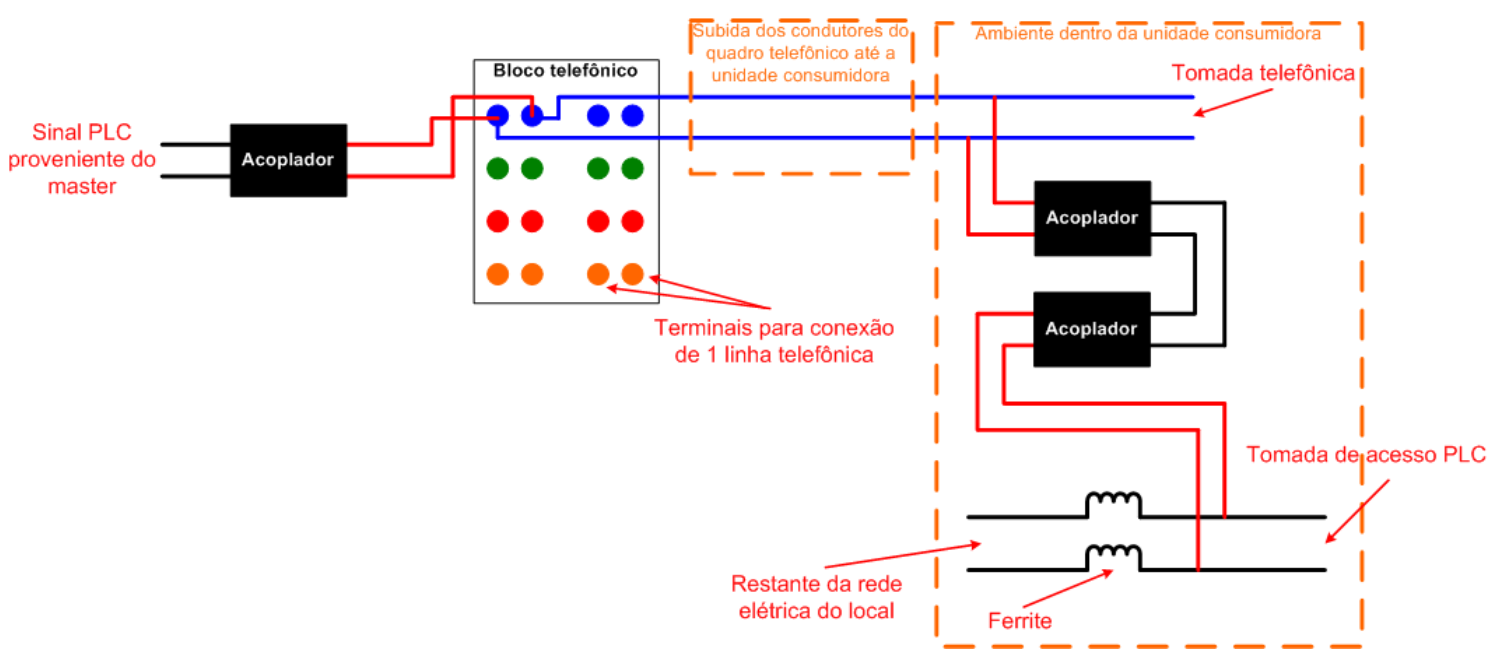

Figura 52 - Esquema básico para utilização da rede telefônica como meio de transporte dos sinais PLC.

Através da análise da Figura 52, verifica-se que a injeção dos sinais é realizada diretamente no quadro de telefonia do local a ser abordado. Deve-se utilizar um acoplador para realizar tal injeção, pois, caso contrário, linhas telefônicas diferentes serão curto circuitadas e isto não pode ocorrer. Uma vez injetado os sinais, estes serão transportados através da edificação até a tomada telefônica da unidade consumidora. Em tal local deve-se proceder com a instalação de dois novos acopladores, os quais serão responsáveis por "extrair" os sinais da rede telefônica e injetá-los na rede elétrica da unidade consumidora. A injeção na rede elétrica pode ser realizada na tomada mais próxima da tomada telefônica ou em outro local a ser definido. Uma vez injetados os sinais na rede elétrica, pode-se utilizar ferrites para confinar os sinais em uma única tomada, conforme apresentado na seção 9.2.

A razão para se utilizar dois acopladores ligados em anti paralelo é a de que, se os cabos de sinal do acoplador forem conectados à rede de telefonia, observa-se que esta para imediatamente de funcionar. Potencialmente, isso se deve ao circuito interno do acoplador e consiste em um ponto a ser mais bem estudado posteriormente. Assim, o esquema proposto de 
ligação dos acopladores resolve o problema e permite a efetiva injeção dos sinais PLC provenientes da rede de telefonia na rede elétrica.

A necessidade de injetar os sinais na rede elétrica dentro da unidade consumidora se deve ao fato do equipamento CPE se acoplar à rede elétrica pelo cabo de alimentação, sendo que maiores detalhes podem ser encontrados na seção 6.4. Portanto, ele deve ser ligado à rede elétrica, tanto para ter acesso ao sinal PLC, assim como para ser energizado.

Do ponto de vista financeiro do projeto, observa-se um aumento no custo com acessórios, pois a utilização de acopladores aumenta, porém este tipo de abordagem, conforme já citado, reduz o tempo de instalação e conseqüentemente o custo associado à mão de obra. No balanço geral, o custo do projeto pode ser reduzido.

Do ponto de vista de IEM com o serviço de telefonia, observa-se que as faixas de frequiência de trabalho de ambas as tecnologias são diferentes. A rede telefônica opera, tipicamente, na faixa de $\mathrm{kHz}$ enquanto a rede PLC opera na faixa de MHz. Apesar disso, verificou-se, na prática, que em alguns aparelhos telefônicos foi possível ouvir um ruído de fundo considerável. Nestes casos utilizou-se um filtro ADSL, comumente utilizado nas redes banda larga ADSL, e o ruído audível foi praticamente eliminado.

Como caso prático, a Figura 53 apresenta fotos de uma instalação realizada através da rede de telefonia em um escritório corporativo.

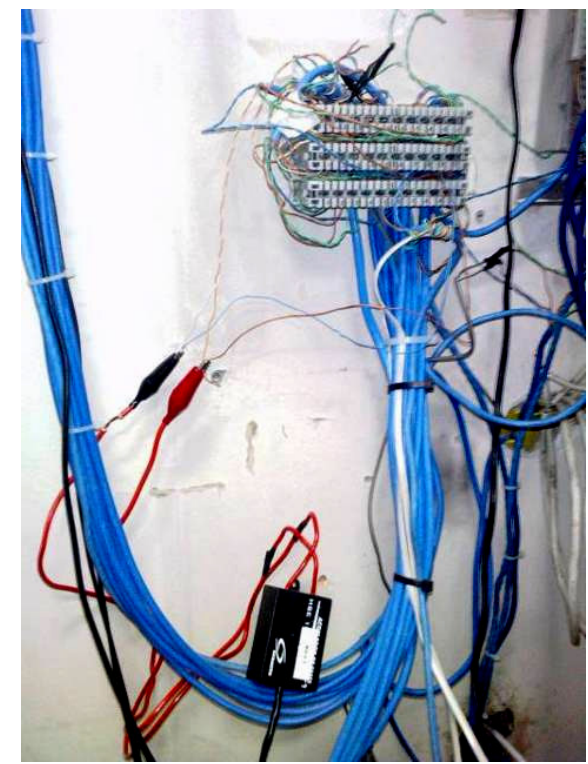

(a)

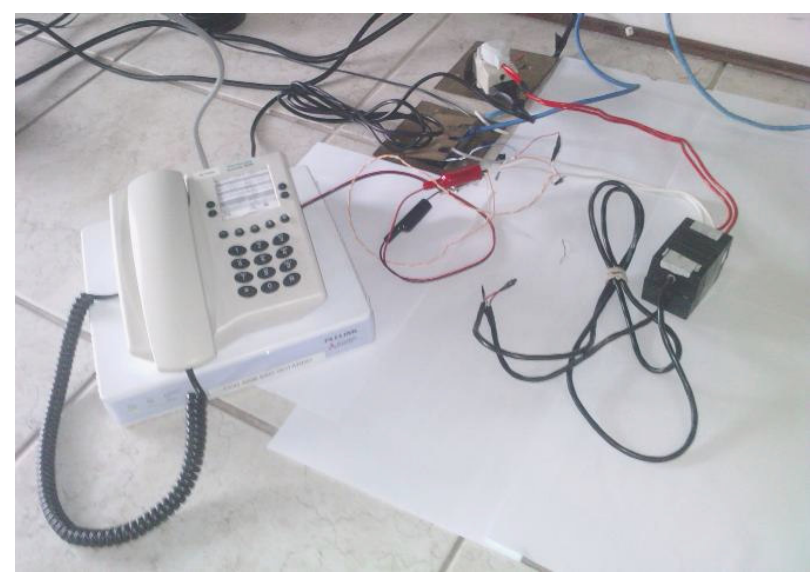

(b)

Figura 53 - Instalação utilizando a rede telefônica. (a) Injeção do sinal na rede telefônica e (b) injeção do sinal na rede elétrica. 


\section{Conclusões}

\subsection{Considerações gerais}

Todo o conteúdo apresentado ao longo deste trabalho é resultado de inúmeras atividades realizadas antes mesmo do início do Mestrado. Tais atividades começaram no início de 2007 através da construção de uma rede de comunicação em média tensão, no estado do Maranhão. Naquele momento ficou clara a falta de mão de obra qualificada, na qual me incluía, além da falta de material bibliográfico de caráter prático sobre a tecnologia PLC.

Desta forma, este trabalho procurou esclarecer e elucidar inúmeros aspectos relacionados à tecnologia, assim como documentar as diversas experiências adquiridas ao longo destes últimos 3 anos.

Na seqüência, será apresentado um resumo das contribuições deste trabalho, assim como serão destacados os itens passíveis de investigações futuras e conseqüentes melhorias relacionadas aos aspectos práticos de implementação da tecnologia.

\subsection{Resumo das contribuições e trabalhos desenvolvidos}

O principal objetivo deste trabalho é o de apresentar e documentar os aspectos práticos de implementação da tecnologia PLC/BPL em seus diversos tipos de aplicação em ambientes reais. Assim, são apresentadas na seqüência as contribuições deste trabalho.

- Esclarecimento de inúmeros aspectos relacionados à tecnologia PLC/BPL apresentando seu princípio de operação, as topologias das redes, suas vantagens, desvantagens e exemplos de aplicação, inclusive na área de Energia. 
- Esclarecimento de alguns aspectos relacionados ao sinal PLC, a capacidade de adaptação do sistema frente a mudanças no canal de comunicação, aspectos relacionados à interferência eletromagnética quando o sistema PLC é o agente interferente ou interferido e os recursos que a tecnologia oferece para a obtenção da compatibilidade eletromagnética entre sistemas.

- A utilização de filtros de linha específicos como acessório de auxílio para manutenção do desempenho das redes PLC/BPL, através da minimização de harmônicos provenientes de cargas elétricas conectadas no mesmo ambiente elétrico onde opera a rede de comunicação.

- A utilização de um conjunto específico de ferramentas voltadas ao trabalho em campo, as quais possuem papel essencial nas implantações, pois permitem análises quantitativas dos níveis de sinal nos diversos pontos de acesso, assim como auxiliam a equipe de instalação na compreensão da distribuição dos sinais PLC na edificação que está sendo abordada.

- Utilização do modelo de Linha de Transmissão e análise de circuitos a parâmetros distribuídos para explicar qualitativamente o comportamento dos sinais PLC nas edificações, além dos aspectos relevantes dos harmônicos provenientes de cargas elétricas não lineares (comumente presentes nas redes elétricas) na implantação e desempenho de redes PLC.

- Apresentação de uma metodologia para o desenvolvimento de projetos de redes PLC, considerando os inúmeros aspectos envolvidos, tais como a estrutura física do local a ser abordado, harmônicos presentes no local, técnicas de mitigação de interferências eletromagnéticas, planejamento de links, medições da intensidade dos sinais nos pontos de interesse e avaliação objetiva da qualidade dos canais de comunicação.

- Apresentação de um modelo de comissionamento de redes PLC, a fim de garantir que a rede de comunicação construída atende os requisitos de projeto, além de documentar a mesma de forma eficiente. A documentação tem papel fundamental nas manutenções da rede de comunicação, sejam elas preventivas ou corretivas, principalmente para as redes de comunicação comerciais, onde o tempo alocado nas atividades deve ser o menor possível. Tal modelo foi incorporado às boas práticas de engenharia pelo projeto OPERA.

- Apresentação de técnicas de abordagem de redes reais seja em ambientes domésticos, internos ou externos. Para cada técnica apresentada foi dado um exemplo prático da mesma com o objetivo de demonstrar sua aplicabilidade nos ambientes reais. 
- Apresentação de técnicas complementares de abordagem (onde foram apresentados esquemas para abordagem de edificações onde outras técnicas não produzem resultados satisfatórios), através da utilização de estruturas auxiliares de transporte dos sinais. Além disso, foi apresentada uma técnica para priorizar determinadas tomadas (circuito elétrico) dentro de uma unidade consumidora, assim como priorizar o acesso em uma determinada tomada. Ademais, apresentou-se uma técnica onde é utilizada a rede de telefonia convencional para transporte dos sinais PLC dentro das edificações. Novamente, para cada técnica apresentada foi dado um exemplo prático da mesma com o objetivo de demonstrar sua aplicabilidade nos ambientes reais.

\subsection{Sugestões para trabalhos futuros}

Existem inúmeros aspectos relacionados à implantação da tecnologia PLC/BPL que podem ser aprimorados, sendo que todos eles podem ser objeto de investigação futura. Na seqüência são apresentados alguns desses itens.

- Até o presente momento não se tem informações quantitativas sobre o comportamento do sinal PLC nos inúmeros ambientes elétricos reais. É de interesse comercial que se tenha, idealmente, uma espécie de catálogo sobre o comportamento dos sinais em cada tipo de instalação e meio físico onde os condutores estão inseridos.

- Outro ponto importante é o aprimoramento da utilização dos núcleos de ferrites. É interessante investigar a curva de magnetização $\mathrm{BxH}$ do material com o objetivo de definir vários conjuntos de bobinas que poderão ser empregadas em ambientes reais. Isso evitará a saturação do material da bobina e aumentará seu potencial de utilização tanto em ambientes internos quanto externos.

- Avaliação da resposta em freqüência dos diversos elementos que compõe as redes elétricas, tais como, disjuntores, medidores, fusíveis, entre outros. O objetivo é conhecer as atenuações que tais elementos podem introduzir e conseqüentemente auxiliar na construção das redes de comunicação. 
- Melhorias nos filtros utilizados para contenção de harmônicos proveniente de cargas não lineares, com o objetivo de garantir maior estabilidade no desempenho das redes PLC, é outro aspecto que merece investigação futura.

- Utilização da tecnologia como ferramenta de auxílio ao monitoramento do sistema elétrico de potência, através da análise de variáveis, como por exemplo, relação sinal ruído.

- Iniciar estudos para integrar a tecnologia aos chamados eletrodomésticos inteligentes.

- Desenvolvimento nacional de acessórios relacionados è tecnologia com o objetivo de reduzir os custos associados aos projetos.

- Estimular estudos de ordem prática relacionados à tecnologia dentro das Universidades, com o objetivo de modificar a atual regulamentação para que a tecnologia tenha a possibilidade de ser plenamente aplicada no Brasil. 


\section{Referências Bibliográficas}

[1] AGÊNCIA NACIONAL DE TELECOMUNICAÇÕES - RESOLUÇÃO No 527, DE 8 DE ABRIL DE 2009 - Aprova o Regulamento sobre Condições de Uso de Radiofrequiências por Sistemas de Banda Larga por meio de Redes de Energia Elétrica.

[2] AGÊNCIA NACIONAL DE ENERGIA ELÉTRICA - ANEEL - RESOLUÇÃO NORMATIVA $\mathbf{N}^{\mathbf{3}}$ 375, DE 25 DE AGOSTO DE 2009 - Regulamenta a utilização das instalações de distribuição de energia elétrica como meio de transporte para a comunicação digital ou analógica de sinais.

[3] HYPERTRADE TELECOM. São Paulo. Disponível em: <http://www.hypertrade.com.br/>. Acessado em: jan. de 2009.

[4] XIAOXIA W.; JIE L.; YAN L. Simulation and Analysis of Power Transmission Line Model. In: IEEE International Symposium on Power Line Communications and Its Applications, 2006. p. 256-260.

[5] BARMADA, S.; RAUGI, M. Simulation of High Frequency Signal Transmission on Power Lines. In: International Symposium on Power Line Communications and Its Applications, 2005. p. 138-142.

[6] HAQ, T.; NEWBURY, J.; MORRIS, K.; ROBERTSON, F.; WILLS, L.; SUMMERS, I. Evaluation of Key Parameters for Determining the Efficiency of Signal Propagation in Broadband PLT Systems. In: International Symposium on Power Line Communications and Its Applications, 2005. p. 228-232.

[7] MAENOU, T.; KATAYAMA, M. Study on Signal Attenuation Characteristics in Power Line Communications. In: IEEE International Symposium on Power Line Communications and Its Applications, 2006. p. 217-221.

[8] IWAO, H.; KIJIMA, H.; TAKATO, K. An influence on transmission characteristics of power line communication when using Surge Protective Devices. In: IEEE International Symposium on Power Line Communications and Its Applications, 2008. p. 218-221.

[9] MING, Z.; LAUBER, W. Evaluation of the Interference Potencial of PLC Systems. In: IEEE International Symposium on Power Line Communications and Its Applications, 2006. p. 296-301. 
[10] MING, Z.; LAUBER, W. Evaluation of the Interference Potencial of In-Home Power. In: IEEE International Symposium on Power Line Communications and Its Applications, 2008. p. 263-268.

[11] BATTERMANN, S.; GARBE, H. Influence of PLC Transmission on the Sensitivity of a Short-Wave Receiving Station. In: International Symposium on Power Line Communications and Its Applications, 2005. p. 224-227.

[12] JOONG-GEUN, R.; RHEE, E.; TEE-SIK, P. Electromagnetic Interferences caused by Power Line Communications in the HF Bands. In: IEEE International Symposium on Power Line Communications and Its Applications, 2008. p. 249-252.

[13] ANTONINI, G.; ORLANDI, A.; RIZZI, R.M.; COSTANZI, A. Systematic analysis of electromagnetic emissions and susceptibility in BPL system. In: IEEE International Symposium on Power Line Communications and Its Applications, 2007. p. 5-10.

[14] HEINA, M.; ROHRICH, A.; HIRSCH, H. Propagation of disturbance signal between PLC modem and radio receiver. In: International Symposium on Power Line Communications and Its Applications, 2005. p. 219-223.

[15] COLVERO, C. P., CARNEIRO, V. R. D., CUNHA, B. F. Revisão dos Procedimentos da Norma ITU-T K-60 para Medição de Interferência de Sistemas PLC/BPL. In: MOMAG 2008 (13 ${ }^{\circ}$ SBMO - Simpósio Brasileiro de Microondas e Optoeletrônica e o $8^{\circ}$ CBMag Congresso Brasileiro de Eletromagnetismo).

[16] TOMIMURA, D.; NETO, V.V. Field Measurements of Broadband PLC: A Case Study in the Brazilian Regulation. In: IEEE Global Telecommunications Conference, 2008. p. 1 4.

[17] KOROVKIN, N.; MARTHE, E.; RACHIDI, F.; SELINA, A. E. Mitigation of electromagnetic field radiated by PLC systems in indoor environment. International Journal of Communication Systems, v. 16, p. 417-426.

[18] VUKICEVIC, A.; RUBINSTEIN, M.; RACHIDI, F.; BERMUDEZ, J. L. On the Impact of Mitigating Radiated Emissions on the Capacity of PLC Systems. In: IEEE International Symposium on Power Line Communications and Its Applications, 2007. p. 487 - 492.

[19] RUBINSTEIN, M.; BERMUDEZ, J.L.; VEKICEVIC, A.; RACHIDI, F.; SCHNEIDER, M.; MARTHE, E. Discussion on the assessment and mitigation of radiation from PLC networks. In: International Symposium on Power Line Communications and Its Applications, 2005. p. $215-218$. 
[20] RUBINSTEIN, M.; BERMUDEZ, J.L.; VUKICEVIC, A.; RACHIDI, F.; SCHNEIDER, M. On the mitigation of radiation from PLC networks. In: 28th General Assembly of International Union of Radio Science (URSI), New Delhi, India, 2005.

[21] ISHIHARA, M.; UMEHARA, D.; MORIHIRO, Y. The Correlation between Radiated Emissions and Power Line Network Components on Indoor Power Line Communications. In: IEEE International Symposium on Power Line Communications and Its Applications, 2006. p. $314-318$.

[22] TOMIMURA, D.; NETO, V.V. A regulatory framework for Broadband PLC. In: IEEE International Symposium on Power Line Communications and Its Applications, 2009. p. $319-324$.

[23] TEIXEIRA, E.A.; REGE, E.L.; MARQUES, F.S.; DE SOUZA, E.M.; JOHNSON, T.M.; RIBEIRO, M.V. Regulation Issues Relating to Broadband PLC: A Brazilian Experience and Perspective. In: International Symposium on Power Line Communications and Its Applications, 2007. p. 523 - 527.

[24] Federal Communications Commission (FCC). Amendment of Part 15 regarding new requirements and measurement guidelines for Access Broadband over Power Line Systems. Washington, DC, 2004.

[25] ANDREOU, G.T.; DIMOULKAS, I.G.; MAZNEIKOU, M.I.; PAPADOPOULOS, T.A.; LABRIDIS, D.P. Performance of Commercially Available Residential PLC Modems. In: IEEE International Symposium on Power Line Communications and Its Applications, 2007. p. $116-120$.

[26] GUTIERREZ, V.; GALACHE, J.A.; AGUERO, R.; MUNOZ, L. Performance Evaluation of a PLC Field Trial: The Behavior of the TCP/IP Stack. In: IEEE International Symposium on Power Line Communications and Its Applications, 2007. p. 378 - 384.

[27] ANATORY, J.; KISSAKA, M.M.; MVUNGI, N.H. Powerline Communications: The Effects of Branches on Network Performance. In: IEEE International Symposium on Power Line Communications and Its Applications, 2006. p. 70 - 75.

[28] CHANG-KUAN, L.; SHIANN-CHANG, Y.; CHEN, H.H. Bandwidth Estimation of inHome Power Line Networks. In: IEEE International Symposium on Power Line Communications and Its Applications, 2007. p. 413 - 418. 
[29] TEIXEIRA, E.A.; MARQUES, F.S.; DE ARAUJO, S.G.; DE SOUZA, E.M.; JOHNSON, T.M.; RIBEIRO, M.V. Modeling and performance analysis of PLC channels with external interference in outdoor and indoor environments. In: IEEE International Symposium on Power Line Communications and Its Applications, 2008. p. 222 - 227.

[30] YU-JU, L.; LATCHMAN, H. On the Effects of Maximum Transmission Unit in Power Line Communication Networks. In: IEEE International Symposium on Power Line Communications and Its Applications, 2007. p. 511 - 516.

[31] VELlanO, N.V.; SOLETTO, K.T.; PIMENTEL, P.R.; CESAR, L.S.; BALDISSIN, A.S.; SILVA, G.R.; CLUDI, C.A.Z.; BARBOSA, C.F.; ROMANO, R.B.; RIBEIRO, A.A.; ARAUJO, F.M.M.; BAGAROLLI, A. PLC Systems Performance Analysis Regarding Power Quality Disturbances. In: IEEE International Symposium on Power Line Communications and Its Applications, 2007. p. 390 - 395.

[32] GUTIERREZ, D.; TORRES, L.M.; BLASCO, F.; CARRERAS, J.; RIVEIRO, J.C. Inhome PLC ready for triple play. In: International Symposium on Power Line Communications and Its Applications, 2005. p. 366 - 370.

[33] ARTEAGA, C.M.; YANG, Y.J. Large scale broadband over powerline field trial on medium voltage overhead circuits. In: IEEE International Symposium on Power Line Communications and Its Applications, 2008. p. 289 - 292.

[34] YANG, Y.J.; ARTEAGA, C.M. Broadband over Powerline field trial for commercial inbuilding application in a Multi-Dwelling-Unit environment. In: IEEE International Symposium on Power Line Communications and Its Applications, 2009. p. 342 - 346.

[35] FINK, D.; RHO, J. J. Feasible connectivity solutions of PLC for rural and remote areas. In: IEEE International Symposium on Power Line Communications and Its Applications, 2008. p. 158 - 163.

[36] MARTUCCI, M.; RIYUITI, A. H.; DE OLIVEIRA JATOBA, P.L. SAMBA project: A test bed for PLC application as a digital inclusion tool. In: IEEE International Symposium on Power Line Communications and Its Applications, 2008. p. 285 - 288.

[37] POLO, E.I.; MAIA, R.F.; MARTUCCI, M.; HIRAKAWA, A.R. SAMBA project: Performance analysis of PLC network as return channel for interactive digital television applications. In: IEEE International Symposium on Power Line Communications and Its Applications, 2009. p. 337 - 341. 
[38] BENATO, R.; CALDON, R. Application of PLC for the Control and the Protection of Future Distribution Networks. In: IEEE International Symposium on Power Line Communications and Its Applications, 2007. p. 499 - 504.

[39] DESIGN OF SYSTEMS ON SILICON (DS2). Valencia, Espanha. Disponível em: $<$ http://www.ds2.es/>. Acessado em jan. de 2009.

[40] SUNGKWAN, C.; DHINGRA, V. Street lighting control based on LonWorks power line communication. In: IEEE International Symposium on Power Line Communications and Its Applications, 2008. p. 396 - 398.

[41] KONATE, C.; KOSONEN, A.; AHOLA, J.; MACHMOUM, M.; DIOURIS, J.F. Induction motor speed control using power line communication. In: IEEE International Symposium on Power Line Communications and Its Applications, 2009. p. 261 - 266.

[42] JONES, C.H.; Communications Over Aircraft Power Lines. In: IEEE International Symposium on Power Line Communications and Its Applications, 2006. p. 149 - 154.

[43] ER, L.; YANGPO, G.; SAMDANI, G.; MUKHTAR, O.; KORHONEN, T. Powerline communication over special systems. In: International Symposium on Power Line Communications and Its Applications, 2005. p. 167 - 171.

[44] HIGH DEFINITION POWER LINE COMMUNICATION (HD-PLC). Japão. Disponível em: <http://www.hd-plc.org/>. Acessado em jan. de 2009.

[45] MURATA, M. M.; FERREIRA, A.E. Vantagens dos serviços convergentes sobre linhas de alta tensão. In: XIII ERIAC - Décimo tercer encuentro regional Iberoamericano de Cigré; 2009.

[46] SIEMENS. Siemens PowerLink Advanced PLC technology in a future-proof concept. Disponível em: $<$ http://w3.energy.siemens.com/cms/00000011/en/reused/Documents/broschuere_cs_powerlin k_eng_1389064.pdf $>$. Acessado em jan. de 2009.

[47] NETCON - ENGENHARIA DE TELECOMUNICAÇÕES. Tecnologia OPLAT e teleproteção. Disponível em: <http://www.netconltda.com.br/net-tecnologia/tec-oplat.htm>. Acessado em mar. de 2009.

[48] XELINE CO. LTD. PowerLine Communication Technology. Disponível em: $<$ http://www.xeline.com/english/business/business tech.htm>. Acessado em dez. de 2008. 
[49] Internet pela rede elétrica enfrenta obstáculos. O Estado de São Paulo, 17 de jan. de 2010. Disponível em: <http://www.estadao.com.br/noticias/economia,internet-pela-redeeletrica-enfrenta-obstaculos,497097,0.htm>. Acessado em jan. de 2010.

[50] TANENBAUM, A. S. Computer Networks. $4^{\text {th }}$ ed. Upper Saddle River, NJ: Prentice Hall PTR, 2003.

[51] PINTO, E. L.; ALBUQUERQUE, C. P. DE. A Técnica de Transmissão OFDM. Revista Científica Periódica - Telecomunicações, v. 5, n. 01, jun. de 2002.

[52] HANZO, L.; MÜNSTER, M.; CHOI, B. J.; KELLER, T. OFDM and MC-CDMA for Broadband Multi-User Communications; OFDM and MC-CDMA for Broadband MultiUser Communications, WLANs and Broadcasting. [Piscataway, N.J.]: IEEE PressChichester [West Sussex]: John Wiley, 2006, 2003.

[53] LI, Y. G.; STUBER, G. L. Orthogonal Frequency Division Multiplexing for Wireless Communications (Signals and Communication Technology). New York: Springer Science+Business Media, 2006.

[54] MITSUBISHI COMPANIES. Mitsubishi Training Manual; Design \& Planning. Japão: Divisão PLC/BPL - Mitsubishi, 2003. (Manual de treinamento).

[55] HOMEPLUG POWERLINE ALLIANCE. Disponível em: <http://www.homeplug.org/>. Acessado em mar. de 2009.

[56] MITSUBISHI COMPANIES. Disponível em: <http://www.mitsubishi.com/>. Acessado em dez. de 2007.

[57] SCHNEIDER ELECTRIC. Disponível em: <http://www.schneider-electric.com/>. Acessado em jan. de 2008.

[58] CORINEX ANYWIRE CONECTIVITY. Disponível em: <http://www.corinex.com/>. Acessado em jun. de 2009.

[59] OK ENGENHARIA E CONSULTORIA LTDA. Disponível em: $<$ http://www.okengenharia.com.br/>. Acessado em fev. de 2008.

[60] ARTECHE. Disponível em: <http://www.arteche.es/>. Acessado em maio de 2009. 
[61] PROMAX ELECTRONICA. Disponível em: $<$ http://www.promaxelectronics.com/ing/products/fichaprod.asp?product=Propower\&IDfamil $\underline{i a=06}>$. Acessado em jan. de 2008.

[62] IPERF PROJECT - UNIVERSITY OF CENTRAL FLORIDA. Disponível em: $<$ http://www.noc.ucf.edu/Tools/Iperf/>. Acessado em nov. de 2007.

[63] VLC MEDIA PLAYER. Disponível em: <http://www.videolan.org/vlc/>. Acessado em nov. de 2007.

[64] SAMBA PROJECT. Disponível em: <http://www.ist-samba.eu/>. Acessado em jun de 2009.

[65] PAUL, C. R. Introduction to Electromagnetic Compatibility. $2^{\text {nd }}$ ed. Hoboken, N.J.: Wiley-Interscience, 2006.

[66] CARDOSO, J. R. Transitórios em Linhas de Transmissão. São Paulo: Epusp, 2004. Apostila para a disciplina de graduação do Departamento de Engenharia de Energia e Automação Elétricas, PEA2303 - Teoria Eletromagnética.

[67] STEVENSON JR, WILLIAM D. Elements of power system analysis. $4^{\text {th }}$ ed. New York: McGraw-Hill, 1982.

[68] ZANETTA JÚNIOR, LUIZ CERA. Transitórios Eletromagnéticos em Sistemas de Potência. São Paulo: EDUSP, 2003.

[69] INSTITUTE OF ELECTRICAL AND ELECTRONICS ENGINEERS. IEEE STD 5191992: IEEE Recommended Practices and Requirements for Harmonic Control in Electrical Power Systems. Disponível em: <http://www.ieee.org/>. Acessado em maio de 2009.

[70] NASSIF, A.B.; ACHARYA, J. An investigation on the harmonic attenuation effect of modern compact fluorescent lamps. In: 13th International Conference on Harmonics and Quality of Power, 2008. p. $1-6$.

[71] MATVOZ, D.; MAKSIC, M. Impact of compact fluorescent lamps on the electric power network. In: 13th International Conference on Harmonics and Quality of Power, 2008. p. $1-6$. 
[72] INTERNATIONAL ELECTROTECHNICAL COMMISSION. EN 61000-3-2: Electromagnetic Compatibility (EMC) - PART 3-2: Limits - Limits for Harmonic Current Emissions (Equipment Input Current $<=16$ A per phase). Disponível em: $<$ http://www.iec.ch/>. Acessado em maio de 2009.

[73] RONNBERG, S.K.; WAHLBERG, M.; BOLLEN, M.H.J.; LUNDMARK, C.M. Equipment currents in the frequency range $9-95 \mathrm{kHz}$, measured in a realistic environment. In: 13th International Conference on Harmonics and Quality of Power, 2008. p. 1 - 8.

[74] GOMES, R.J.R.; BRASIL, D.O.C.; CORREIA, D.M.; MONTEIRO, A.M.; MEDEIROS, J.R.; ARAUJO, D.S. Brazilian Transmission System power quality indices. In: 13th International Conference on Harmonics and Quality of Power, 2008. p. 1 - 7.

[75] GOSBELL, V.J.; BROWNE, T.J.; PERERA, S. Harmonic allocation using IEC/TR 61000-3-6 at the distribution/transmission interface. In: 13th International Conference on Harmonics and Quality of Power, 2008. p. $1-6$.

[76] BROWNE, T.J.; GOSBELL, V.J.; PERERA, S. Conditions for the assessment of the harmonic compliance of an installation. In: 13th International Conference on Harmonics and Quality of Power, 2008. p. 1 - 6.

[77] AMORNVIPAS, C.; HOFMANN, L. Method for analyzing effect of switching operations on system resonant behavior. In: 13th International Conference on Harmonics and Quality of Power, 2008. p. 1 - 6.

[78] PFAJFAR, T.; BLAZIC, B.; PAPIC, I. Methods for estimating customer voltage harmonic emission levels. In: 13th International Conference on Harmonics and Quality of Power, 2008. p. $1-6$.

[79] FARHADI, A. Modeling, simulation, and reduction of conducted electromagnetic interference due to a PWM buck type switching power supply. In: 13th International Conference on Harmonics and Quality of Power, 2008. p. 1 - 6.

[80] MOHOD, S.W.; AWARE, M.V. Power quality issues \& it's mitigation technique in wind energy generation. In: 13th International Conference on Harmonics and Quality of Power, 2008. p. $1-6$.

[81] ELPHICK, S.; GOSBELL, V.; BARR, R. The Australian Long Term Power Quality Monitoring Project. In: 13th International Conference on Harmonics and Quality of Power, 2008. p. $1-6$. 
[82] JUHLIN, L-E; HUBBARD, R.; LUCCA, G.; ÖHLIN, H. G.; RAJOTTE, C.; SIEW, W.H.; THOMAS, D.; VARJU, GY. Technical Brochure No 391 - JWG C4.202. Guide for measurement of radio frequency Interference from HV and MV substations. Revista Electra, Brasil, n. 245, p. 56 - 68, agosto 2009. 


\section{ANEXO A - Revisão de conceitos básicos}

\section{A.1 Linhas de transmissão}

As linhas de transmissão (LT) são comumente encontradas em nosso dia a dia, sendo que elas podem ser classificadas, basicamente, em dois tipos, a saber [65] [66] [67].

- Linhas de transmissão de energia: São responsáveis pelo transporte de grandes blocos de energia elétrica. Muitas vezes possuem grandes extensões, operam em altas tensões e baixa freqüência;

- Linhas de transmissão de sinais: São responsáveis pelo transporte de informações e pequena quantidade de energia elétrica. Muitas vezes possuem pequenas distâncias, operam em baixas tensões e altas freqüências. Como exemplo pode-se citar as linhas telefônicas, as trilhas de um circuito impresso, redes de computadores, entre outros.

O modelo de linha de transmissão aplica-se neste trabalho na avaliação da distribuição e comportamento dos sinais PLC/BPL nas edificações. Conforme já citado no capítulo 8 a distribuição dos sinais PLC/BPL é fortemente influenciada pelas características elétricas e magnéticas do meio físico utilizado para transportar os sinais.

\section{A.1.1 Modelo e parâmetros da LT}

Mencionam-se os seguintes parâmetros relacionados ao modelo de LT, considerados por unidade de comprimento:

- R: Resistência ôhmica $(\Omega / m)$;

- L: Indutância própria $(\mathrm{H} / \mathrm{m})$; 
- C: Capacitância própria $(\mathrm{F} / \mathrm{m})$;

- G: Condutância (S/m).

Para cada fenômeno físico, temos então a associação de um elemento de circuito que o representa de maneira mais adequada.

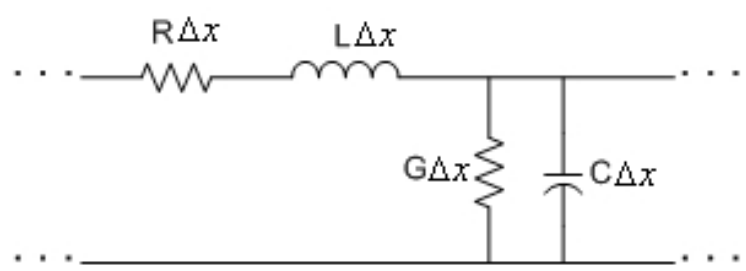

Figura 54 - Modelo de LT de comprimento $\Delta x$.

Assim, menciona-se que neste trabalho, ao se considerar o modelo de Linha de Transmissão sem perdas, tem-se que $R=0$ e $G=0$.

Aplicando-se as Leis de Kirchoff ao circuito da Figura 54, obtêm-se as equações para a tensão e para a corrente na Linha de Transmissão [65] [66] [67].

$$
\begin{aligned}
& \frac{\partial^{2} V(x)}{\partial x^{2}}=L C \frac{\partial^{2} V(x)}{\partial t^{2}} \\
& \frac{\partial^{2} I(x)}{\partial x^{2}}=L C \frac{\partial^{2} I(x)}{\partial t^{2}}
\end{aligned}
$$

A solução geral da equação de onda para tensões e correntes é apresentada a seguir.

$$
\begin{gathered}
V(x, t)=V_{+}(x, t)+V_{-}(x, t) \\
I(x, t)=I_{+}(x, t)+I_{-}(x, t)
\end{gathered}
$$

Os termos com índice "+" correspondem a ondas de tensão ou corrente que se propagam no sentido de propagação do fenômeno e são chamados de ondas progressivas ou incidentes, já os termos com índice “_“" correspondem a ondas denominadas regressivas ou ondas refletidas. A relação entre tensões e correntes em uma linha de transmissão pode ser expressa como segue.

$$
\frac{V_{+}}{I_{+}}=Z_{0}
$$


O termo $Z_{0}$ é denominado "Impedância Característica da Linha de Transmissão" e depende da geometria dos condutores da linha e das propriedades magnéticas e elétricas do meio circundante. Para o caso da LT sem perdas, tem-se:

$$
Z_{0}=\sqrt{\frac{L}{C}}
$$

Além da impedância da característica da linha é importante conhecer-se a "velocidade de propagação" do sinal. Destaca-se que esta pode ser calculada através da expressão:

$$
v=\frac{1}{\sqrt{L C}}
$$

Outro parâmetro importante da Linha de Transmissão é o chamado "tempo de trânsito", que equivale ao tempo que o sinal demora a percorrer toda a linha, ou seja, é a relação entre o comprimento da linha e a velocidade de propagação do sinal. Desta maneira, este parâmetro pode ser calculado por:

$$
\tau=\frac{l}{v}
$$

Adicionalmente, podem-se definir outras duas grandezas significativas para a análise do comportamento dos sinais PLC/BPL nas edificações, a saber [65] [66] [67].

- Coeficiente de reflexão: representa a fração da onda incidente que retorna ao trecho original da LT. Este pode ser determinado por:

$$
\Gamma=\frac{V_{-}}{V_{+}}=\frac{R_{L}-Z_{0}}{R_{L}+Z_{0}}
$$

- Coeficiente de transmissão: representa a fração da onda incidente que é transmitida ao trecho da LT, à jusante, do ponto considerado. Pode ser determinado por:

$$
\sigma=\frac{V_{L}}{V_{+}}=\frac{2 R_{L}}{R_{L}+Z_{0}}
$$




\section{A.1.2 Parâmetros distribuídos x parâmetros concentrados}

A metodologia completa de análise de linhas de transmissão a parâmetros distribuídos pode ser encontrada, em detalhes, em diversas publicações [65] [66] [67].

Destaca-se que a análise a parâmetros distribuídos deve ser realizada, considerando-se a comparação entre o comprimento de onda $(\lambda)$ dos sinais envolvidos e o as dimensões do circuito $(D)$ em análise. Opta-se pela análise a parâmetros concentrados quando se tem que $D \ll 0,01 \lambda$. Já para os casos em que $D \gg 0,1 \lambda$ a aplicação da análise a parâmetros distribuídos se faz necessária. Para os casos intermediários existe um compromisso entre a precisão desejada e a simplicidade na resolução do problema [66].

Considerando que os sinais PLC/BPL banda larga estão compreendidos entre $1 \mathrm{MHz}$ e $35 \mathrm{MHz}$ são apresentados na seqüência seus respectivos comprimentos de onda, considerando a velocidade de propagação como sendo a do vácuo $\left(v=3 \times 10^{8} \mathrm{~m} / \mathrm{s}\right)$.

$$
\begin{array}{cc}
v=\lambda_{1} \cdot f_{1} & v=\lambda_{2} \cdot f_{2} \\
f_{1}=1 M H z & f_{2}=35 M H z \\
\lambda_{1}=\frac{3 \times 10^{8}}{1 \times 10^{6}} & \lambda_{2}=\frac{3 \times 10^{8}}{35 \times 10^{6}} \\
\lambda_{1}=300 m & \lambda_{2}=8,57 m \\
0,1 \lambda_{1}=30 m & 0,1 \lambda_{2}=0,857 m
\end{array}
$$

$\mathrm{Na}$ prática verifica-se que as dimensões das edificações e redes elétricas onde a tecnologia PLC/BPL é comumente utilizada implicam que as análises sejam realizadas considerando as técnicas a parâmetros distribuídos.

Desta forma, deve-se ter sempre em mente tal modelo de LT e técnica de análise, mesmo que estas sejam aplicadas de forma qualitativa ao problema. Nestas condições verifica-se que os sinais PLC/BPL não estarão presentes apenas nos condutores onde serão injetados, mas sim estarão presentes, potencialmente, em inúmeros outros condutores, sejam eles outras fases dentro do mesmo circuito elétrico, ou condutores de outros circuitos. Ainda assim é possível encontrar sinais em unidades consumidoras diferentes daquelas onde os sinais foram originalmente injetados. 
Além disso, segundo o modelo de análise, os sinais PLC/BPL sofrerão grande influência do meio físico que circunda os condutores. Assim, é de se esperar que dielétricos diferentes do ar ocasionem maiores atenuações aos sinais, fato este que foi verificado na prática. Como exemplo de tais situações pode-se citar as redes elétricas subterrâneas, trechos elétricos alagados, condutores inseridos em tubulações metálicas ou esteiras metálicas. Outra forma de interpretar tais atenuações é considerar o ramo capacitivo do modelo de LT, cuja impedância capacitiva associada será tão menor quanto maior for a permissividade elétrica do meio, assim como menor for a distância entre os condutores [68]. Neste ponto deve estar claro para o leitor que a LT é um filtro natural do tipo passa baixa. Maiores detalhes sobre o cálculo dos parâmetros de uma LT podem ser encontrados em [67] [68].

Tais considerações são de extrema importância para o desenvolvimento dos projetos de redes, assim como na implementação das técnicas de injeção de sinais PLC/BPL. A Figura 55 apresenta uma ilustração comparativa entre uma rede elétrica (a) modelada para a faixa de frequiência de $60 \mathrm{~Hz}$ e a mesma rede (b) modelada para mais altas freqüências. É justamente a Figura 55 (b) que ajuda na compreensão do comportamento dos sinais PLC/BPL nas edificações.

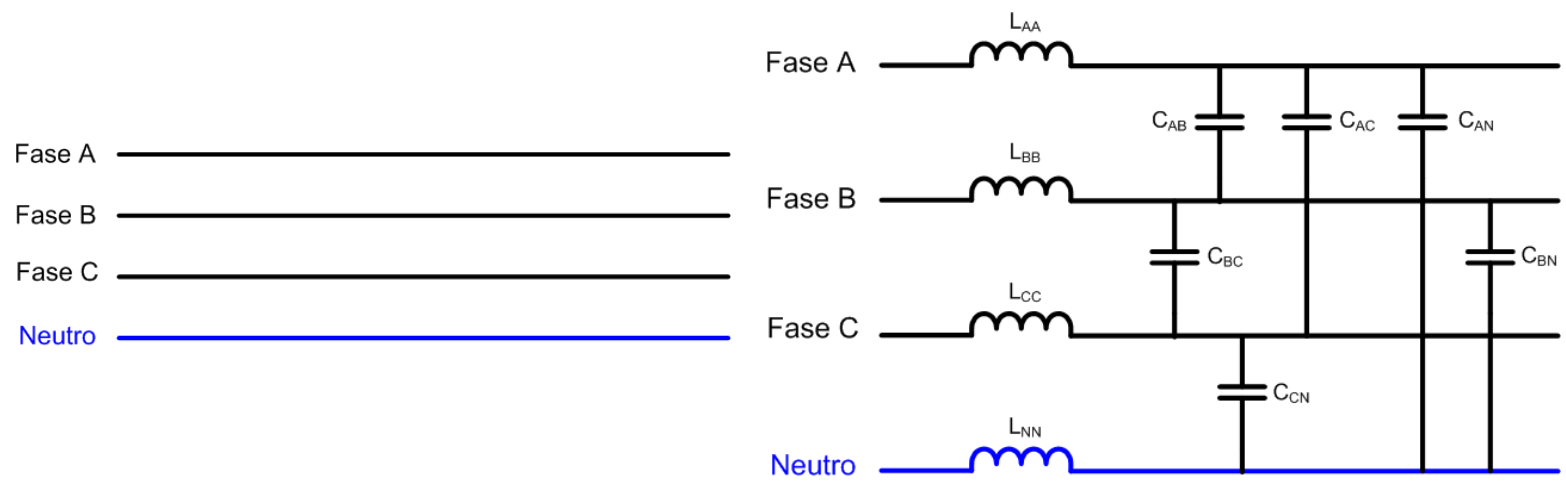

(a)

(b)

Figura 55 - Ilustração comparativa entre a (a) rede elétrica modelada em $60 \mathrm{~Hz}$ e a mesma rede (b) modelada em alta freqüência. 


\section{A.2 Harmônicos}

\section{A.2.1 Introdução}

$\mathrm{Na}$ atualidade é cada vez maior a utilização de equipamentos elétricos e eletrônicos, os quais, em sua grande maioria, constituem-se em cargas não lineares para o sistema elétrico de potência (SEP).

Entende-se por carga não linear toda e qualquer carga elétrica que absorve corrente não senoidal quando alimentada por tensão senoidal. Entre elas pode-se destacar todo tipo de equipamento conversor $\mathrm{CA}-\mathrm{CC}$ ou $\mathrm{CC}-\mathrm{CA}$, ou seja, todo equipamento eletrônico que utiliza corrente contínua para seu funcionamento, como computadores, carregadores de celular, televisão, rádios, monitores, aparelhos telefônicos, além de lâmpadas fluorescentes compactas (LFC), fornos a arco, compensadores estáticos de reativos, inversores, drives de acionamento PWM, entre outros [69].

Como exemplo de carga não linear, a Figura 56 apresenta a forma de onda da corrente absorvida por 3 lâmpadas fluorescentes compactas de potências diferentes [70].
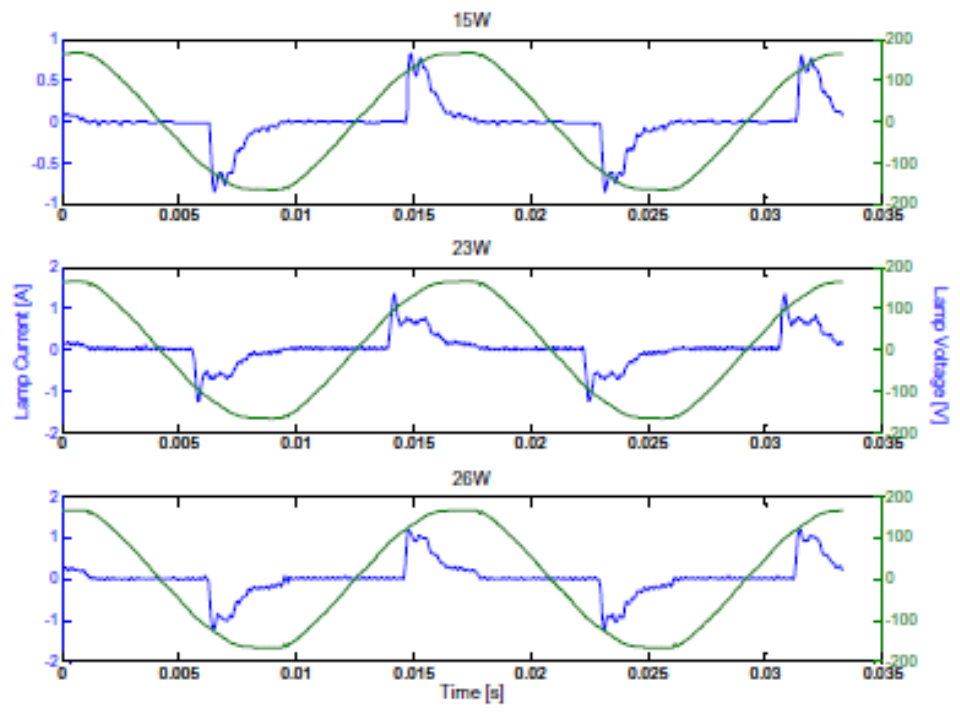

Figura 56 - Forma de onda da corrente absorvida por LFCs. 
Observa-se que, enquanto as tensões de alimentação são senoidais, as correntes absorvidas são fortemente não lineares, o que implica em um conteúdo harmônico bastante elevado. Tal conteúdo harmônico pode ser quantificado através de uma grandeza chamada taxa de distorção harmônica (THD), para tensão e corrente, a qual pode ser calculada através das equações (13) e (14) a seguir [69].

$$
\begin{gathered}
V T H D=\frac{\sqrt{V_{2}^{2}+V_{3}^{2}+\ldots+V_{n}^{2}}}{V_{1}} \\
I T H D=\frac{\sqrt{I_{2}^{2}+I_{3}^{2}+\ldots+I_{n}^{2}}}{I_{1}}
\end{gathered}
$$

Onde $V_{1}$ e $I_{1}$ são valores eficazes (RMS).

O Fator de Potência total (FP) pode ser calculado de acordo com as equações (15) e (16).

$$
P F=\frac{P}{S}=\frac{P_{1}+P_{H}}{S}
$$

Onde,

$$
P_{H}=\sum_{h \neq 1} V_{h} I_{h} \cos \theta_{h}
$$

O termo $\theta_{k}$ representa a diferença de fase entre tensão e corrente da h-ésima componente.

Quando $V T H D<5 \%$ e $I T H D>40 \%$, vale a equação (17).

$$
P F=\frac{P_{r m s}}{S_{r m s}}=\frac{P_{1}+P_{H}}{S_{r m s}} \approx \frac{1}{\sqrt{1+I T H D^{2}}} \cdot F P F
$$

Na qual FPF é o fator de potência apenas para a componente de $60 \mathrm{hz}$ e $P_{r m s}$ é o valor total de potência ativa.

Desta forma, a Tabela 4 apresenta o resultado da análise de 12 tipos de lâmpadas diferentes, assim como a Figura 57 apresenta o espectro por unidade (pu) das correntes absorvidas [70]. 
Tabela 4 - Características das lâmpadas testadas [70].

\begin{tabular}{cccccccc}
\hline $\begin{array}{c}\text { POTÊNCIA } \\
\text { NOMINAL } \\
(\mathrm{W})\end{array}$ & $\mathrm{P}_{r m s}(\mathrm{~W})$ & $\mathrm{VTHD}(\%)$ & $\mathrm{ITHD}(\%)$ & $I_{r m s}(\mathrm{~A})$ & $I_{1}(\mathrm{~A})$ & FPF & PF \\
\hline 15 & 16,80 & 2,56 & 119,59 & 0,25 & 0,16 & 0,89 & 0,57 \\
13 & 14,54 & 2,52 & 105,97 & 0,19 & 0,13 & 0,92 & 0,63 \\
9 & 10,19 & 2,51 & 99,35 & 0,13 & 0,10 & 0,90 & 0,64 \\
23 & 25,34 & 2,48 & 92,30 & 0,35 & 0,26 & 0,81 & 0,60 \\
13 & 12,33 & 2,51 & 143,69 & 0,19 & 0,11 & 0,94 & 0,54 \\
27 & 29,36 & 2,54 & 95,40 & 0,40 & 0,29 & 0,85 & 0,62 \\
30 & 29,30 & 2,56 & 97,44 & 0,40 & 0,29 & 0,85 & 0,61 \\
10 & 9,76 & 2,59 & 118,37 & 0,13 & 0,09 & 0,94 & 0,61 \\
26 & 29,58 & 2,55 & 101,41 & 0,39 & 0,27 & 0,91 & 0,64 \\
5 & 4,80 & 2,52 & 123,61 & 0,07 & 0,05 & 0,86 & 0,54 \\
27 & 25,28 & 2,54 & 116,11 & 0,37 & 0,24 & 0,88 & 0,58 \\
14 & 14,67 & 2,54 & 119,32 & 0,20 & 0,13 & 0,94 & 0,60 \\
\hline
\end{tabular}

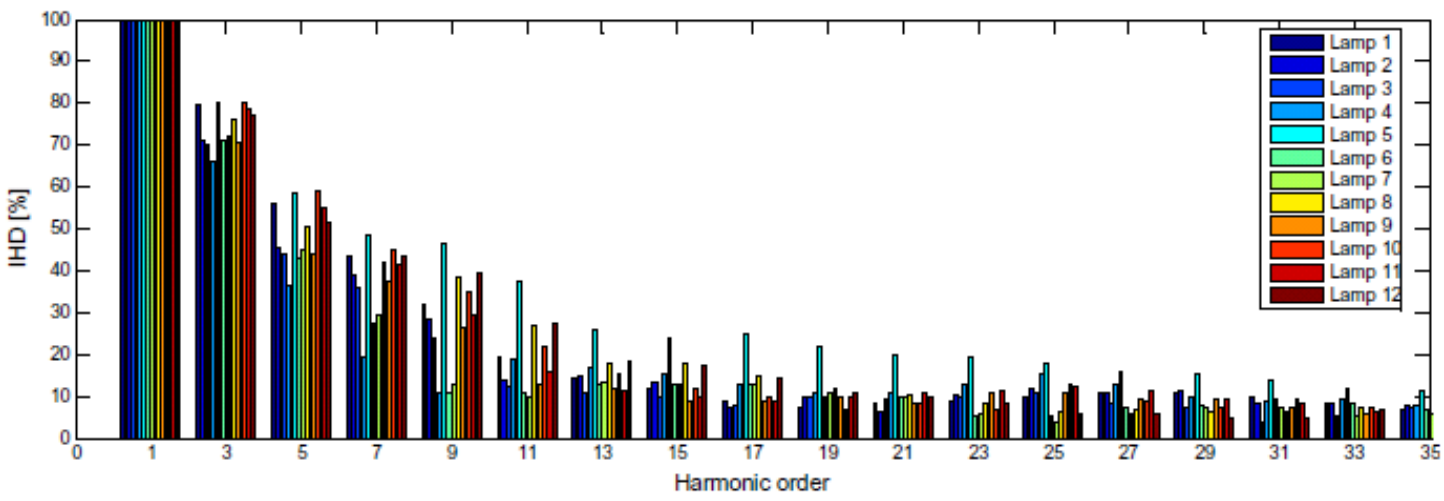

Figura 57 - Espectro (em pu) das correntes absorvidas [70].

Através da análise dos dados acima, observa-se que o fator de potência na frequiência fundamental é relativamente elevado, porém o fator de potência total é muito baixo, o que indica, neste caso, alto conteúdo harmônico proveniente de tais cargas de iluminação. Verifica-se que a amplitude dos harmônicos de ordem 35 corresponde a cerca de $10 \%$ da fundamental. Desta forma, para frequiências ainda mais elevadas têm-se amplitudes consideráveis, as quais podem ser encontradas até a faixa de $\mathrm{MHz}$ [31]. A Figura 58 apresenta o espectro observado na casa do presente autor no momento em que diversas cargas eletrônicas estavam ligadas, comprovando a presença de harmônicos na faixa de MHz. 


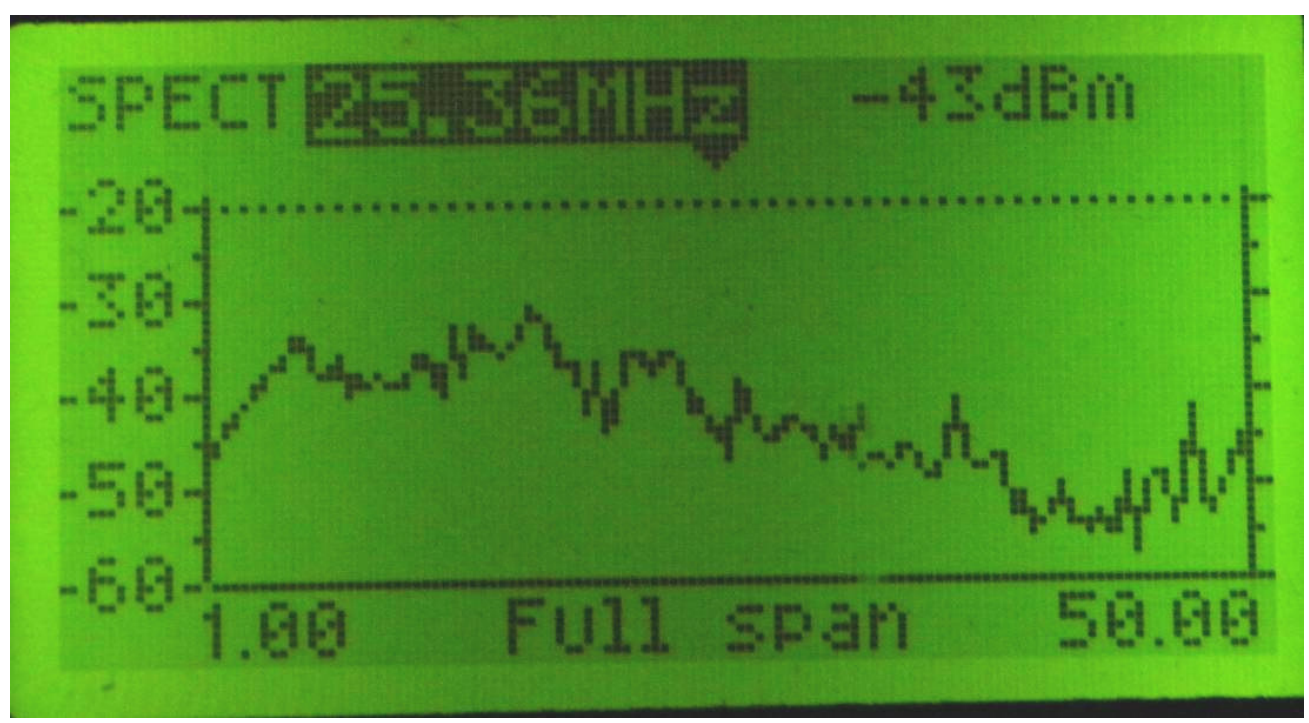

Figura 58 - Espectro verificado na casa do presente autor.

Ainda no que se refere às cargas de iluminação, destacam-se os trabalhos sobre o impacto das mesmas nas redes de potência, tais como [71]. Verifica-se que, na união européia, toda carga elétrica que absorve até 16A por fase, tem de estar de acordo com a norma IEC 61000-3-2 [72], a qual trata especificamente sobre as distorções harmônicas. Na prática, verifica-se que nem todos os equipamentos/dispositivos comercializados no Brasil seguem esta norma.

Outro aspecto importante relacionado ao comportamento dos harmônicos dentro das edificações é a sua distribuição. Verifica-se que muitas vezes o perfil das correntes absorvidas por equipamentos similares apresentam grandes diferenças dependendo da edificação [73]. Além disso, dependendo da impedância, tanto da rede, quanto dos equipamentos a ela conectados, verifica-se que as correntes podem circular, de forma mais pronunciada, entre as próprias cargas, ao invés de circular entre a carga e a rede da concessionária [73].

\section{A.2.2 Importância para as redes PLC/BPL}

Tais harmônicos produzem efeitos indesejáveis nas redes elétricas de potência, tais como mau funcionamento de equipamentos de comunicação e processamento de sinais, aquecimento e vibrações em motores elétricos, vibrações em transformadores, resultando em ruído audível, 
desgaste em isolamentos, aumento das perdas joule do sistema, possibilidade de ressonância no sistema com bancos de capacitores, (resultando muitas vezes em destruição dos mesmos), além da redução da vida útil de todos esses equipamentos. Somam-se ainda os problemas ocasionados em sistemas de rádio, televisão, sistemas de gravação e reprodução de áudio. Como tais equipamentos são alimentados em baixa tensão, através de um ramal secundário, é frequiente sua exposição aos efeitos das perturbações de tensão, as quais muitas vezes introduzem harmônicos no sistema com intensidades elevadas (muitas vezes superiores a $5 \mathrm{kV}$ ) e com freqüências na faixa de RF. Muitas vezes são esses os sinais responsáveis por interferências prejudiciais (IEM) aos sistemas de controle e circuitos de comunicação [69].

Existem, ainda, os efeitos prejudiciais aos equipamentos de medição, instrumentação, religadoras e relés, os quais muitas vezes podem ser catastróficos. Como exemplo, pode-se citar as interferências em sistemas telefônicos [69].

Dada a importância dos problemas decorrentes dos harmônicos presentes nas redes elétricas, verifica-se a existência de muitos trabalhos na literatura [74] [75] [76] [77] [78] [79] [80], uma vez que as potências envolvidas no fenômeno são grandes o suficiente para perturbar, de maneira considerável, o sistema elétrico. Considerando a intensidade dos sinais envolvidos, facilmente encontram-se harmônicos, conforme já citado, na faixa de $\mathrm{MHz}$, justamente a faixa de operação dos sistemas PLC/BPL de banda larga.

Destacam-se ainda os trabalhos de monitoramento contínuo de qualidade de energia, os quais incluem os harmônicos [31] [81].

Neste ponto deve estar claro que a presença dos harmônicos nas redes elétricas de potência é algo comum e inerente ao princípio de funcionamento de muitos de seus elementos. Desta forma, a presença de tais sinais deve ser fortemente considerada no desenvolvimento dos projetos de redes PLC/BPL.

Considerando um ramal secundário, é de se esperar que a intensidade dos sinais presentes na faixa de $\mathrm{MHz}$ acompanhe a curva de carga do referido ramal. Como exemplo, considere-se um ramal típico para a alimentação residencial. Nesta situação é de se esperar, por exemplo, que no fim do dia o nível de sinais presentes na faixa de $\mathrm{MHz}$ aumente, uma vez que nesse horário tem-se um aumento de potência consumida, típico de ramais que alimentam residências.

Ainda tomando o exemplo acima, pode-se mencionar a presença de cargas de iluminação pública, as quais, muitas vezes, introduzem na rede grande conteúdo harmônico, os quais 
podem prejudicar o desempenho das redes PLC/BPL. Recorda-se que a tecnologia possui capacidade de adaptação de forma a conviver com tais sinais, porém, dependendo do nível dos harmônicos existentes, o desempenho pode ser prejudicado a ponto de interromper o enlace de comunicação. Na seção 7.5 deste trabalho são apresentadas técnicas para se contornar potenciais problemas com harmônicos de forma a minimizá-los e melhorar o desempenho da rede.

Um aspecto pouco mencionado são as emissões não intencionais de tais harmônicos. Uma vez que a intensidade de tais sinais (na faixa de $\mathrm{MHz}$ ) é da mesma ordem de grandeza, senão maior, que os sinais PLC/BPL, verifica-se certa incoerência na preocupação excessiva de ocorrência de IEM causadas pelo sistema de comunicação aqui tratado. Até o presente momento não se verificou nenhum relato de IEM causado por sistemas PLC/BPL em operação comercial no Brasil. O mesmo não ocorre com alguns dos sinais provenientes de cargas elétricas, uma vez que já foi verificada interferência em rádios AM [82].

Como exemplo, pode-se citar a Figura 59, a qual apresenta o encarte de uma lâmpada fluorescente compacta comumente comercializada no Brasil. O retângulo em vermelho destaca a mensagem que tal lâmpada pode causar interferência em equipamentos eletroeletrônicos.

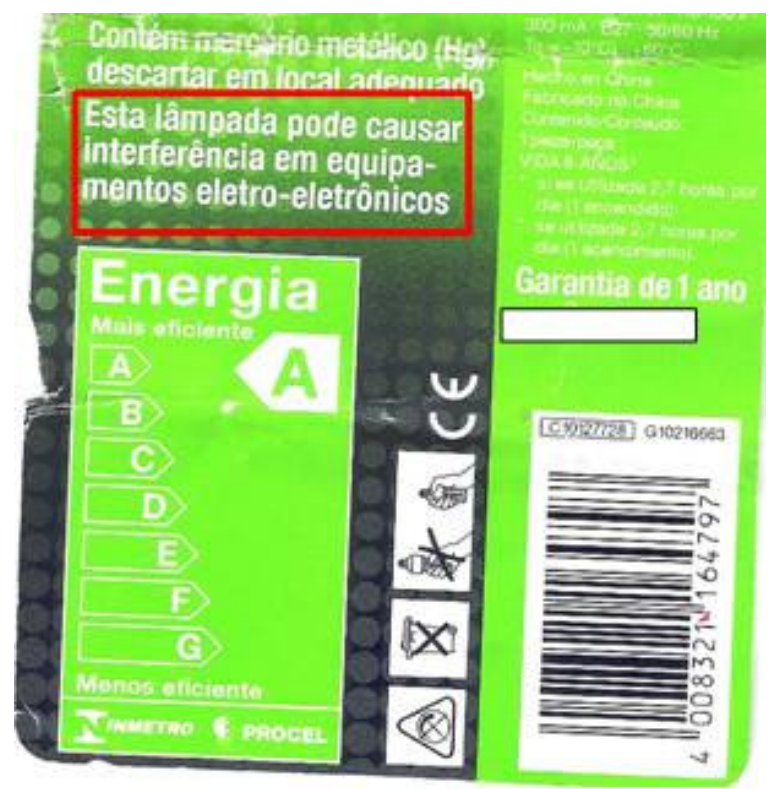

Figura 59 - Encarte de lâmpada fluorescente compacta comumente comercializada no Brasil.

Geralmente as redes PLC/BPL são implementadas em ambientes residenciais ou comerciais, onde muitas vezes as cargas tipicamente encontradas são no-breaks, fontes chaveadas 
(computadores, por exemplo), carregadores de celular, eletrodomésticos em geral e lâmpadas. No caso particular das cargas que utilizam motores universais (furadeiras, batedeiras, liquidificadores, etc) verifica-se a presença de componentes harmônicas de grande intensidade, as quais podem prejudicar muito o desempenho das redes de comunicação. Porém estas últimas são cargas que ficam em operação por pequenos intervalos de tempo e, portanto, a mitigação de tais como fontes de interferência é uma decisão que deve ser tomada considerando os requisitos de projeto da rede de comunicação e o custo envolvido, uma vez que cessada a fonte de interferência a comunicação é rapidamente restabelecida. 